\title{
Politische Soziologie der Corona-Proteste
}

\author{
Grundauswertung
}

17.12.2020

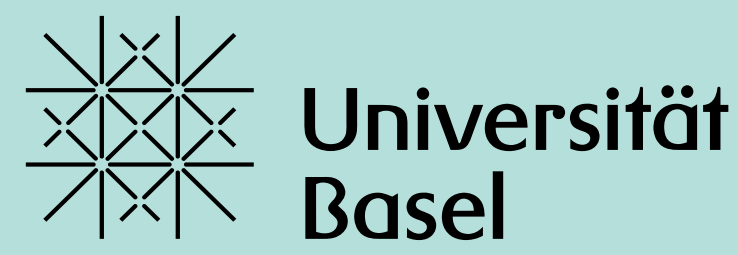

Prof. Dr. Oliver Nachtwey

Dr. Robert Schäfer

Dr. des. Nadine Frei

Universität Basel

Institut für Soziologie

Petersgraben 27

4051 Basel 


\section{Gliederung der Studie}

Einleitung: Die Corona-Massnahmen und ihre Gegner:innen ........................... 1

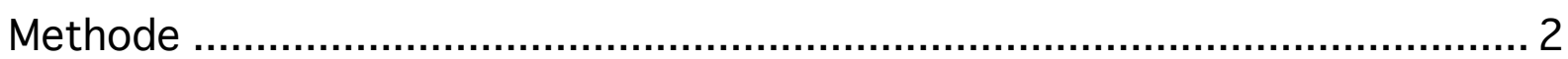

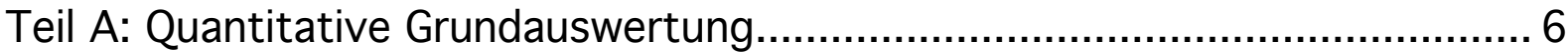

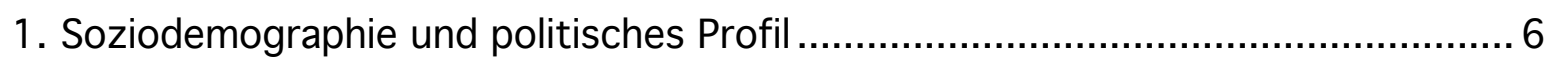

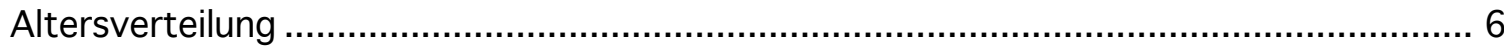

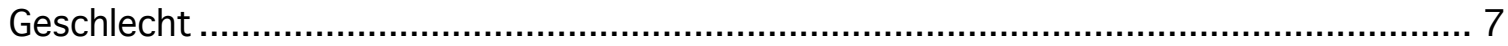

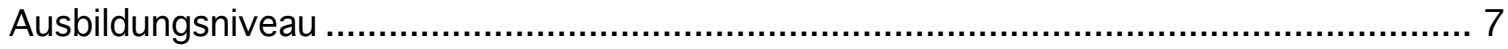

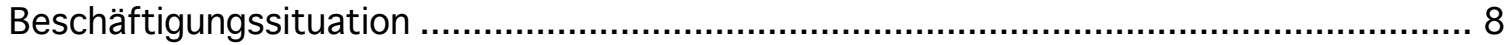

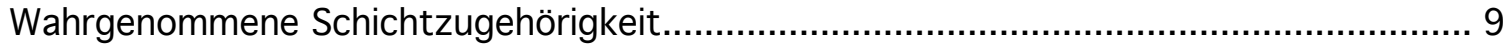

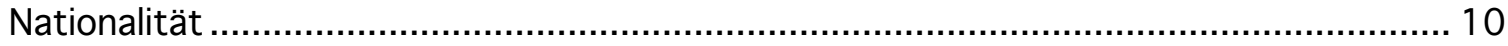

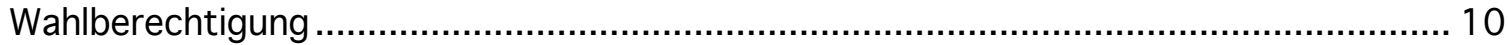

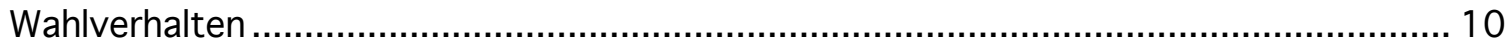

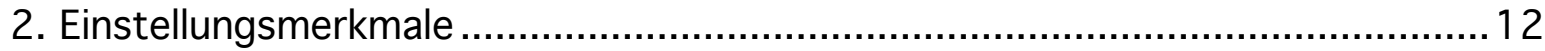

Medienkritik in der Corona-Krise ........................................................................ 12

Regierungskritik in der Corona-Krise ................................................................... 14

Verschwörungstheorien ……………………………………………………... 21

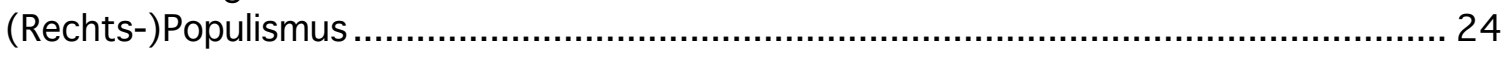

Rechtsautoritäres Denken.............................................................................. 27

Antisemitismus und Nationalsozialismus .............................................................. 32

Anthroposophisches/ Esoterisches Denken.............................................................. 33

Impfen

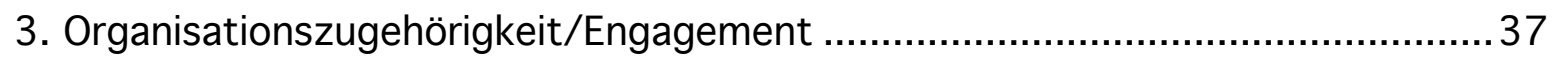

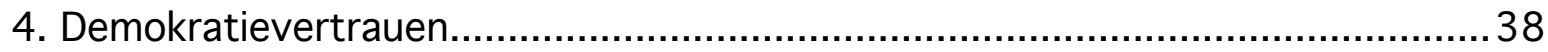

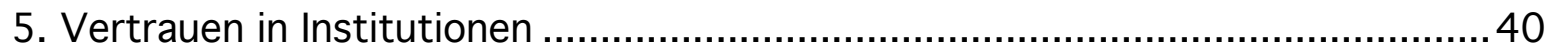

6. Ausgewählte bivariate Befunde................................................................ 44

Einfluss ausgewählter Indikatoren auf den Bezug zur Natur.......................................... 44

Einfluss ausgewählter Indikatoren auf populistische Haltungen...................................... 46

Einfluss ausgewählter Indikatoren auf rechtsextreme Haltungen .................................... 47

Einfluss ausgewählter Indikatoren auf konspirative Haltungen ........................................ 49

Wählerwanderungen BRD (Anhand der geäusserten Wahlabsicht) ................................. 50

7. Résumé quantitativer Teil: Wer sind die Querdenker:innen? ..............................5 51

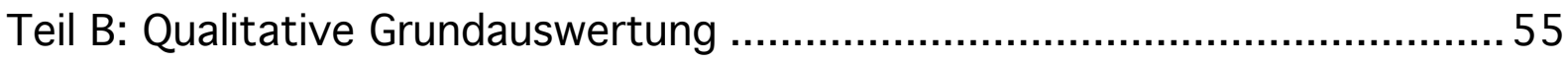

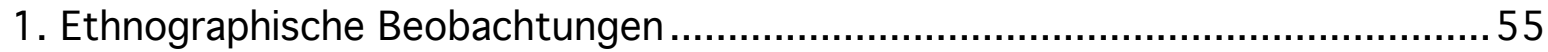

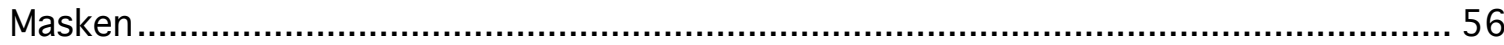

Kritik an etablierten Autoritäten............................................................................ 56

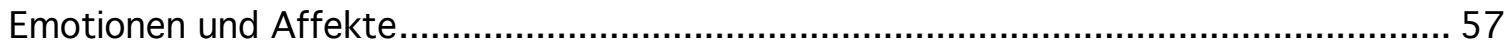

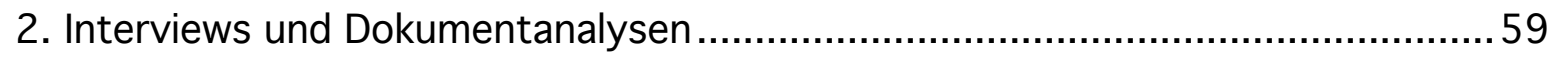

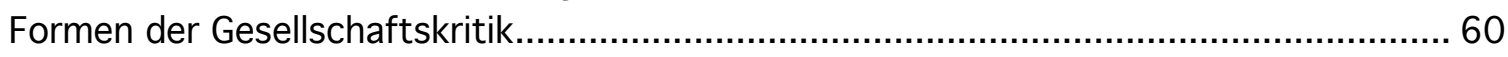

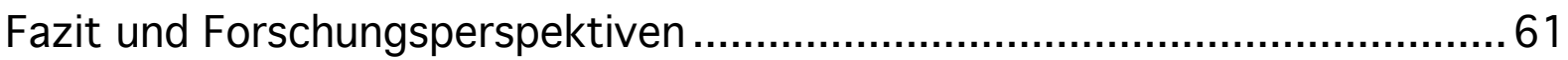




\section{Einleitung: Die Corona-Massnahmen und ihre Gegner:innen ${ }^{1}$}

Die Corona-Krise hält die Welt in Atem. Insbesondere in den europäischen Gesellschaften sind bezüglich des richtigen Umgangs mit der Pandemie politische Konflikte entstanden, nicht zuletzt deshalb, weil eine Minderheit der Bürger:innen die Angemessenheit der Freiheitsbeschränkungen zur Eindämmung der Pandemie in Zweifel zieht. Vor allem das Tragen von Masken und die Einhaltung von Sicherheitsabständen wird in der Bewegung der Kritiker:innen der CoronaMassnahmen (im Folgenden der Einfachheit halber als Synonym: Querdenker:innen) in Frage gestellt.

Der Konflikt resultiert aus einer Verknüpfung von einer Vielzahl von Faktoren: Der Staat sieht sich gezwungen, in einem in der europäischen Nachkriegsgeschichte nicht gekannten Mass in die Bewegungsfreiheit der Bürger:innen einzugreifen, die wirtschaftliche Freiheit zeitweilig drastisch einzuschränken und neue Verhaltensnormen (Maske und Abstand) zu bestimmen. Angesichts der Notlage hat die Exekutive in vielen Ländern Prozesse der Deliberation und Legitimation verkürzt oder umgangen.

Dieser Konflikt ist vor allem deshalb von grosser Brisanz, weil er sich über die Frage des Wissens über die Realität von Covid-19 entfacht. Die Kritiker:innen sehen - wie in unserer Studie deutlich wird - die Gefährlichkeit des Virus drastisch überbewertet und von daher die Massnahmen als nicht verhältnismässig an. Die Verweigerung des Maskentragens und des Abstandsgebots als Form des Protests begünstigt es jedoch, dass dieses Verhalten als Gefährdung der eigenen und der Gesundheit anderer wahrgenommen wird. Dies führt gerade bei Versammlungen und Demonstrationen zu einem Trade-Off zwischen der Wahrung der Demonstrationsfreiheit und dem Gesundheitsschutz.

\footnotetext{
1 Wir danken Johannes Truffer, Verena Hartleitner, Matthias Zaugg, Heidi Franke, Dieter Rucht, Simon Teune, Johanna Lauber und dem Institut für Protest- und Bewegungsforschung für ihre Unterstützung.
} 
Im Forschungsprojekt «Politische Soziologie der Corona-Proteste» werden am Fachbereich Soziologie an der Universität Basel die aktuellen Coronaproteste in der Schweiz und in Deutschland empirisch untersucht. Ziel der Untersuchungen ist es, die Motivation, Werte und Überzeugungen der Teilnehmer:innen an Kundgebungen, Aktionen und Demonstrationen, die sich gegen die coronabedingten Massnahmen richten, zu analysieren.

Um diese neuen Proteste umfassend untersuchen zu können, wird im Forschungsprojekt ein breiter empirischer Ansatz (Mixed-Methods) verfolgt. Dazu gehören eine quantitative Online-Umfrage, ethnographische Beobachtungen, qualitative Interviews und Dokumentenanalysen.

In diesem Working-Paper stellen wir die Grundauswertung unserer quantitativen Online-Befragung vor. Im zweiten Teil diskutieren wir erste Ergebnisse der qualitativen Materialauswertung. Weitere, tiefergehende Analysen folgen zu einem späteren Zeitpunkt.

\section{Methode}

Der erste Feldzugang fand auf Demonstrationen und Kundgebungen in der Schweiz und in Deutschland statt. Aufgrund der epidemiologischen Lage hatten wir uns jedoch nach ersten Pretests dazu entschlossen, den quantitativen Teil der Studie nicht - wie ursprünglich geplant - mit Paper\&Pencil-Fragebögen durchzuführen, sondern über offene Telegram-Chats Teilnehmende für eine Online-Befragung zu rekrutieren.

Hierfür haben wir eine Einladung zur Umfrage mit einem Link zum Online-Befragungs-Tool Limesurvey - auf dem wir unsere Befragung programmiert haben in Telegram-Gruppen von Corona-Massnahmen-Kritiker:innen und Querdenker:innen gepostet. 
Insgesamt wurden mehr als 1150 Fragebögen ausgefüllt. ${ }^{2}$ Der zugrundeliegende Fragebogen wurde anhand allgemein geltender Qualitätsstandards konzipiert und orientierte sich an erprobten Befragungsinstrumenten: Der Fragebogen baute auf getesteten Items aus dem Institut für Protest- und Bewegungsforschung, dem Sozio-ökonomischen Panel und der Leipziger Autoritarismusstudie auf. Hinzu kamen neu entwickelte Items, die sich spezifisch auf die Proteste gegen die Corona-Massnahmen bezogen.

Es wurden mehrere Pretests des Fragebogens, u.a. auf einer Demonstration in Konstanz am 04.10.2020, durchgeführt. Die Feldzeit der Onlinebefragung betrug sechs Tage, vom 18.-24.11.2020. Bei der vorliegenden Auswertung handelt es sich allerdings um explorative Ergebnisse. Mit innen lässt sich ein Überblick über den Forschungsgegenstand und bestimmte Einstellungsmuster gewinnen, es kann jedoch kein Anspruch auf Repräsentativität erhoben werden.

Die Grundgesamtheit der Befragung bilden Personen, die zum Zeitpunkt der Befragung Mitglied in einer offenen Telegram-Gruppe waren, die direkt mit der politischen Szene der Corona-Kritiker:innen im Zusammenhang steht. Wir haben über systematische Recherchen im Internet Gruppen mit mehr als 200 Teilnehmer:innen zusammengetragen. In der Feldzeit wurde in alle Gruppen, die offen zugänglich waren, mindestens dreimal die Umfrage gepostet.

Bei unseren Feldrecherchen haben wir festgestellt, dass viele Gruppen der Corona-Kritiker:innen sich transnational vernetzen und gezielt Demonstrationen an Orten wie in Konstanz veranstalten, in denen eine länderübergreifende Mobilisierung möglich ist. Deshalb haben wir auch Gruppen aus der Schweiz und (in geringerem Masse auch aus Österreich) mit in unsere Forschung einbezogen. Bei spezifischen Aspekten wie Parlamentswahlen weisen wir die nationalen Unterschiede aus; bei Fragen bezüglich der Werte und Einstellungen betrachten

\footnotetext{
2 Die Fragebögen beinhalteten auch offene Fragen, die nach den Motiven der Teilnehmer:innen fragen. Dies hat noch ca. 150 Seiten qualitatives Textmaterial hervorgebracht, das wir erst später analysieren können.
} 
wir die Bewegung der Corona-Kritiker:innen in den meisten Fällen jedoch als transnationales Phänomen. ${ }^{3}$

Die Telegram-Chat-Gruppen, in denen effektiv Postings gemacht werden konnten, umfassten insgesamt etwa 75'000 Teilnehmende, von denen jedoch viele mutmasslich in mehreren Gruppen aktiv waren. Durch unser Verfahren des «Convenience Sampling» konnten wir eine hohe Anzahl von Teilnehmenden (3700 Personen haben die erste Seite der Studie angeklickt) erreichen, allerdings wissen wir zu wenig über die Grundgesamtheit, d.h. die Anzahl der aktiven Teilnehmer:innen in den Telegram-Chatgruppen.

Wir konnten zudem nicht feststellen, wie viele Personen in den Telegram-Gruppen unseren Link überhaupt wahrgenommen haben. Es ist davon auszugehen, dass viele Personen inn nicht gesehen haben, da einige Gruppen durch ein sehr hohes Volumen an Kommunikation gekennzeichnet sind. Auch wurden wir in einigen - vor allem grösseren und professioneller geführten - Gruppen durch Moderator:innen bzw. Bots geblockt. Eine Rücklaufquote ist somit nicht befriedigend bestimmbar.

Ferner gehen wir davon aus, dass in unserer Untersuchung mehrere Faktoren einen Bias hervorrufen. Es ist anzunehmen, dass in der Gesamtpopulation der Kritiker:innen von Corona-Massnahmen viele Personen öffentlichen Institutionen - wie etwa der Wissenschaft - skeptisch gegenüber stehen und deshalb an der Studie nicht teilgenommen haben. In einigen Telegram-Gruppen wurde explizit vor der Teilnahme an unserer Studie gewarnt.

Zudem können wir eine Overcoverage von Personen vermuten, die die Bewegung der Corona-Kritiker:innen in ein positives Licht rücken möchten. Da die Teilnahme über Selbstselektion stattgefunden hat, kann dies nicht gewichtet und korrigiert werden. Ebenfalls können wir nicht ausschliessen, dass gerade bei kritischen Fragen oder drastischen Items nicht immer ehrlich geantwortet

\footnotetext{
${ }^{3}$ In der Studie präsentieren wir ausgewählte nationale Differenzierungen für die Schweiz und Deutschland.
} 
wurde. Dieses Problem der sozialen Erwünschtheit von Antworten ist jedoch ein allgemeineres Problem der Umfrageforschung. Onlinebefragungen haben jedoch den Vorteil, dass eine erhöhte Anonymität gewährleistet und ein Interviewer:inneneffekt bzgl. der sozialen Erwünschtheit auf das Antwortverhalten reduziert werden kann. ${ }^{4}$

Unter Berücksichtigung dieser Faktoren sind wir gleichwohl überzeugt, durch die hohe Fallzahl wichtige Erkenntnisse über die Bewegung der Corona-Kritiker:innen gewonnen zu haben und damit einen Beitrag zur laufenden Diskussion über die neue Bewegung zu leisten.

\footnotetext{
${ }^{4}$ Ausserdem ist zu berücksichtigen, dass bei bestimmten Items eine Forced-Choice-Option aktiviert wurde. Um die Gefahr eines Abbruches der Befragung (Unit-Non-Response) und von unehrlichen Antworten zu reduzieren, haben wir die Möglichkeit zu "Keine Angabe" angeboten. Vergleiche hierzu auch: Jacob, R., Heinz, A. und J.-P.- Décieux (2019): Umfrage: Einführung in die Methoden der Umfrageforschung, Berlin: De Gruyter. Oder grundlegender zur Beforschung von Protestbewegungen folgende Studie: Brinkmann, U., Nachtwey, O. und F. Décieux (2013): Wer sind die 99\%? Eine empirische Untersuchung der OccupyProteste. OBS-Arbeitspapier Nr. 6, Frankfurt am Main: Otto-Brenner-Stiftung. Online verfügbar unter: https://www.otto-brenner-stiftung.de/wissenschaftsportal/publikationen/titel/wer-sind-die99/aktion/show/obspaec/Publication/ Zuletzt aufgerufen am: 16.12.2020).
} 


\section{Teil A: Quantitative Grundauswertung}

\section{Soziodemographie und politisches Profil}

\section{Altersverteilung}

\section{Statistiken}

Alter

\begin{tabular}{|c|c|c|c|}
\hline \multirow[t]{2}{*}{ N } & Gültig & 1152 & \multirow{9}{*}{$\begin{array}{l}\text { Die Altersverteilung zeigt, dass ein Grossteil } \\
\text { (75\%) der Befragten über } 38 \text { Jahre alt ist. } \\
\text { Gerade junge Menschen sind schwach in der } \\
\text { Umfrage vertreten: Nur } 6 \text { TN sind unter } 20 \\
\text { Jahre alt, nur } 37 \text { TN sind unter } 25 \text { Jahren. } \\
\text { Nicht einmal } 10 \% \text { sind unter } 30 \text { Jahre alt. } \\
\text { Die Verteilung der Altersgruppen ist jedoch } \\
\text { fast normalverteilt - um einen Median von } 48 \\
\text { Jahren. }\end{array}$} \\
\hline & Fehlend & 0 & \\
\hline \multicolumn{2}{|l|}{ Mittelwert } & 47,15 & \\
\hline \multicolumn{2}{|l|}{ Median } & 48,00 & \\
\hline \multicolumn{2}{|l|}{ Schiefe } &,- 086 & \\
\hline \multicolumn{2}{|c|}{ Standardfehler der Schiefe } & ,072 & \\
\hline \multirow[t]{5}{*}{ Perzentile } & 25 & 38,00 & \\
\hline & 50 & 48,00 & \\
\hline & 75 & 56,00 & \\
\hline & 80 & 57,00 & \\
\hline & 90 & 62,00 & \\
\hline
\end{tabular}

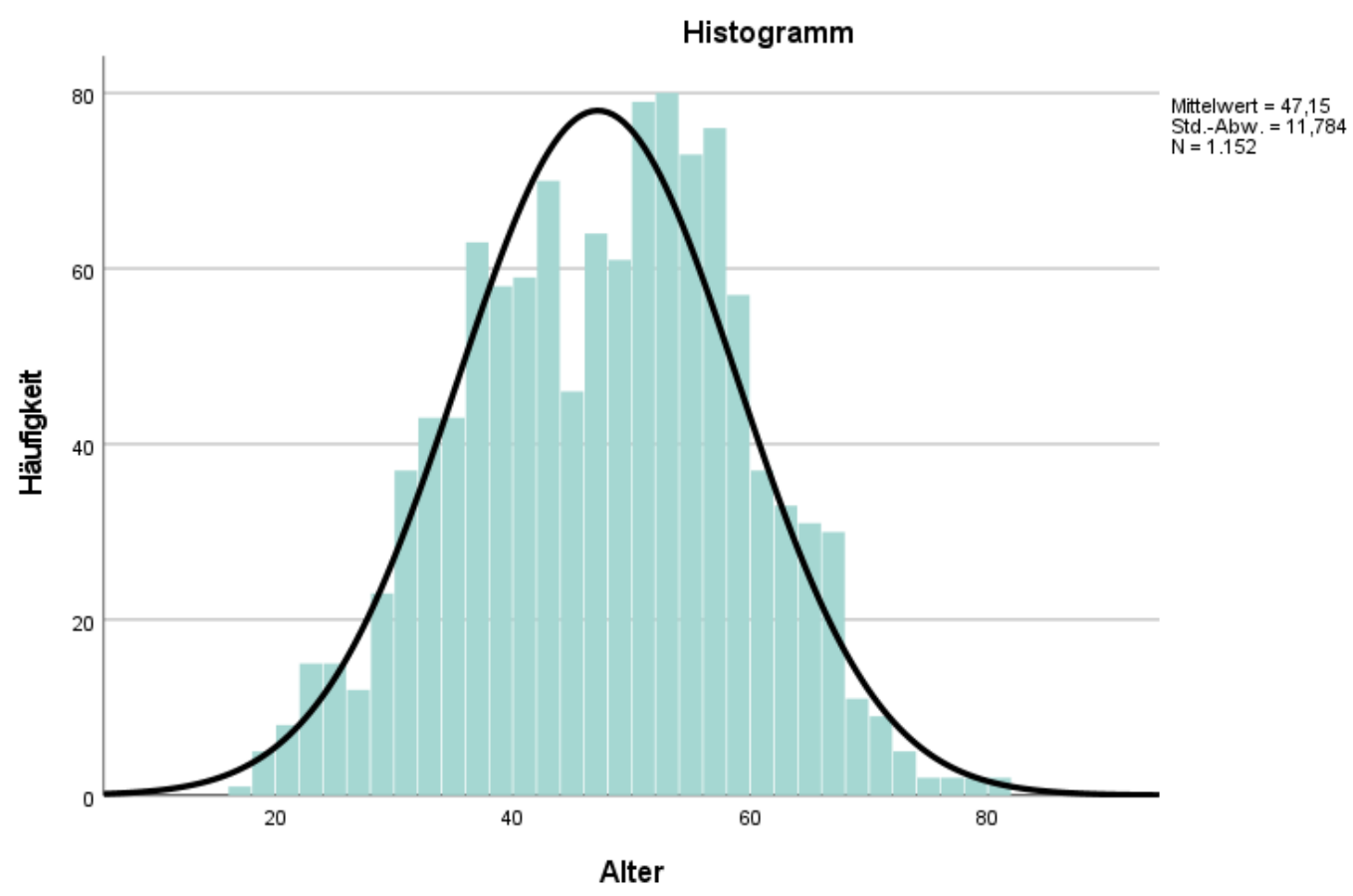




\section{Geschlecht}

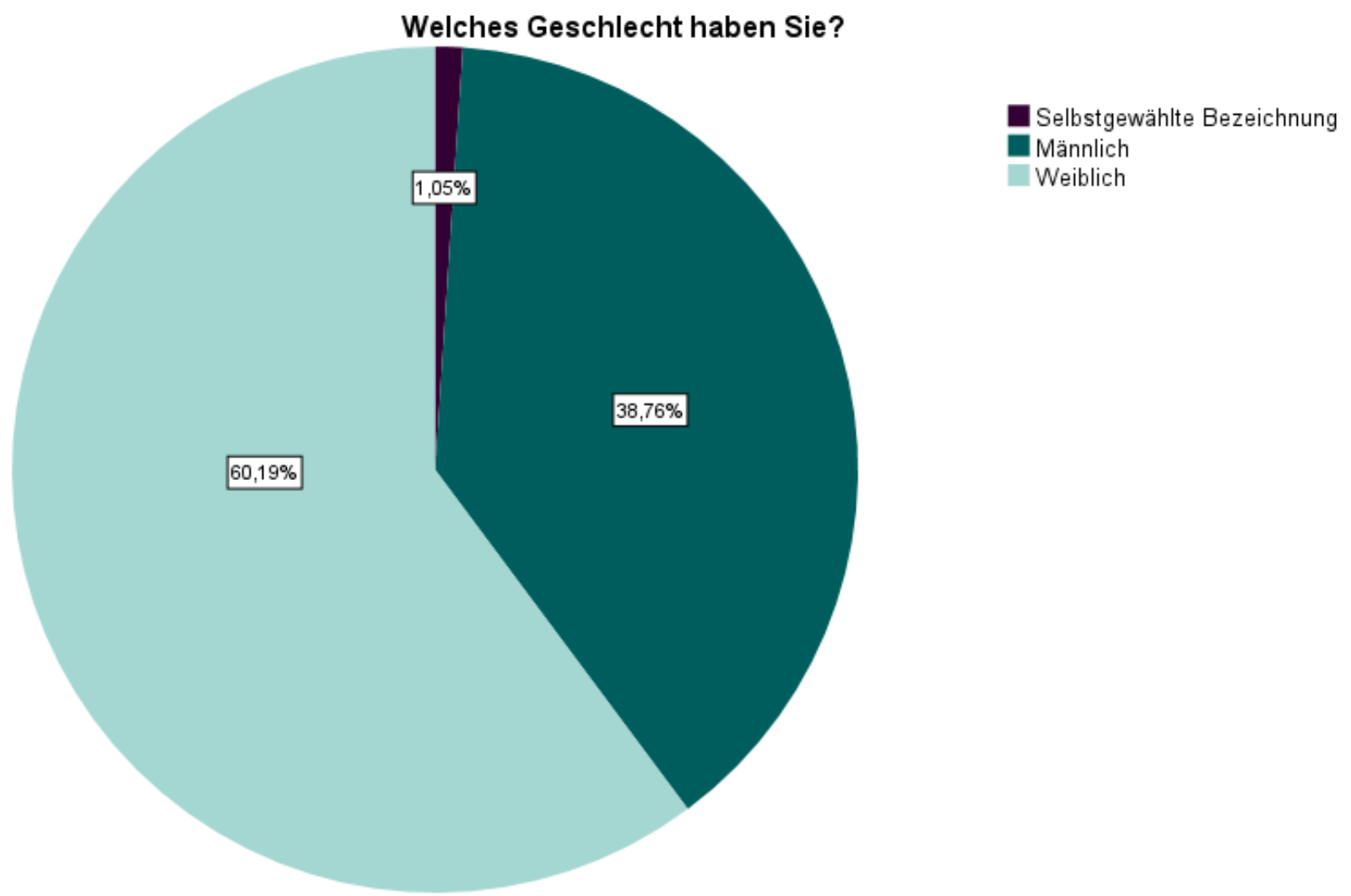

\section{Ausbildungsniveau}

Höchster Bildungsabschluss

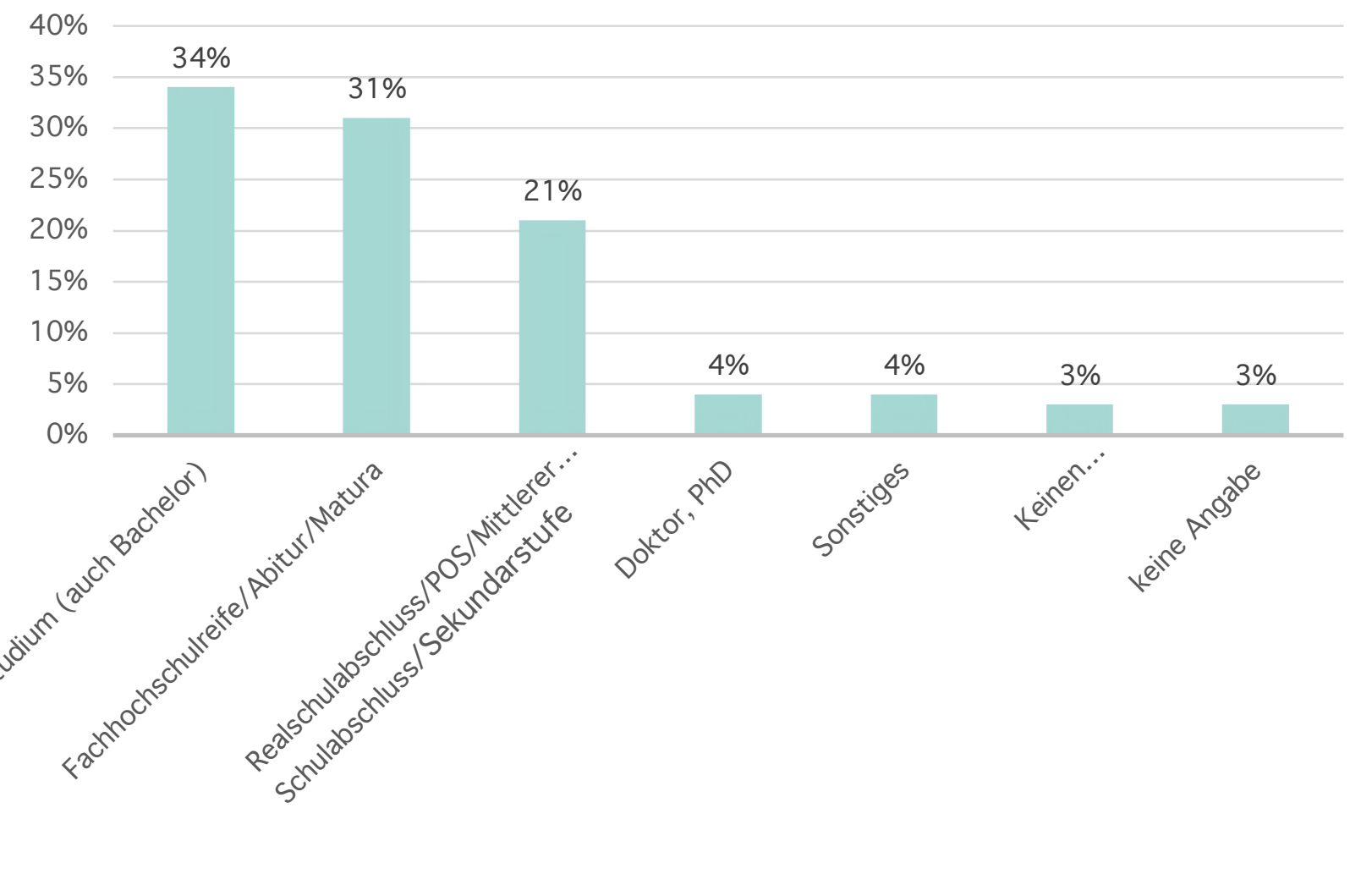




\section{Beschäftigungssituation}

\section{Erwerbsstatus}

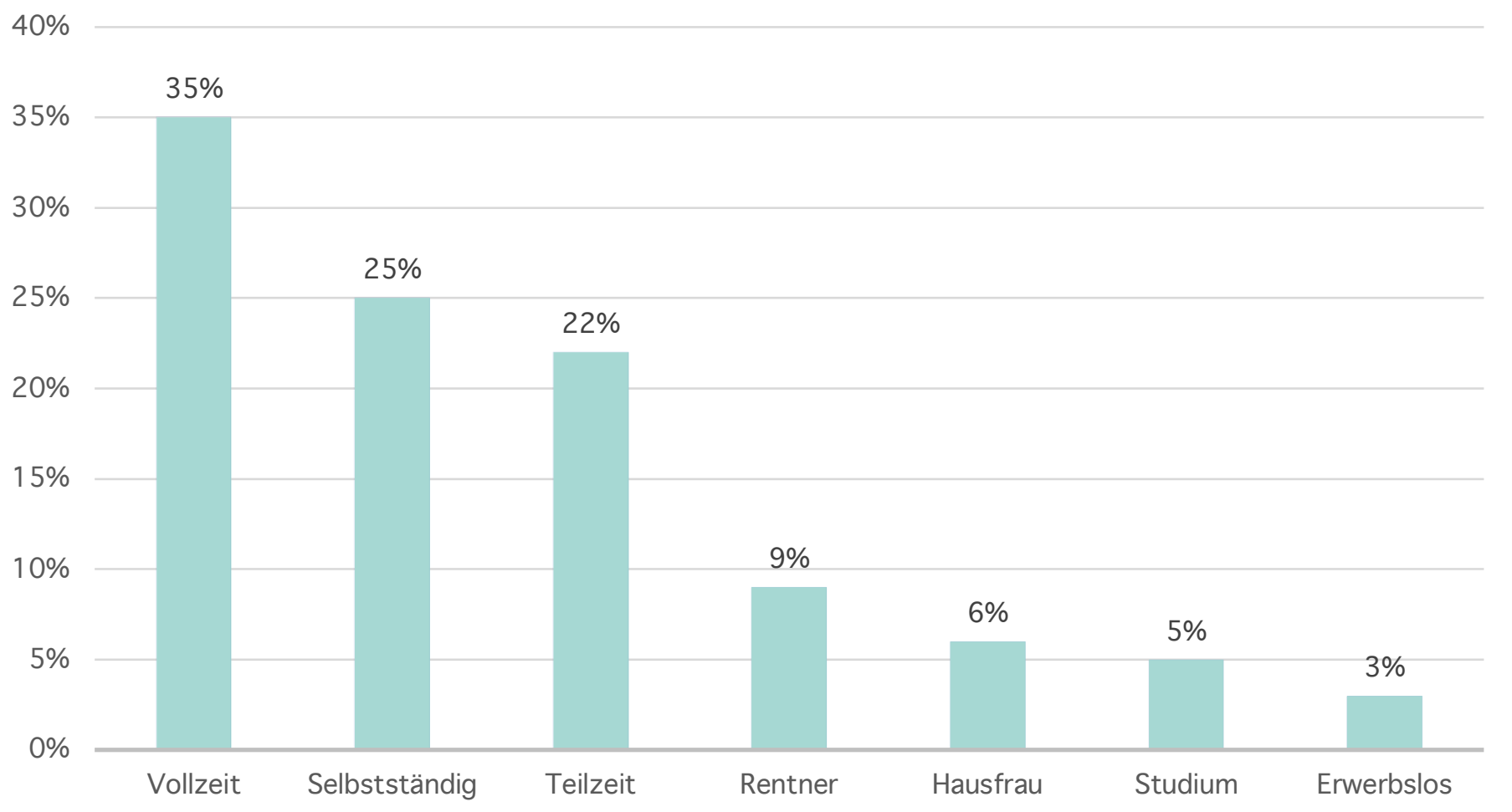

\section{Anteil der Selbstständigen De, AT und $\mathrm{CH}$ im Vergleich zur Studie}

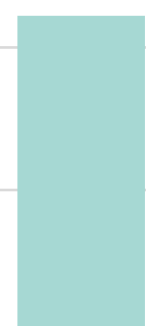




\section{Haben Sie oder hatten Sie selbst in ihrem Beruf Personalverantwortung?}

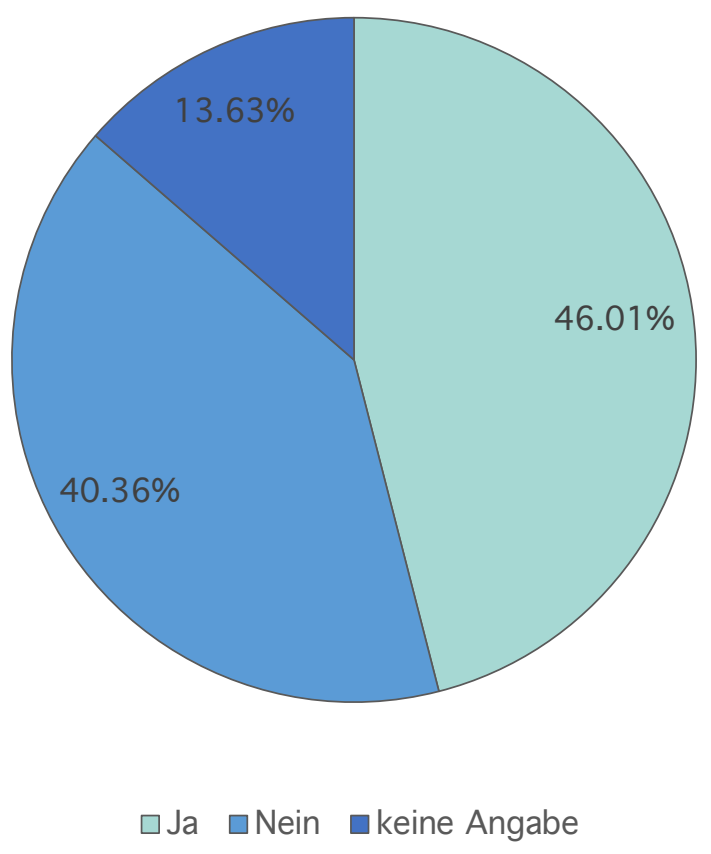

\section{Wahrgenommene Schichtzugehörigkeit}

Menschen beschreiben sich manchmal als Angehörige der Arbeiterschicht, der Mittelschicht oder der Unteroder Oberschicht. Als Angehöriger welcher Schicht würden Sie sich beschreiben?

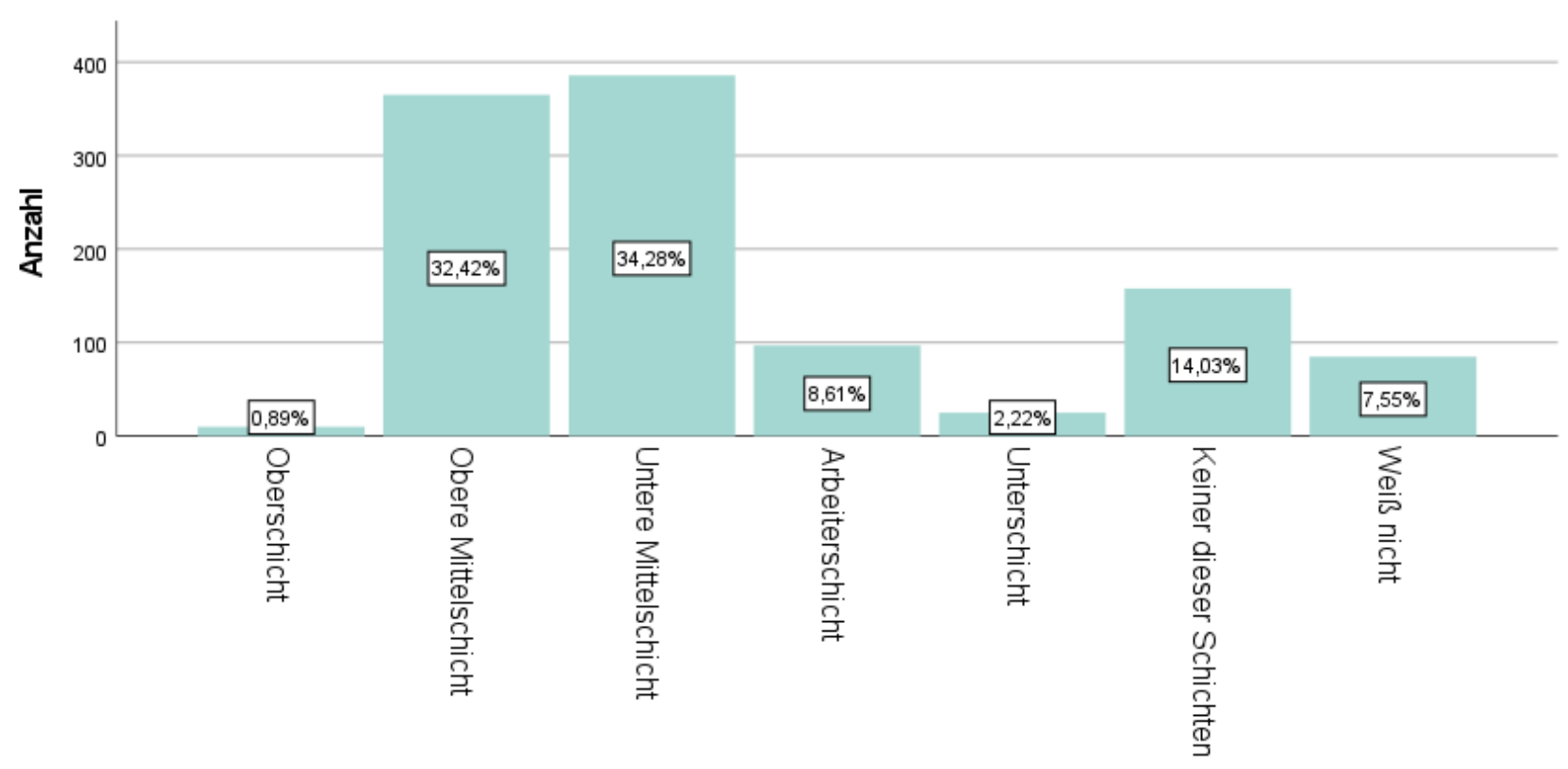


Nationalität bei Geburt

BRD

$806(70 \%)$

Schweiz $191(16,6 \%)$

Österreich $67 \quad(5,8 \%)$

Andere

$88(7,8 \%)$

\section{Wahlberechtigung}

BRD

$822(71,4 \%)$

Schweiz $210(18,2 \%)$

Österreich 69 (6\%)

Andere

\section{Wahlverhalten}

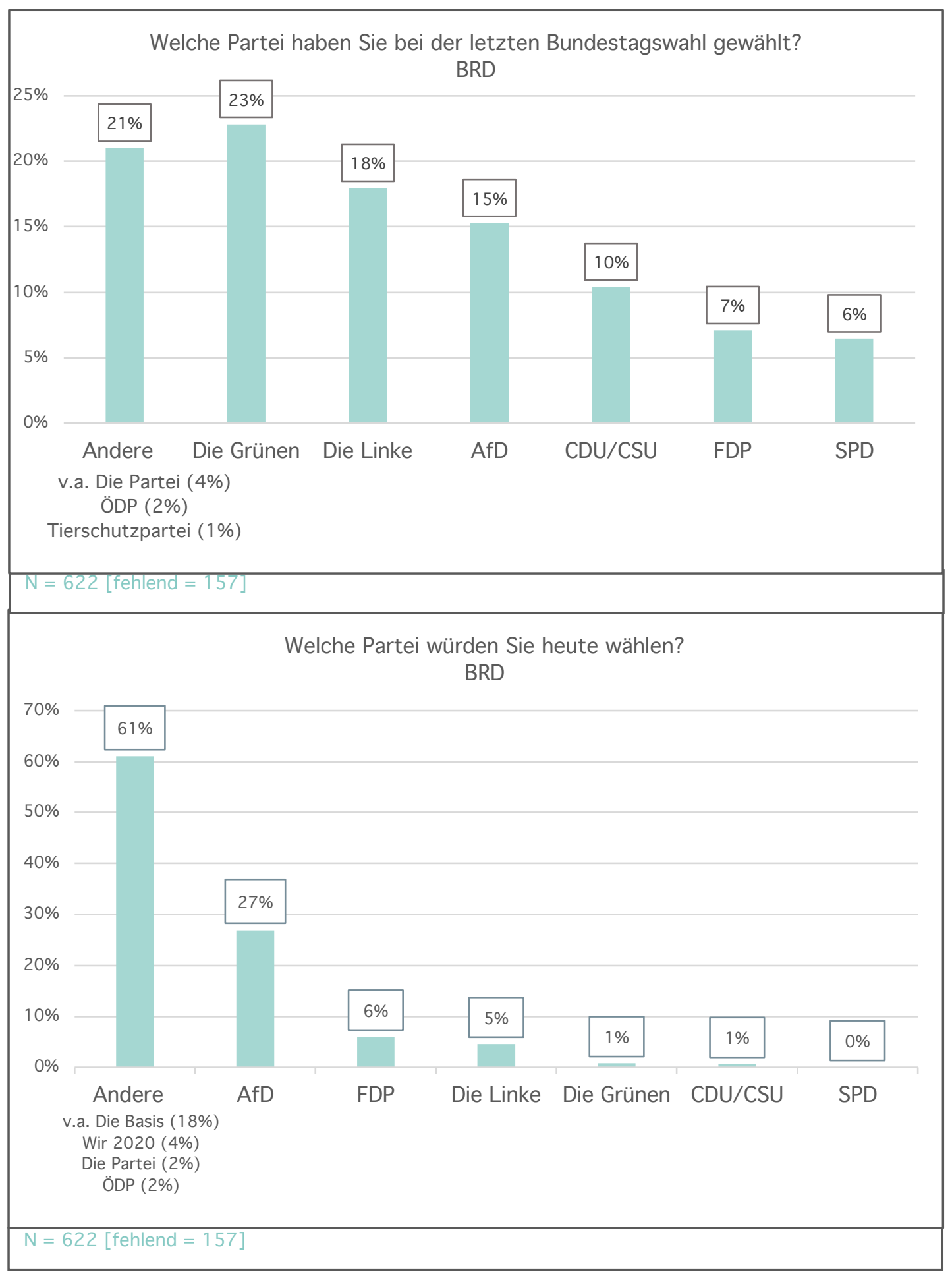




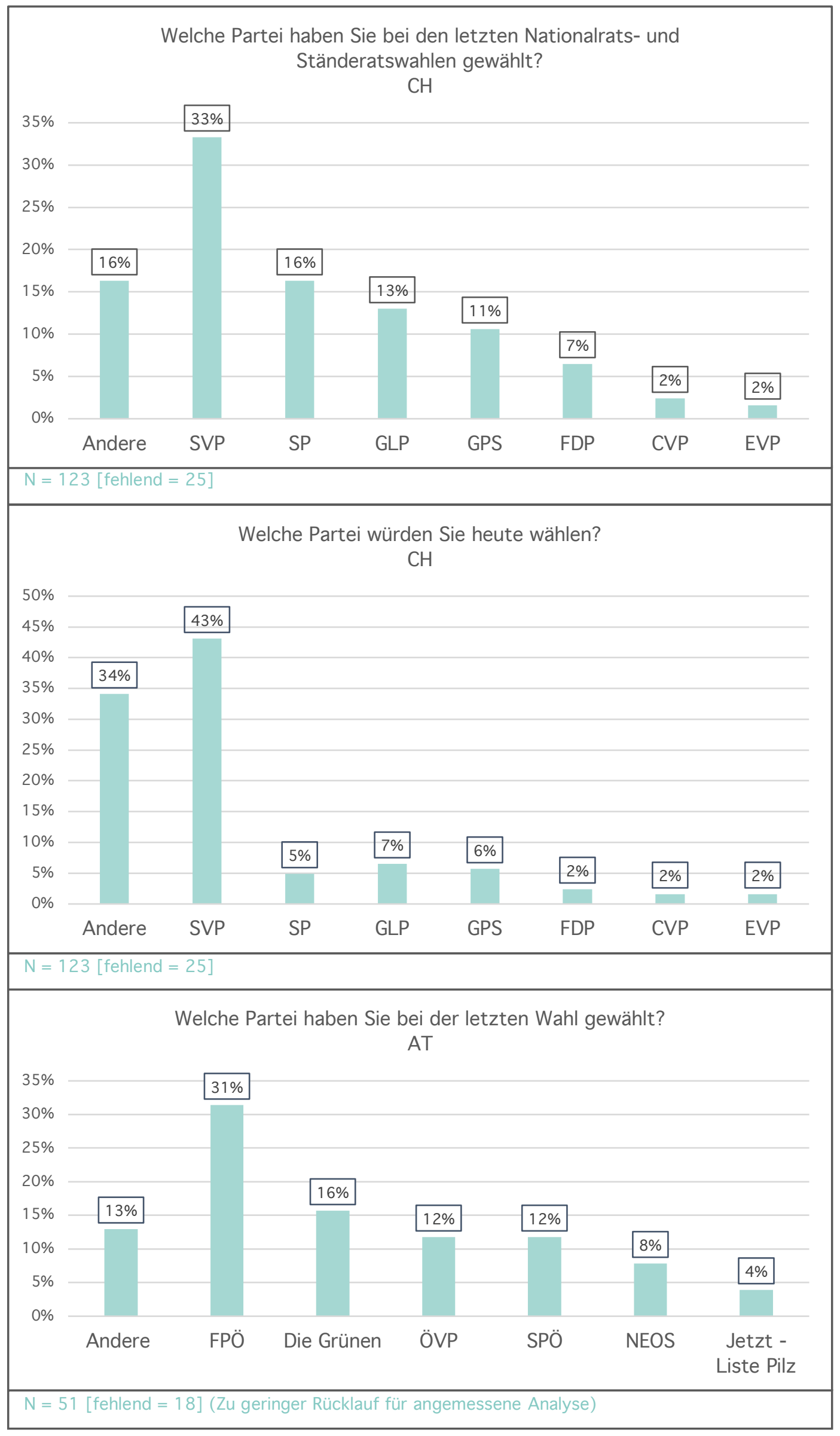




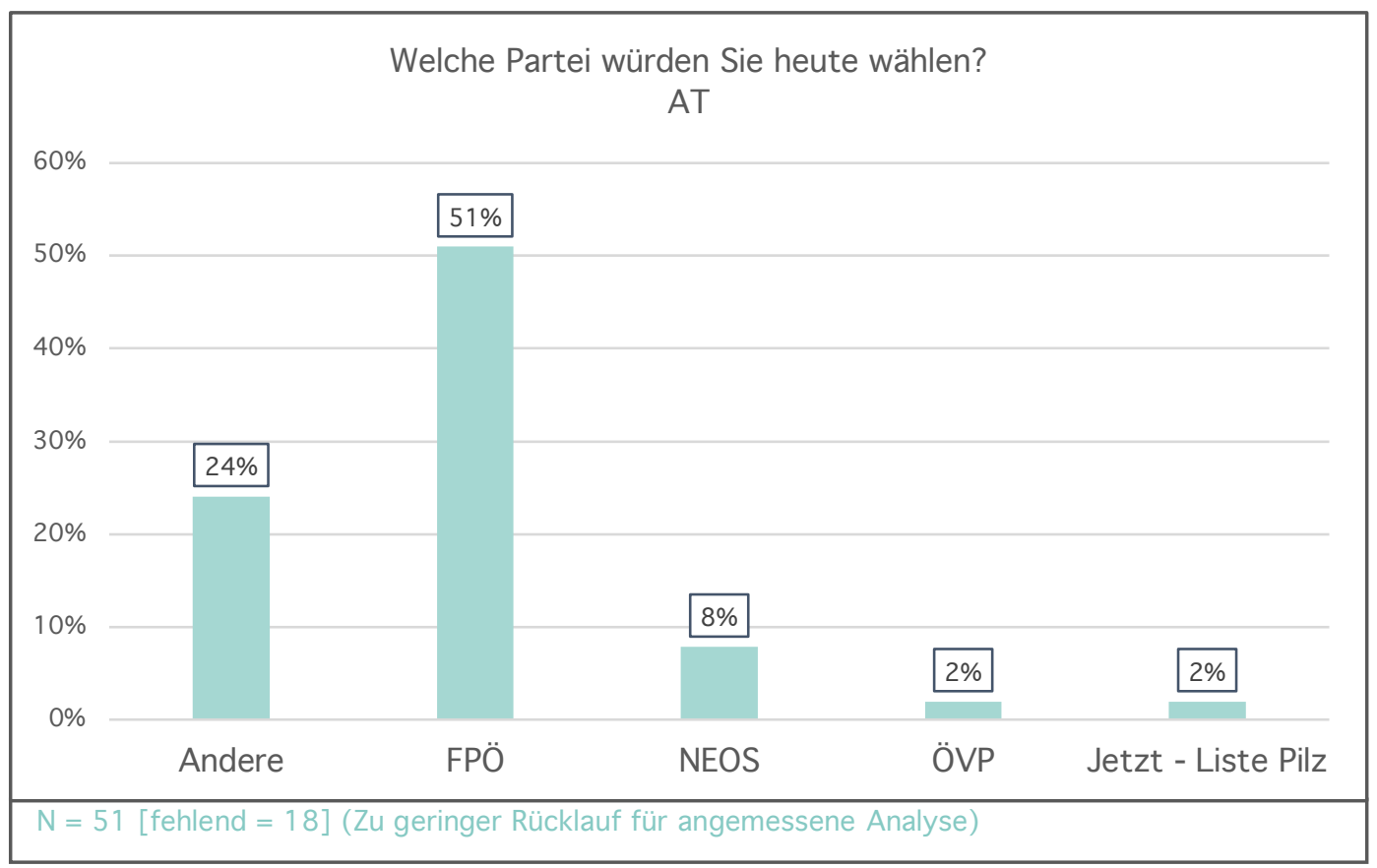

\section{Einstellungsmerkmale}

Medienkritik in der Corona-Krise

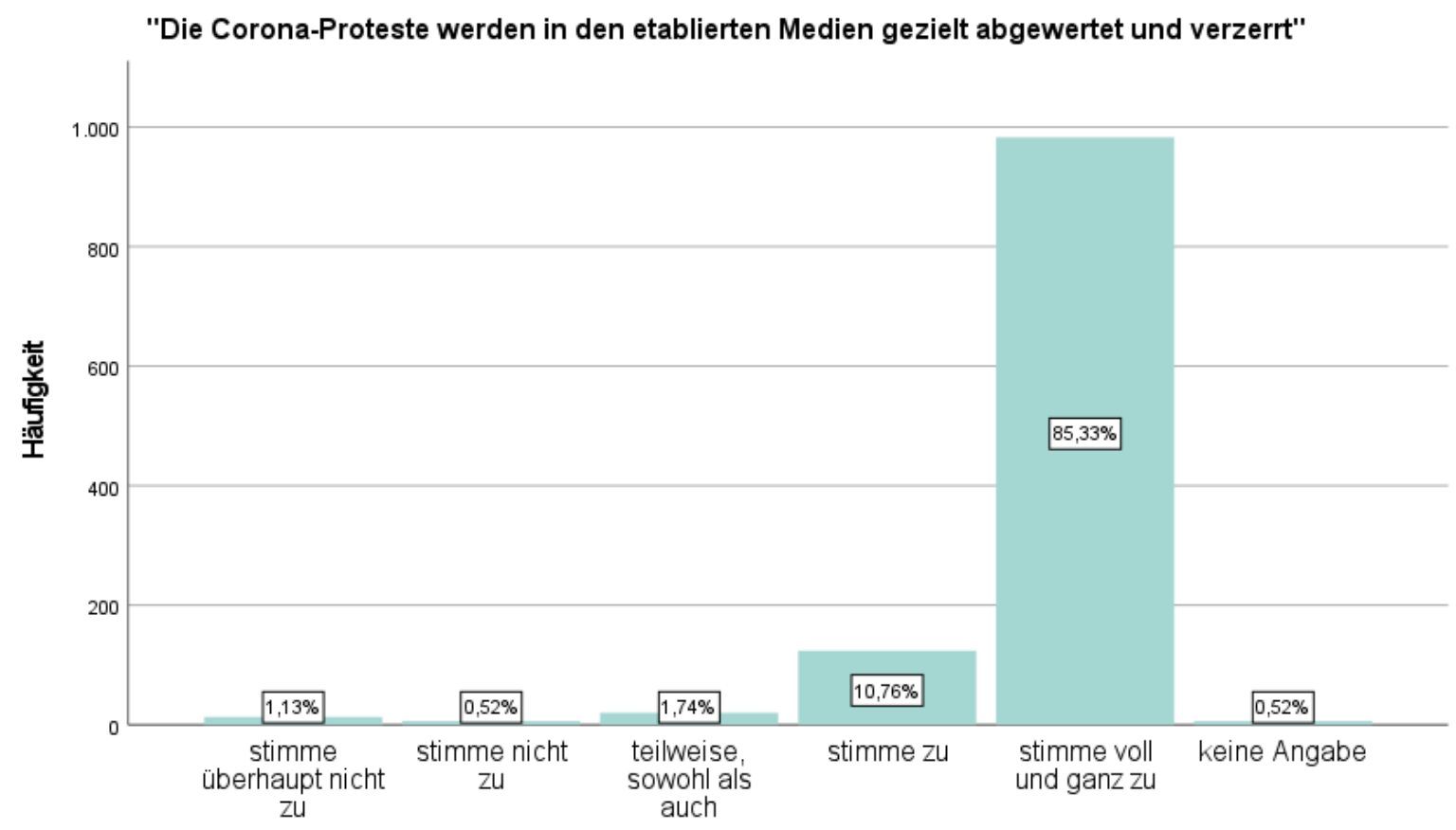



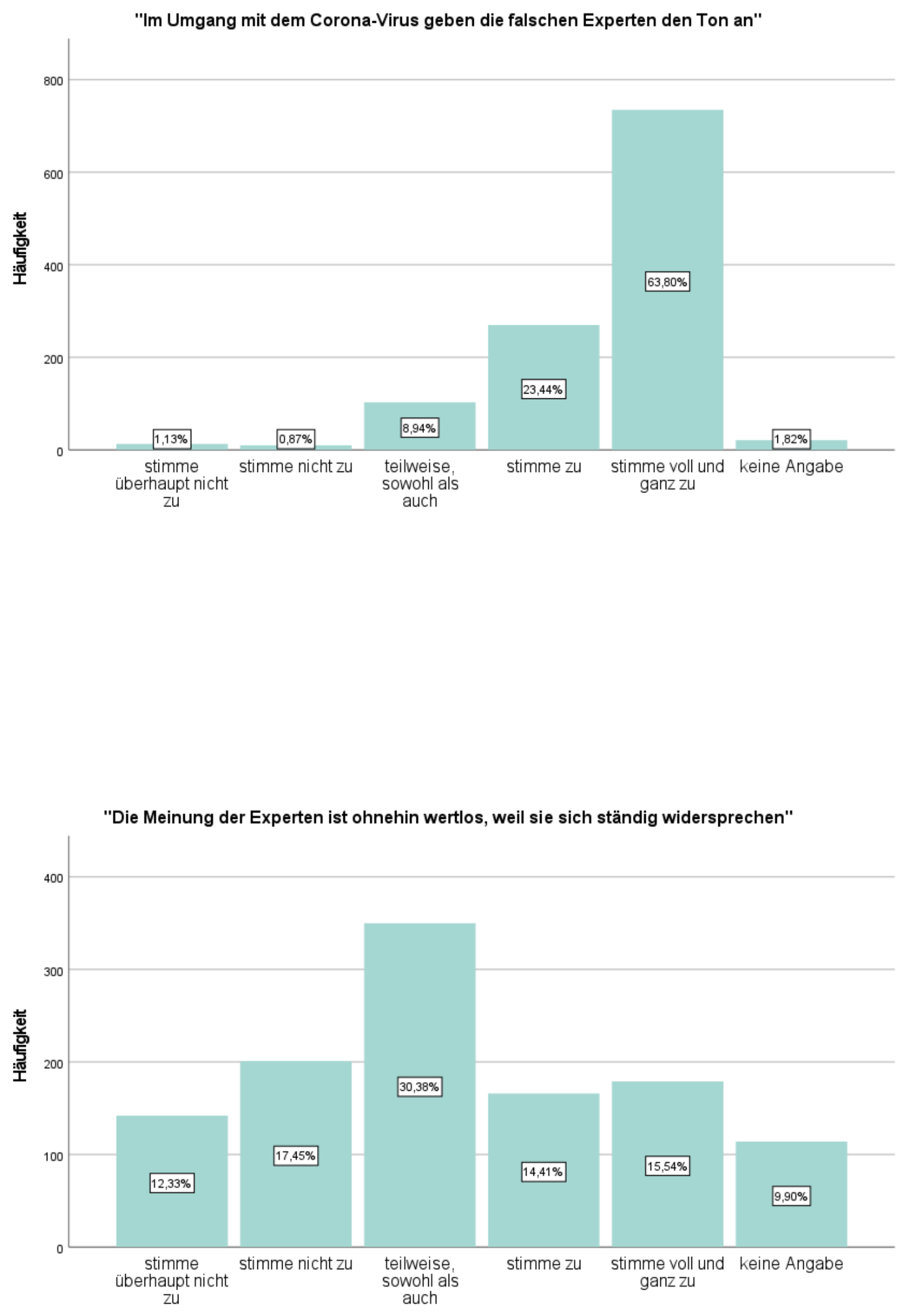


\section{Regierungskritik in der Corona-Krise}
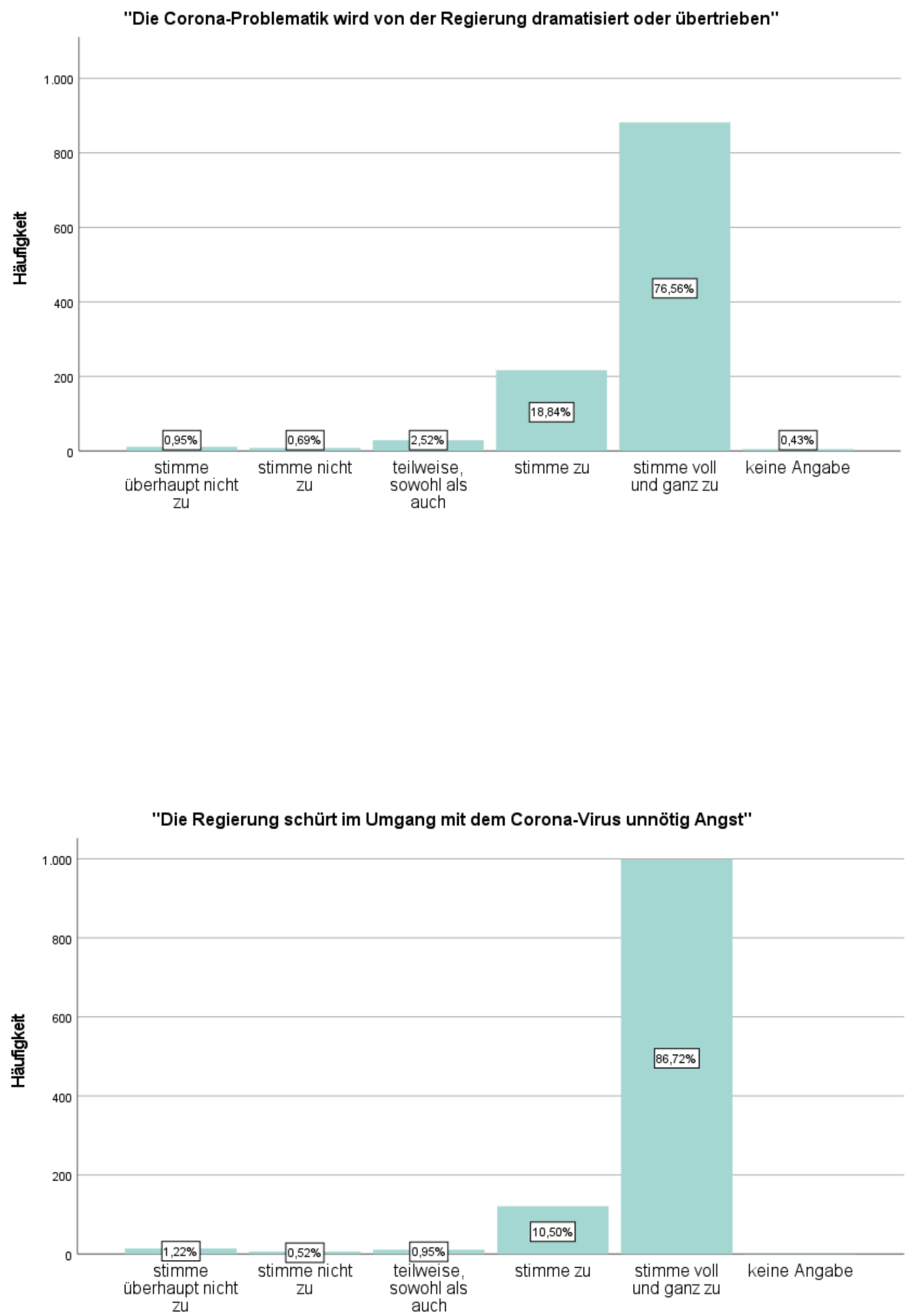


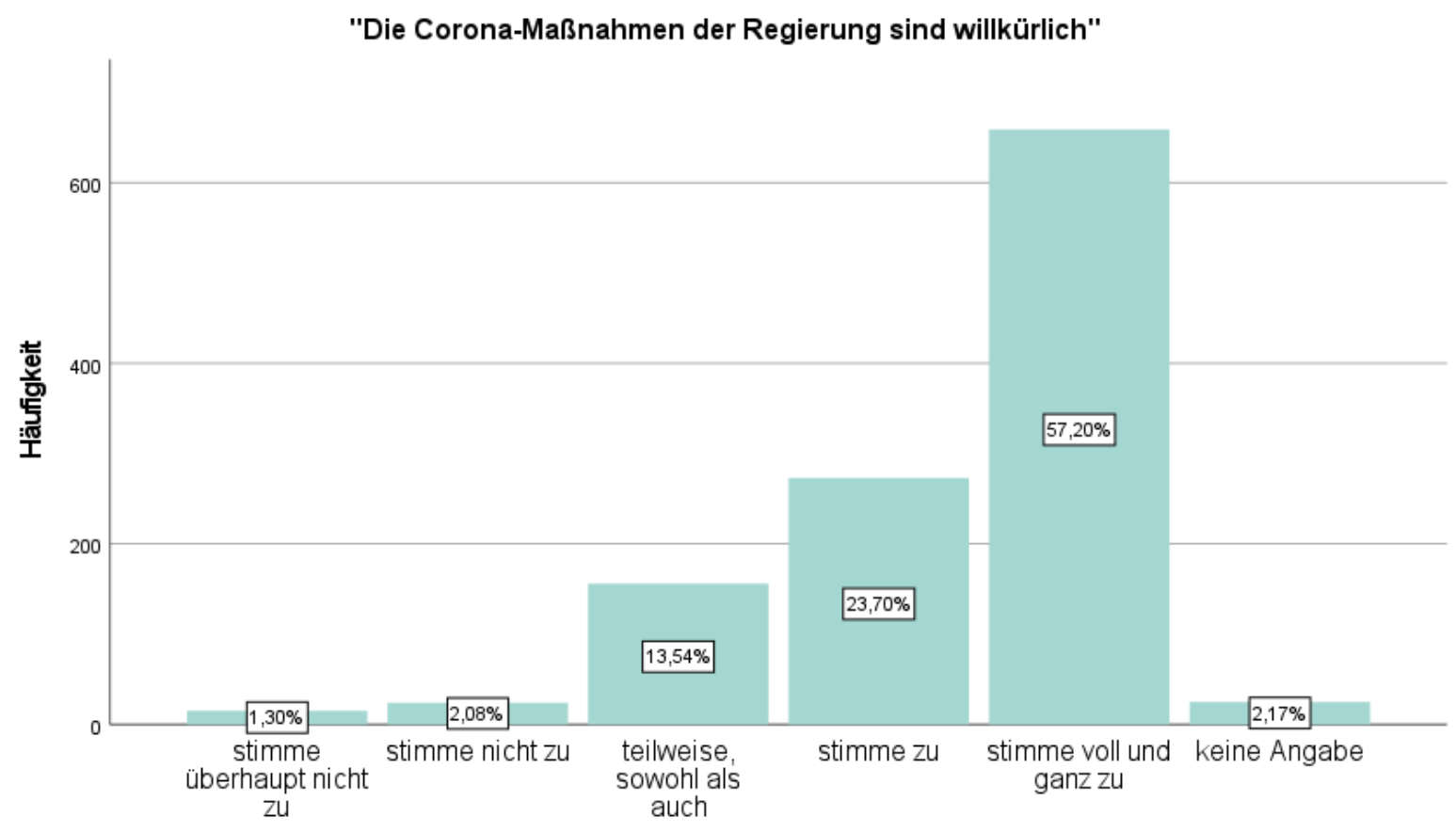

"Der Staat hat für die von Coronamassnahmen wirtschaftlich betroffenen Menschen effektive finanzielle Hilfen zur Verfügung gestellt"

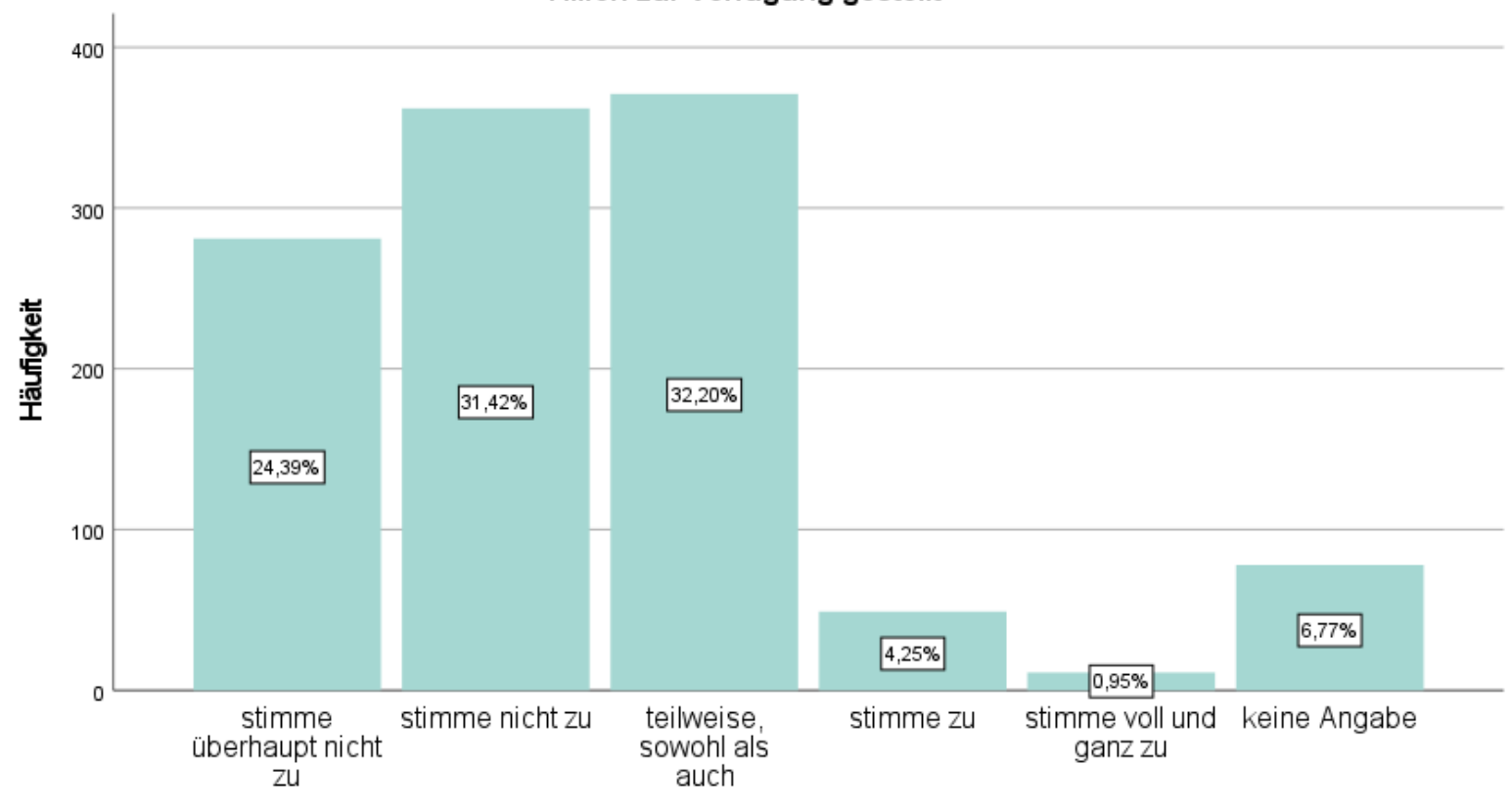



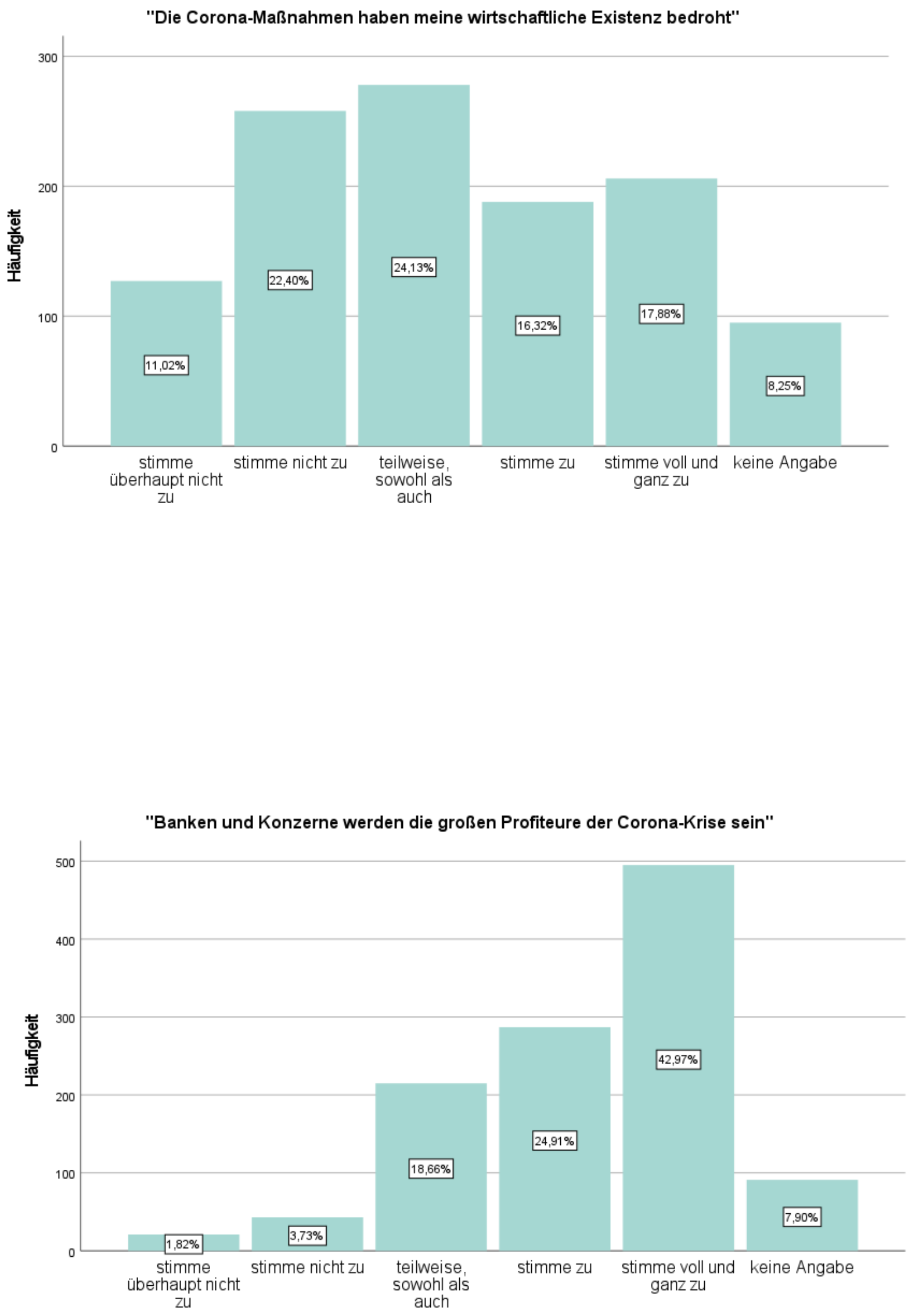
"Die Corona-Maßnahmen der Regierung sind überwiegend unwirksam"

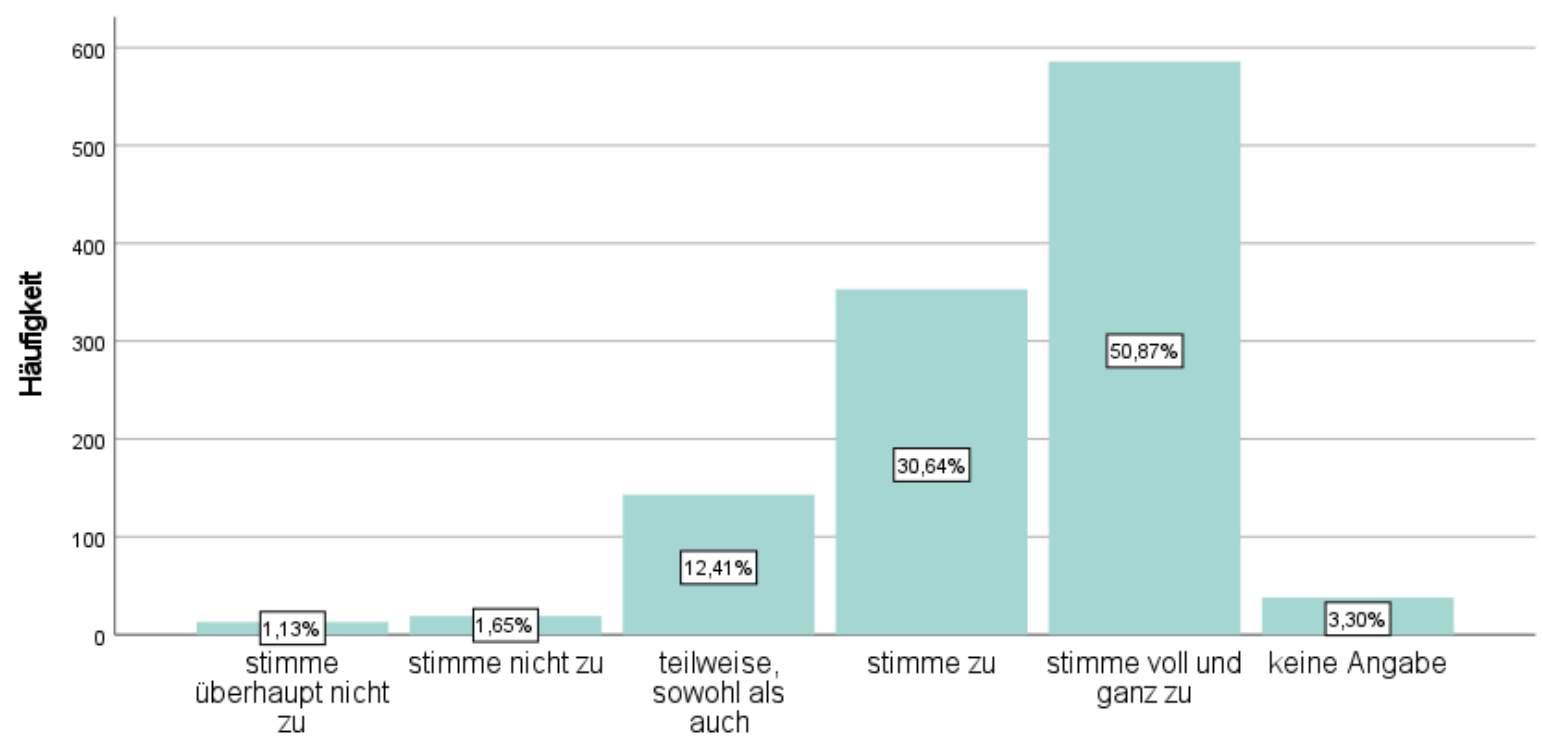

"Die Corona-Maßnahmen bedrohen Meinungsfreiheit und Demokratie"

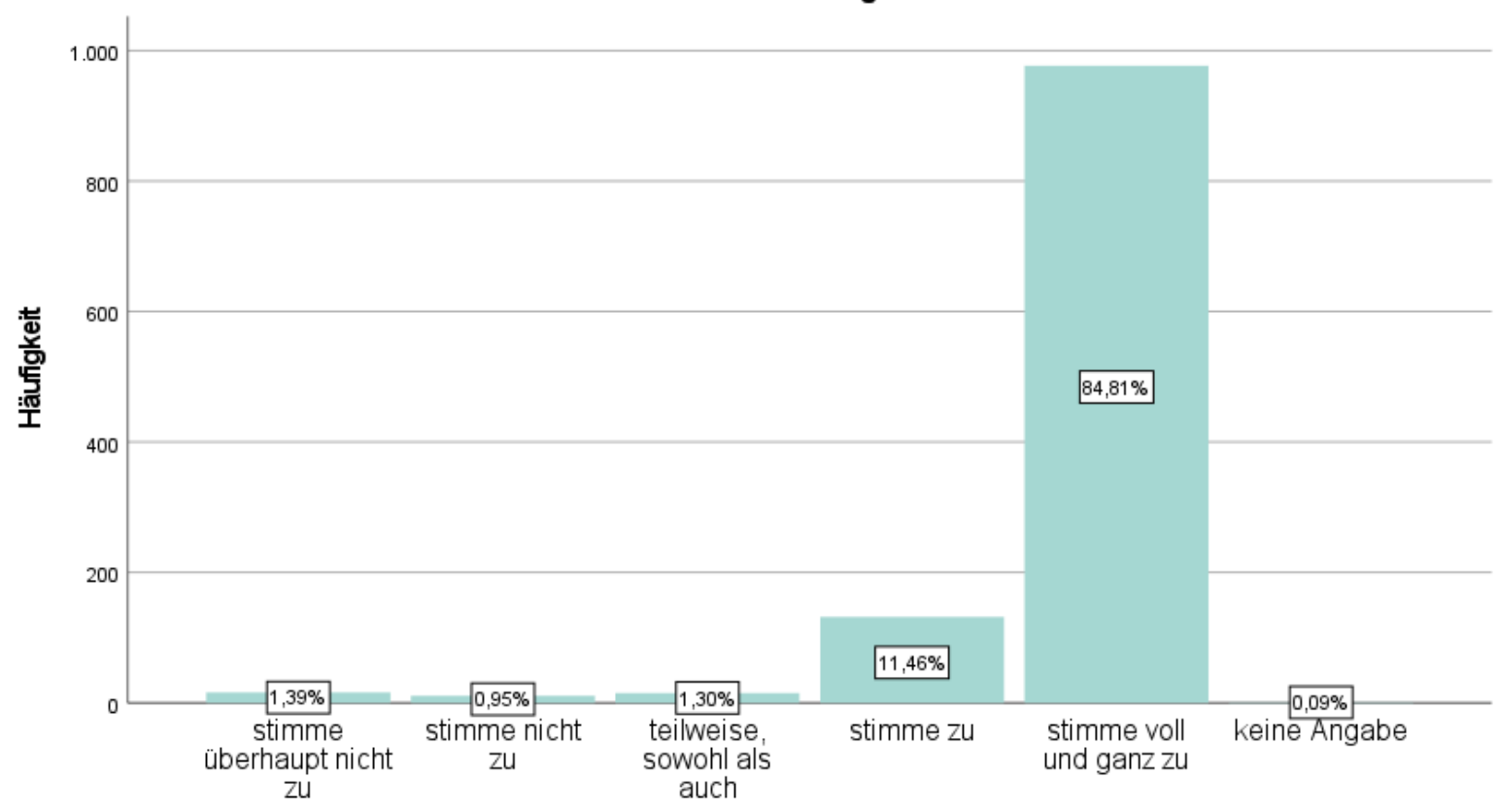



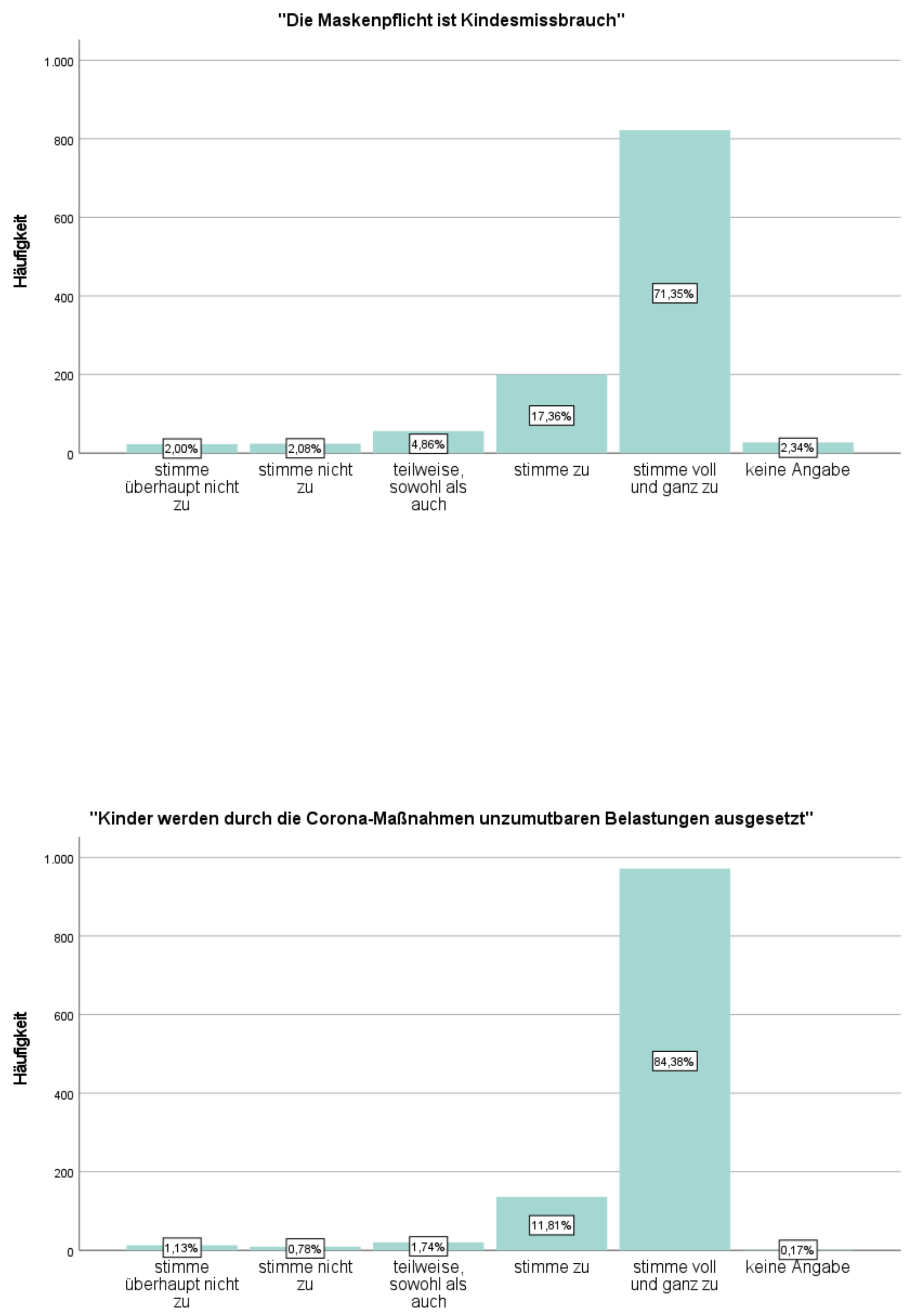
"Das Home-Schooling hat gezeigt, dass wir keine Schulen brauchen, um unsere Kinder unterrichten zu können"

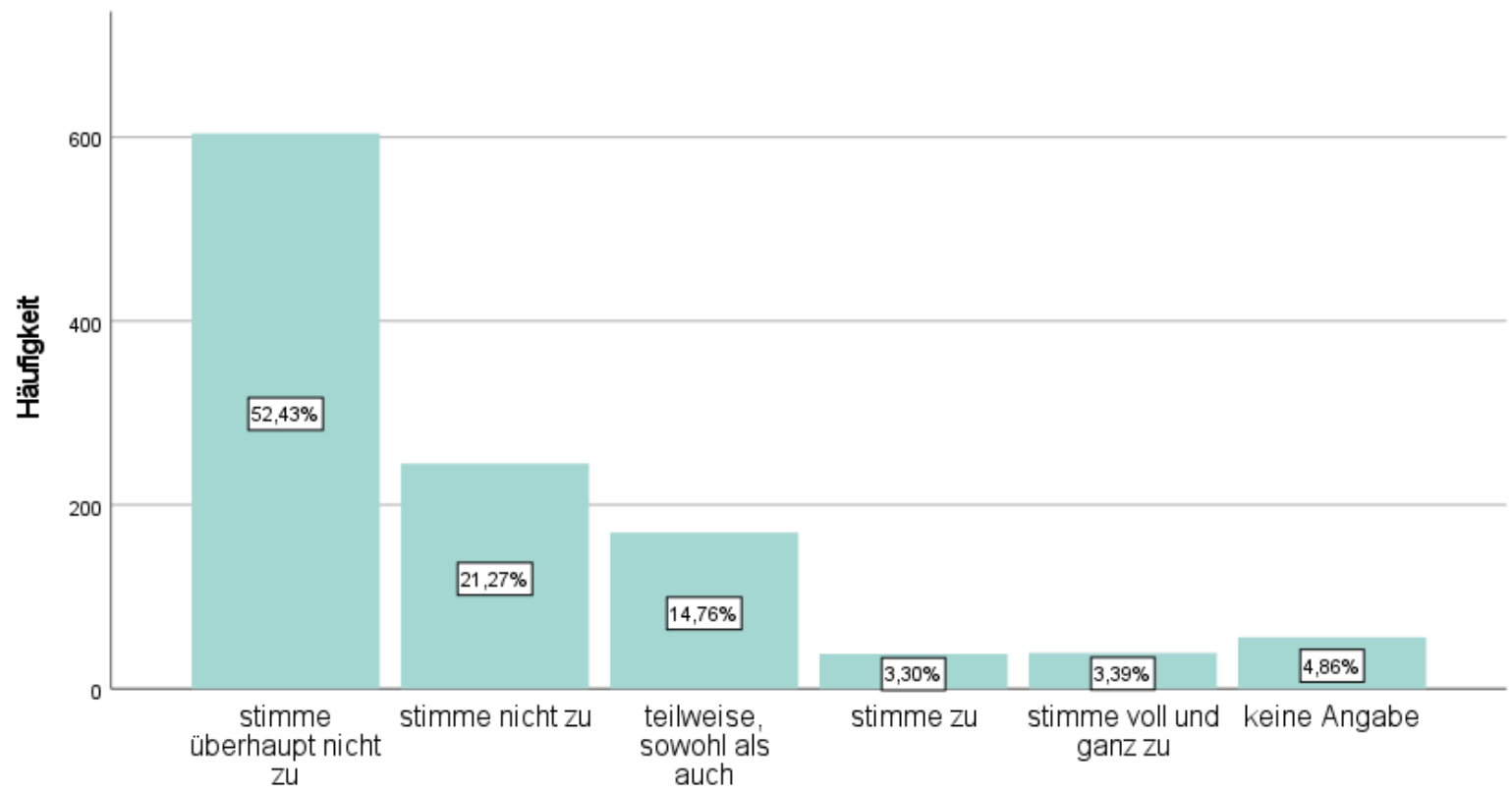

"Der Lockdown hat meine familiären Bindungen verbessert"

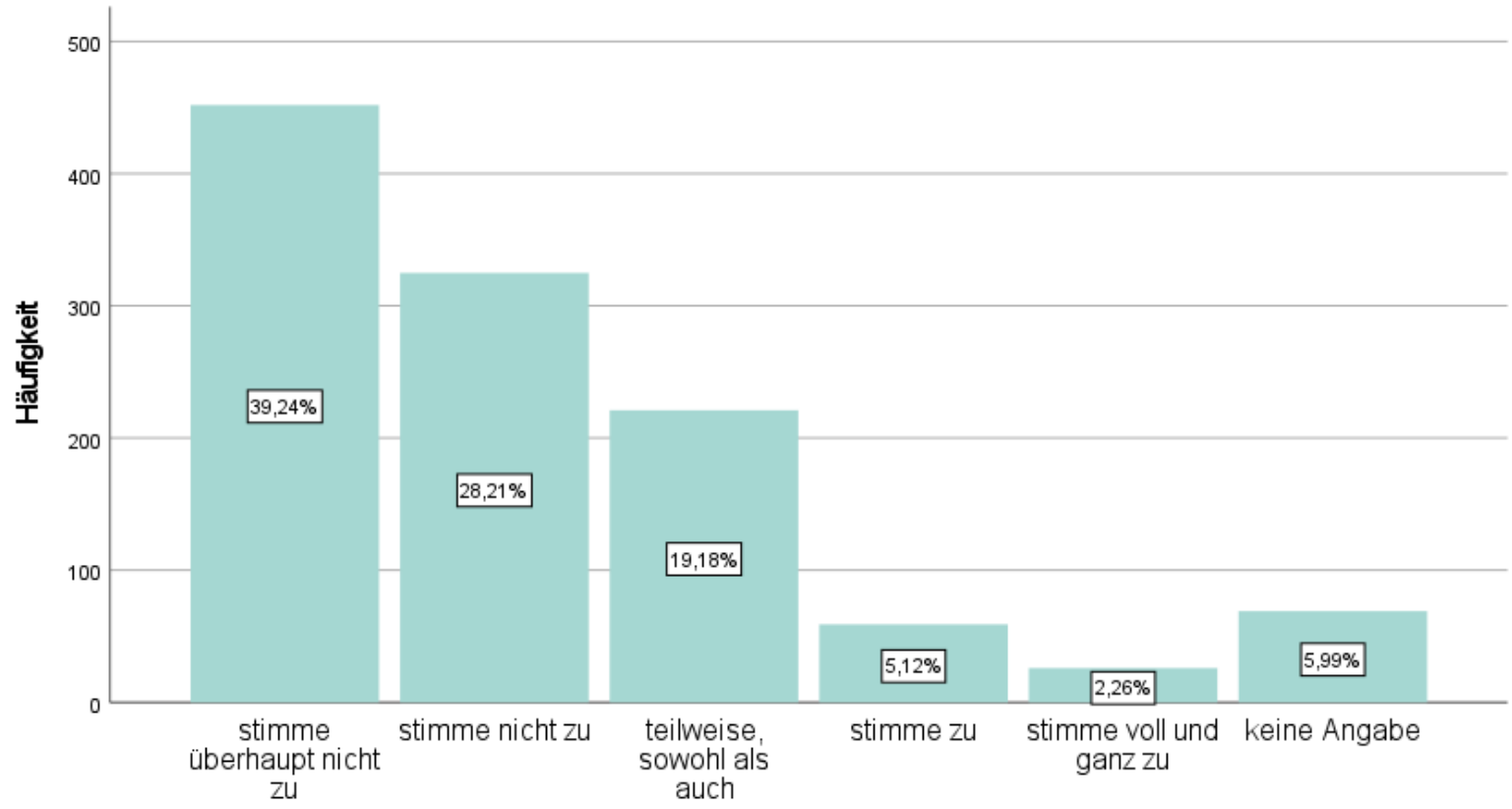


"Das Tragen einer einfachen Maske dient mehr dem eigenen Schutz als dem Schutz meiner Mitmenschen"

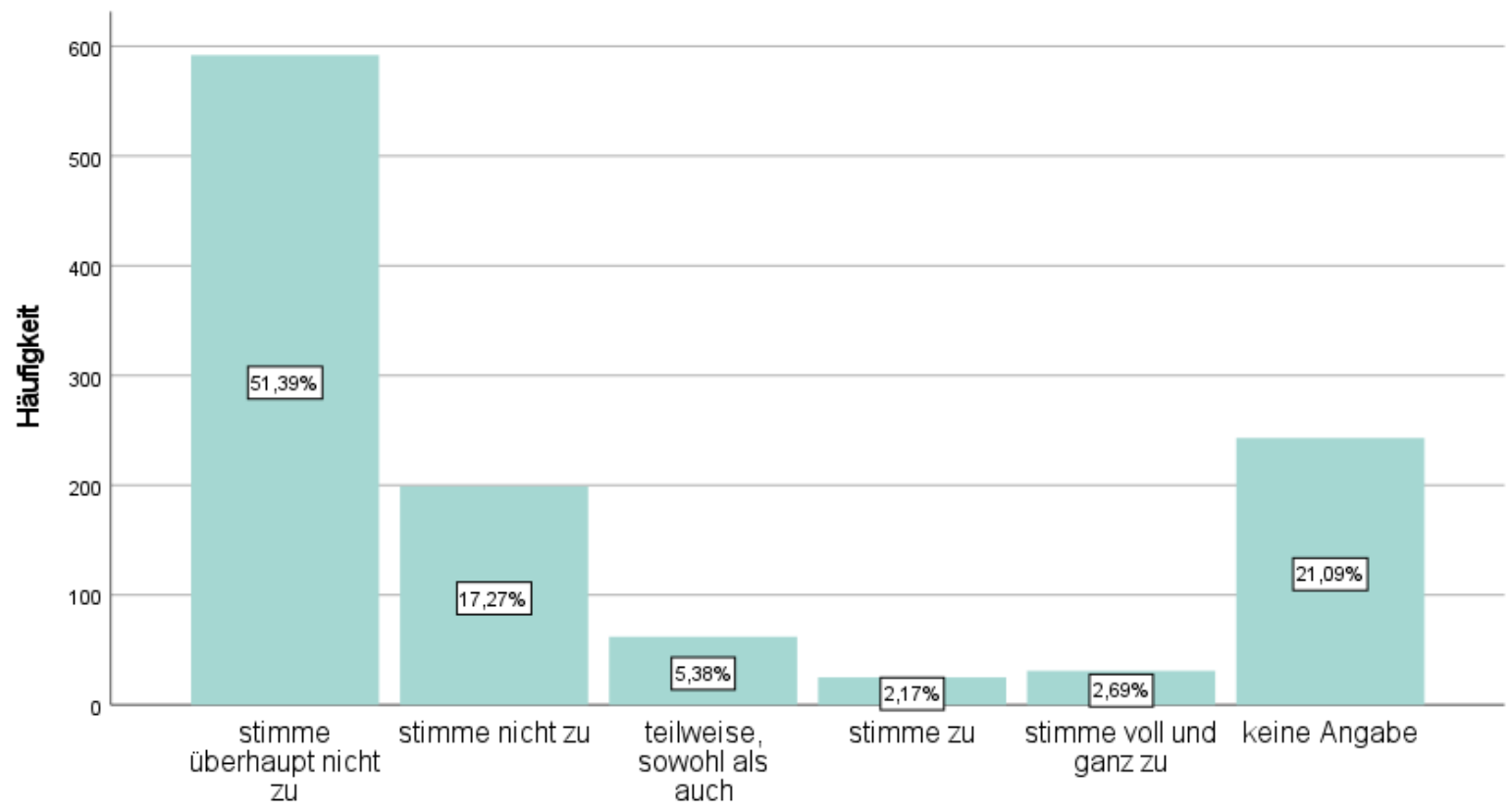

"Das Corona-Virus ist nicht gefährlicher als eine schwere Grippe"

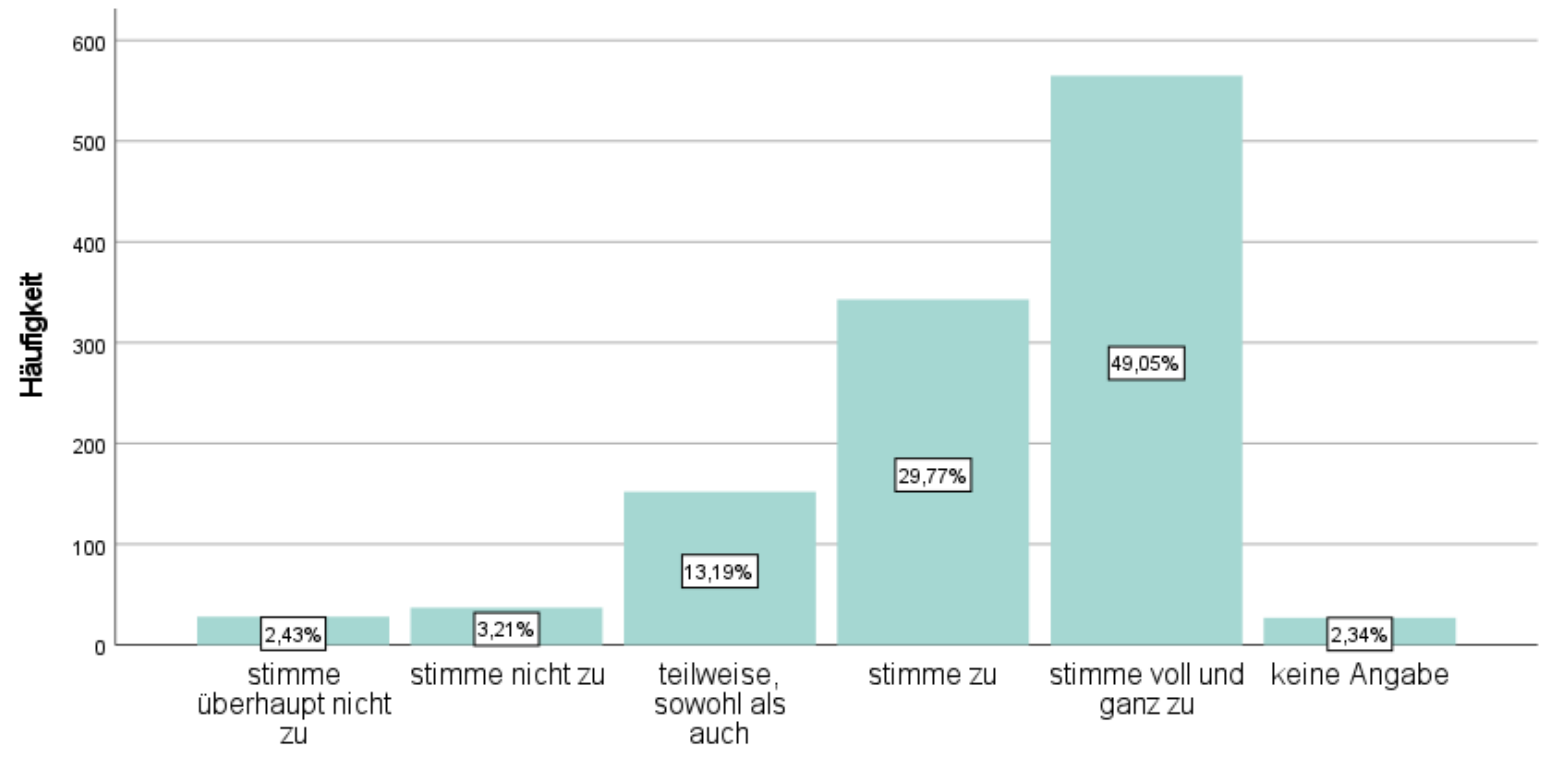




\section{Verschwörungstheorien}

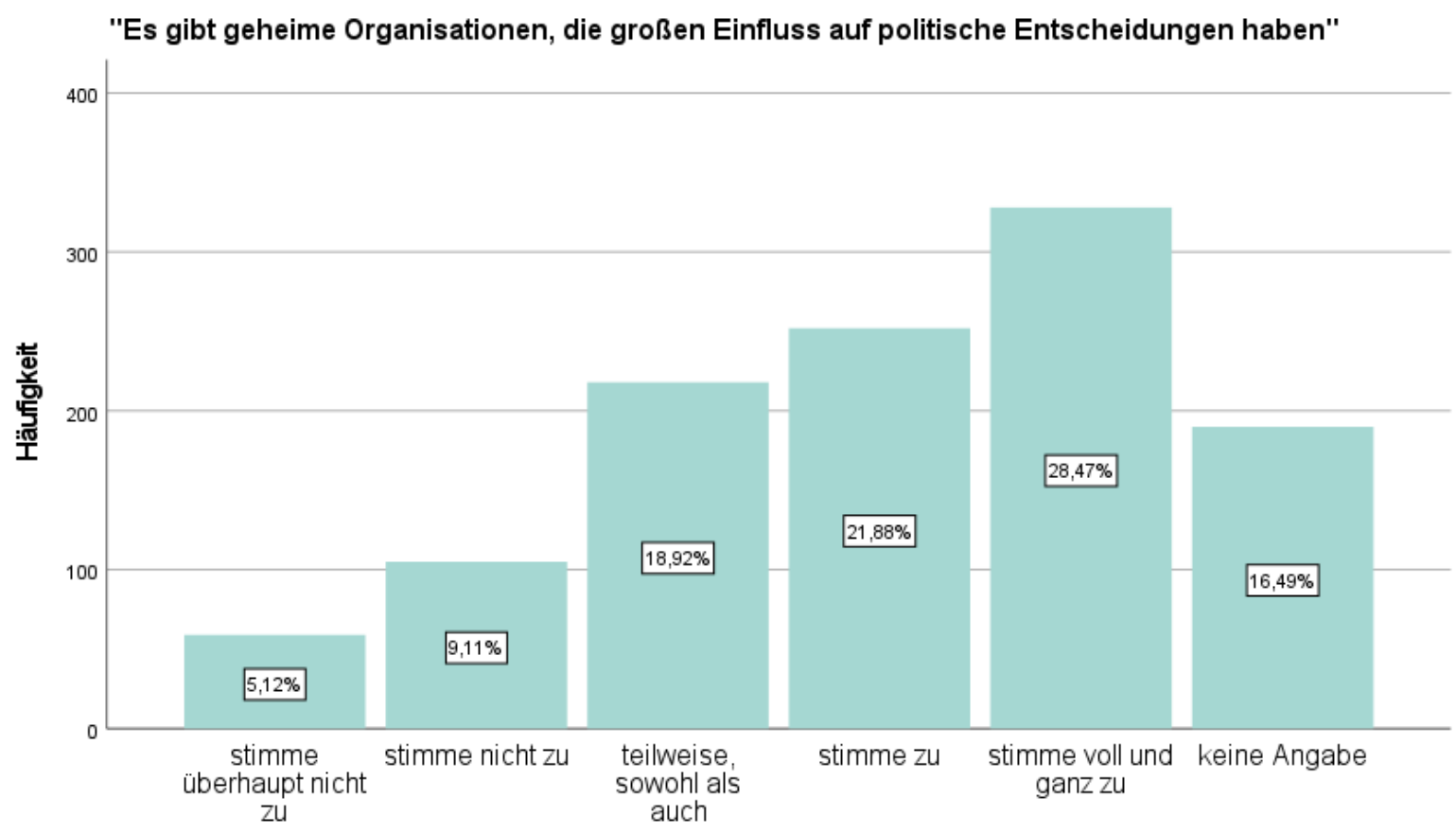

"Politiker und andere Führungspersönlichkeiten sind nur Marionetten der dahinterstehenden Mächte"

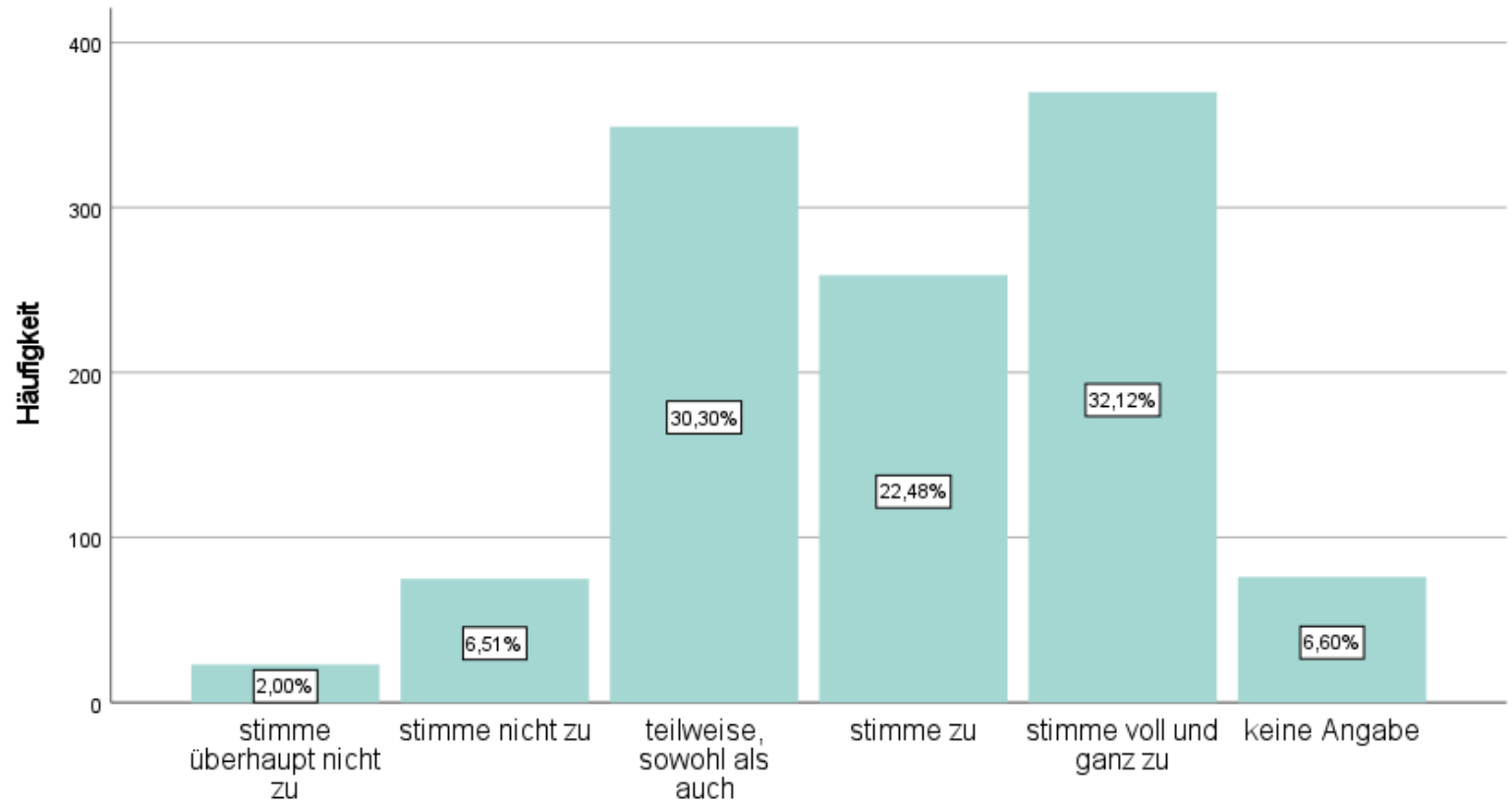



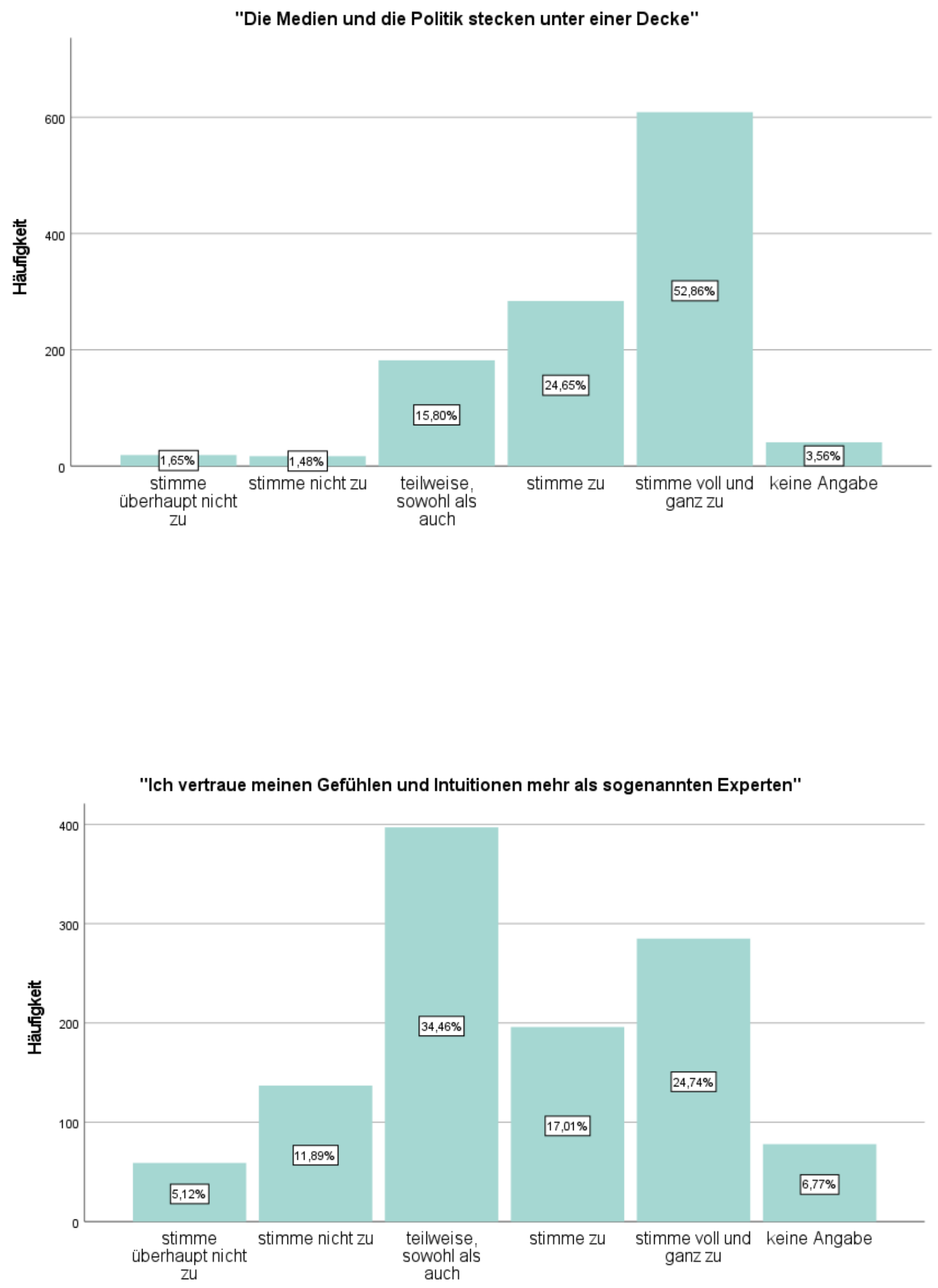

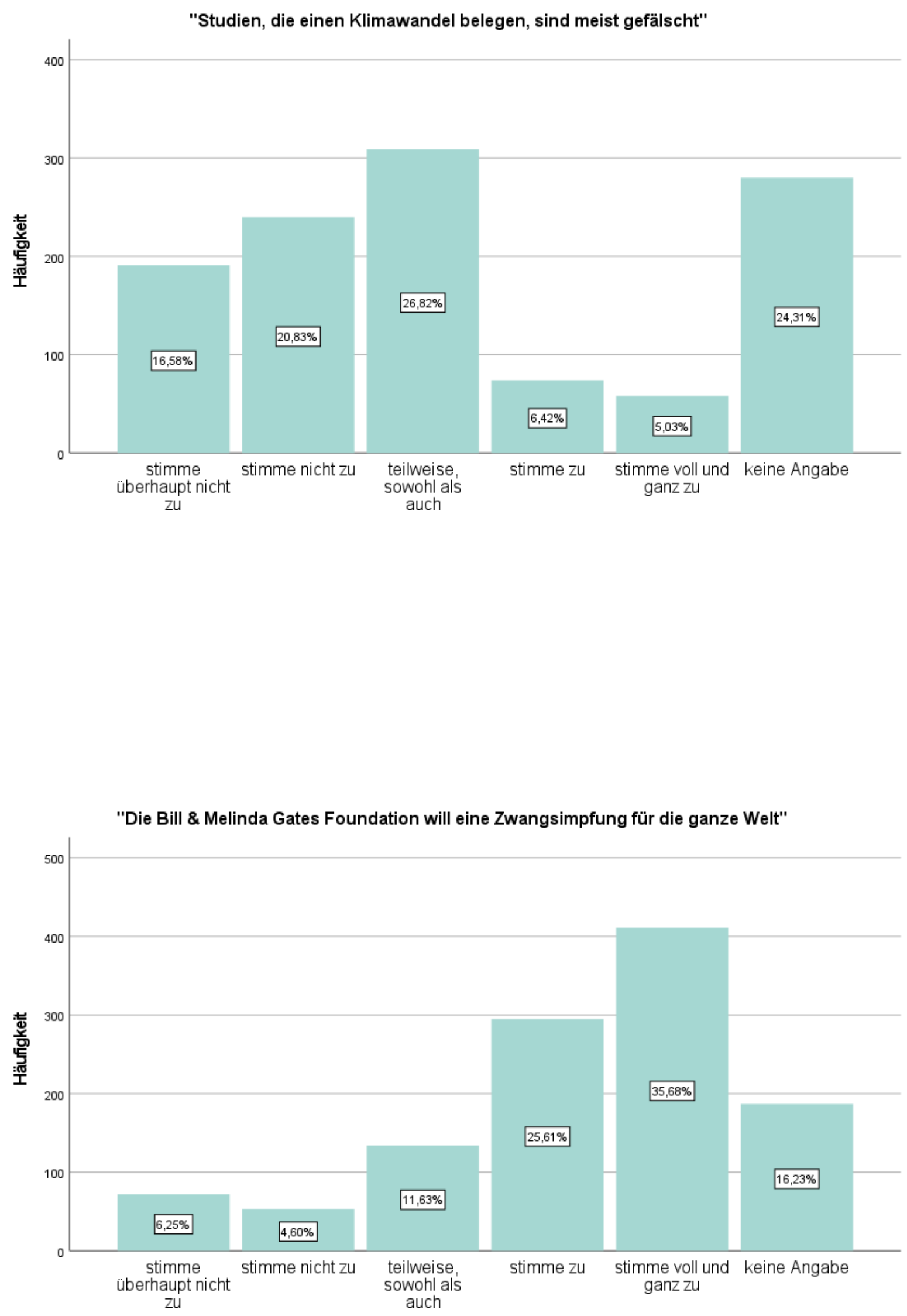


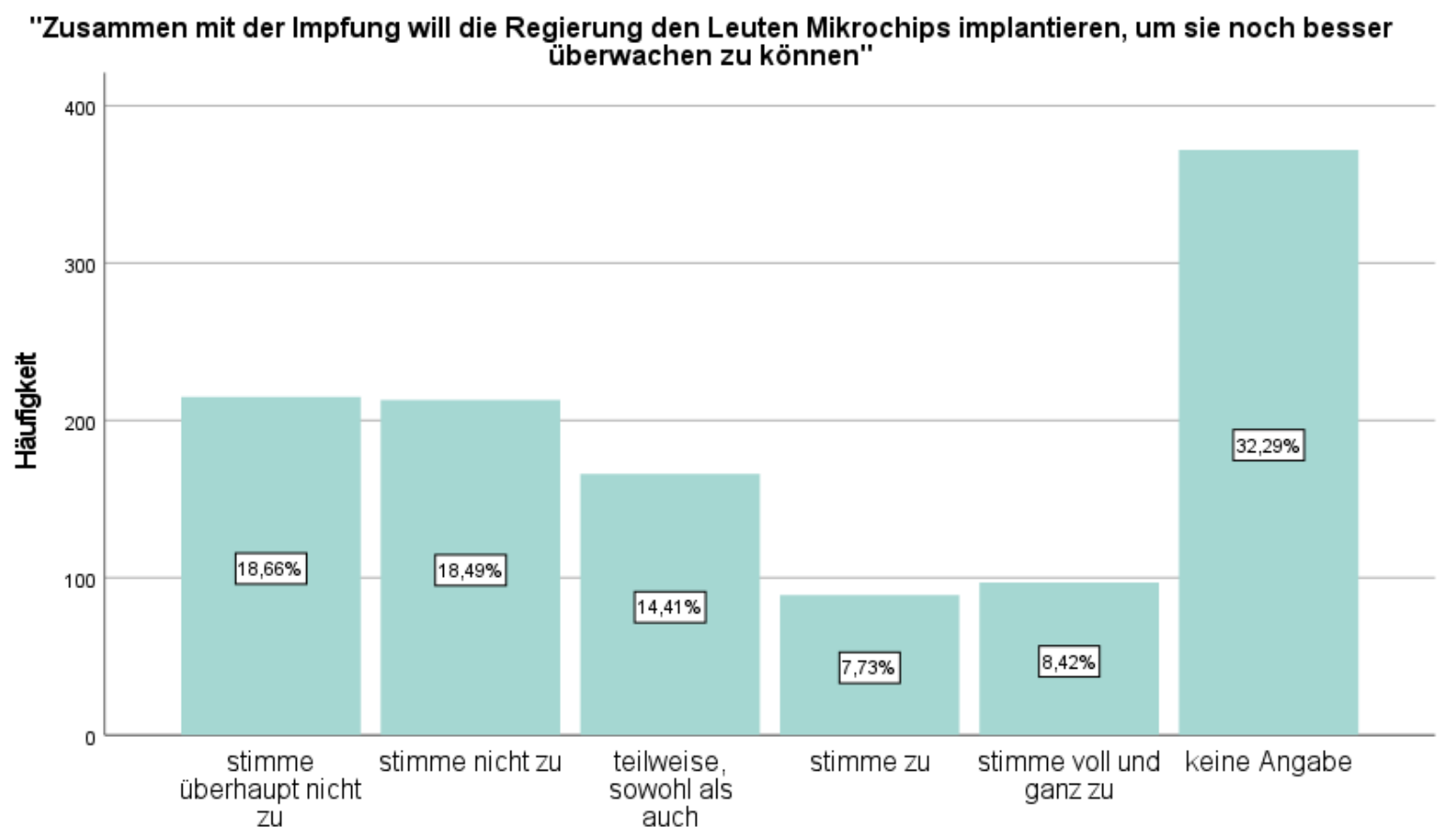

(Rechts-)Populismus

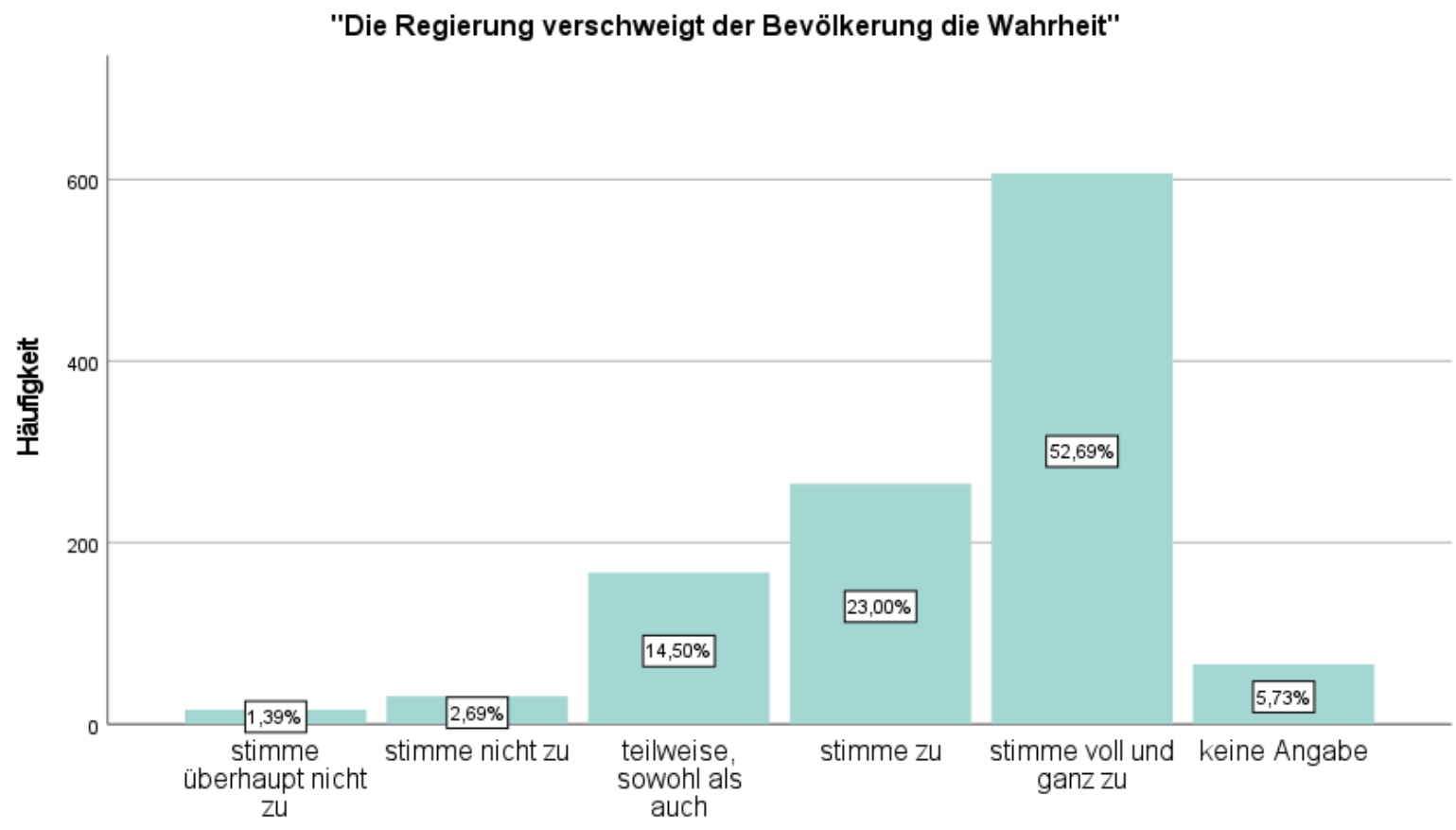



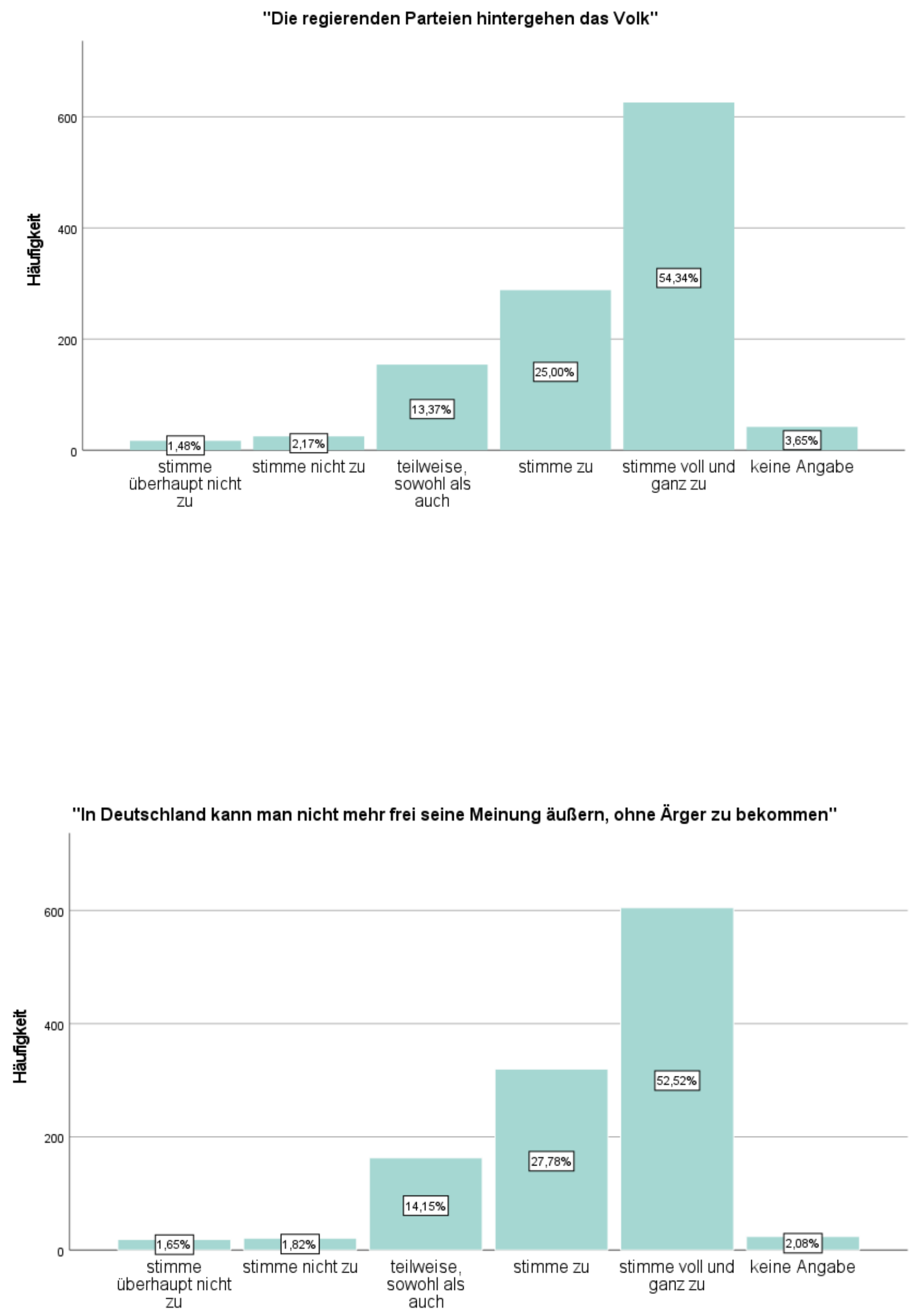

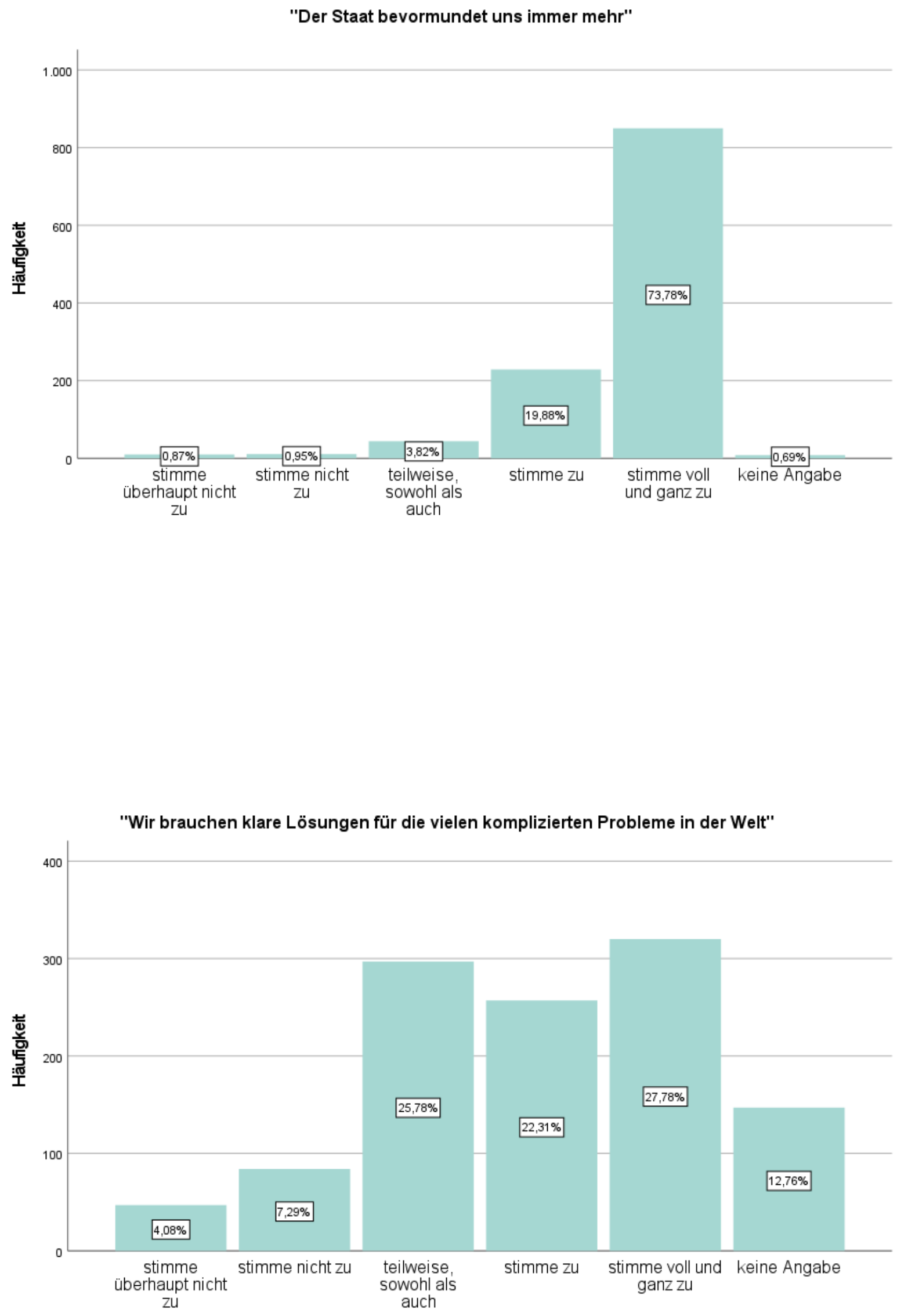

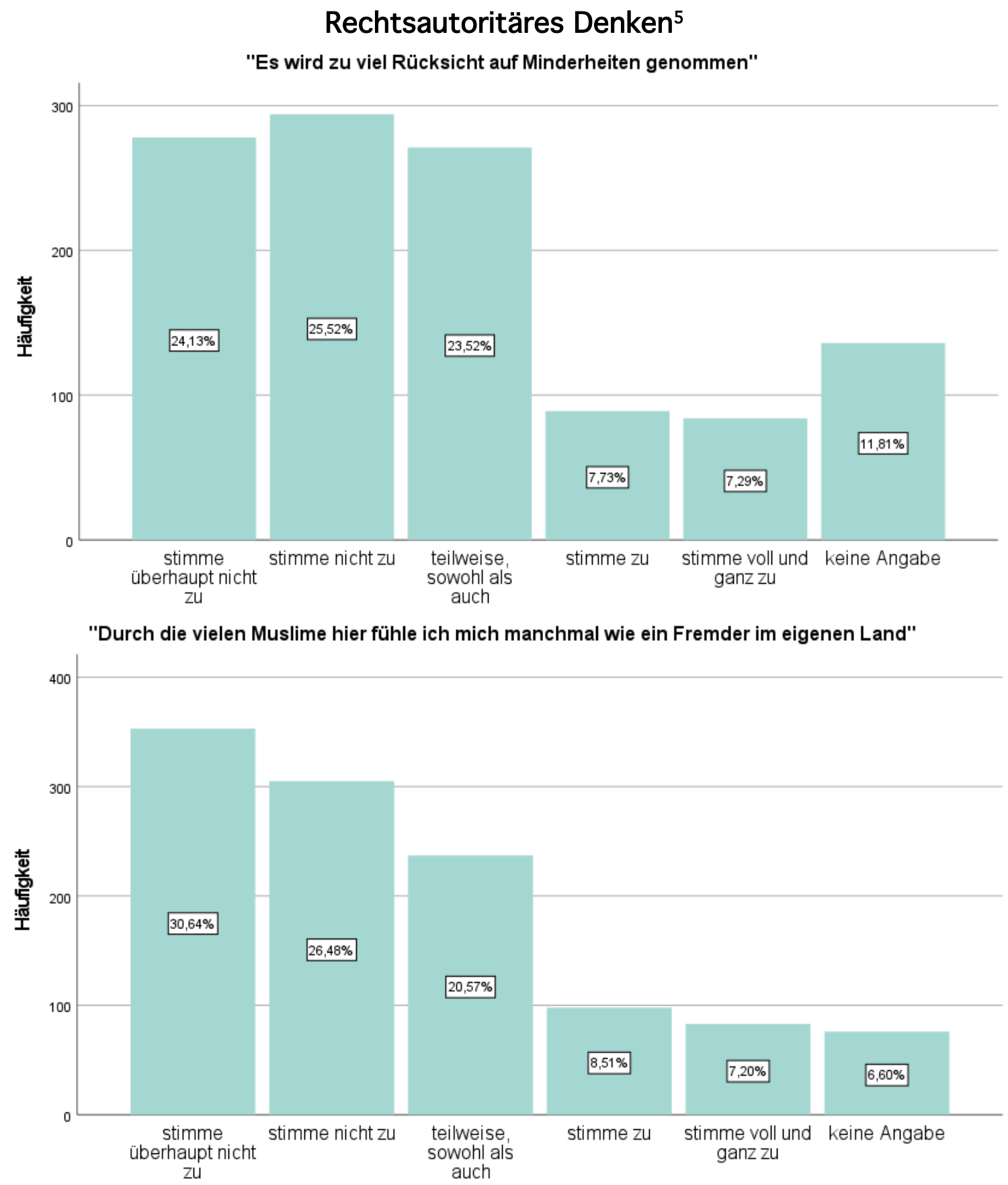

${ }^{5}$ Zur Einordnung der Ergebnisse werden in den nächsten Unterkapiteln vereinzelt Befunde der Leipziger Autoritarismus-Studie von Decker et al. (2020: 36) - in denen die Items identisch waren - jeweils vergleichend unter die eigenen Messungen gestellt. Wir haben die Leipziger Studie als Referenzstudie gewählt, da sie zu den wichtigsten repräsentativen Studien für die Bevölkerung in Deutschland gehört. Ein gewichtiger Unterschied zur Leipziger Studie liegt neben der unterschiedlichen Stichprobe allerdings darin, dass in unserer Studie die Befragten jeweils eine Antwort auf die Items geben mussten, aber die Möglichkeit hatten mit «keine Angabe» zu antworten. Wir haben diesen Weg gewählt, da unsere Befragung - im Gegensatz zu jener aus Leipzig - eine Online-Studie darstellt und bei einigen Items die Gefahr einer Nichtbeantwortung oder eines Abbruchs zu hoch gewesen wäre. In der Leipziger Studie konnte man nur auf die «neutrale» Mittelkategorie ausweichen. Da beide Studien folglich unterschiedliche Skalen verwendet haben, kann man sie nicht vollständig vergleichen. Die Werte bezüglich Zustimmung und Ablenhung sind noch jedoch Anhaltspunkte für eine Einordnung der Querdenker-Bewegung zur deutschen Gesamtbevölkerung. Die Beiträge der Leipziger Autoritarismus-Studie sind visuell durch einen grauen Rahmen abgehoben. Quelle: Decker, O. und E. Brähler (Hg.)(2020): Autoritäre Dynamiken: Alte Ressentiments - neue Radikalität. Giessen: Psychosozial. 


\section{"Wenn Arbeitsplätze knapp werden, sollte man die Ausländer wieder in ihre Heimat zurückschicken"}
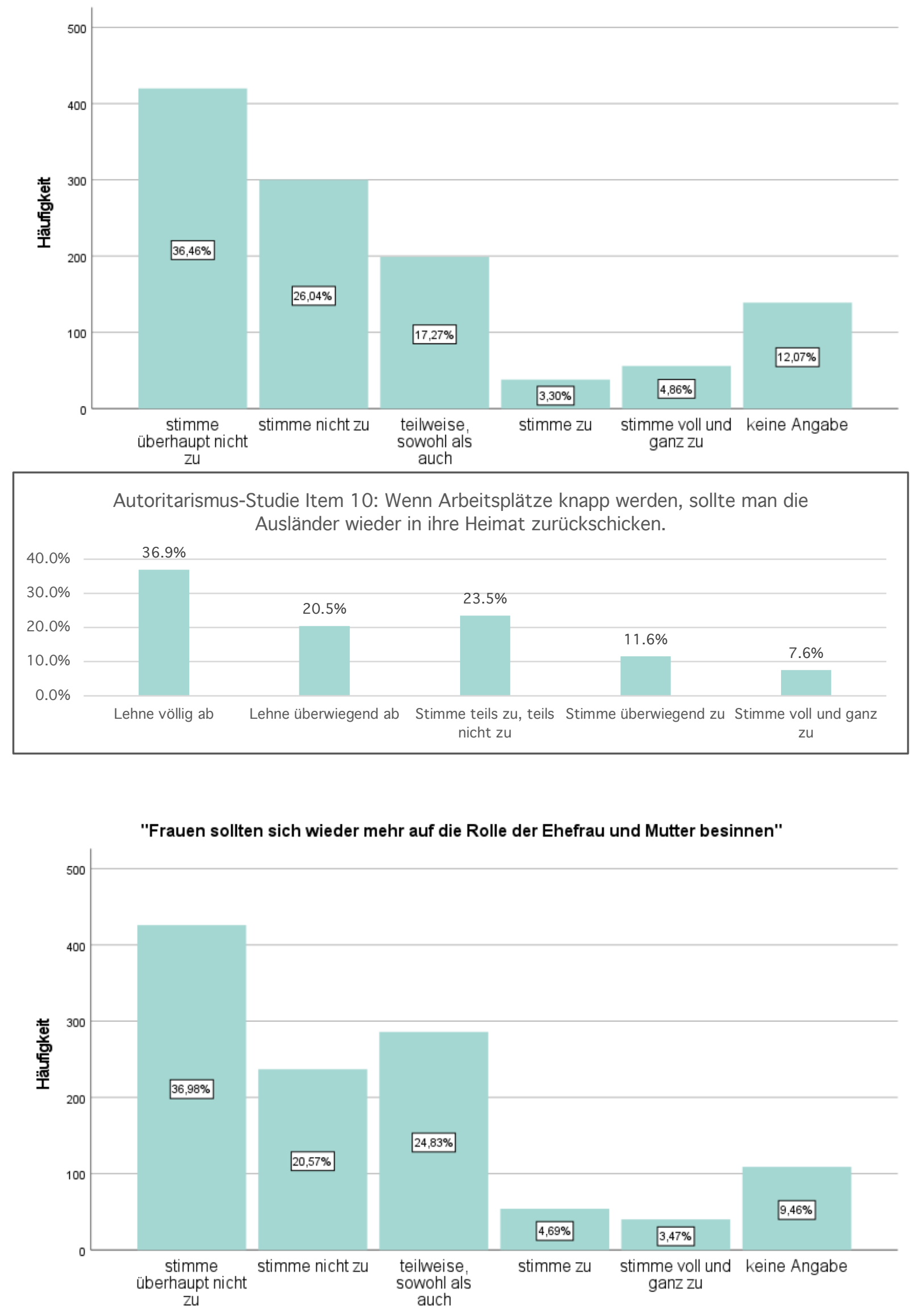


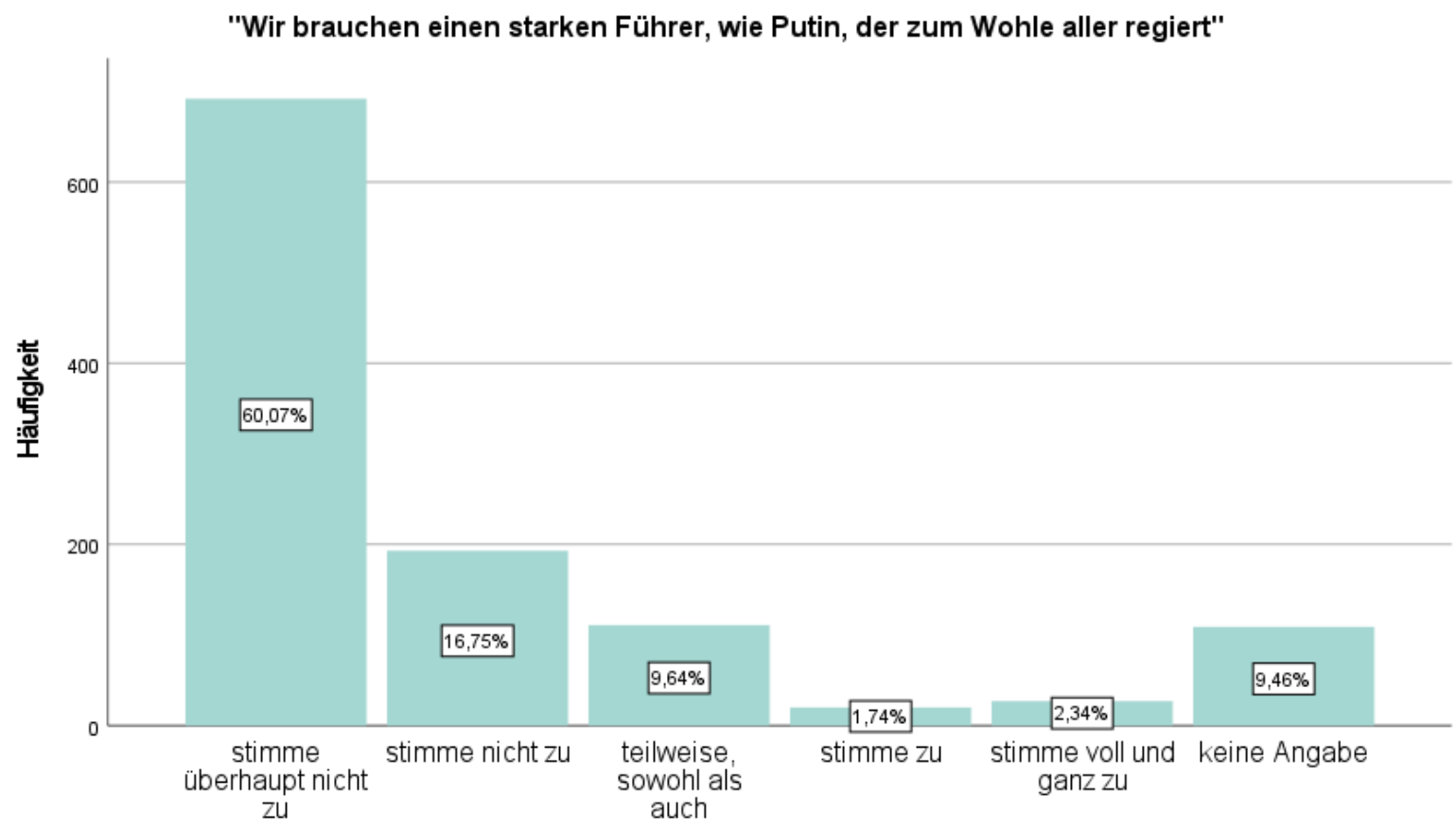

"Es gibt wertvolles und unwertes Leben"

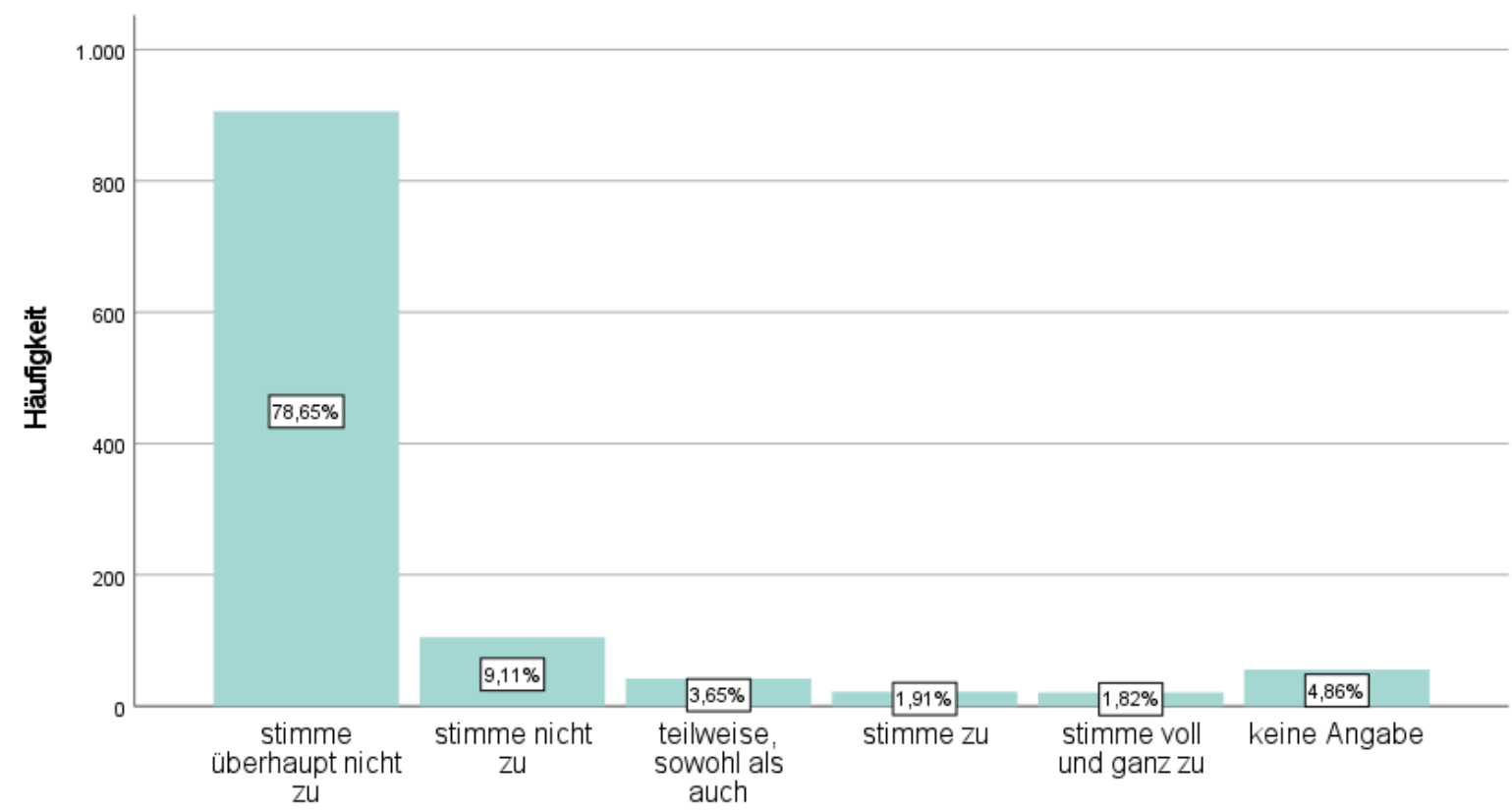

Autoritarismus-Studie Item 15: Es gibt wertvolles und unwertes Leben.

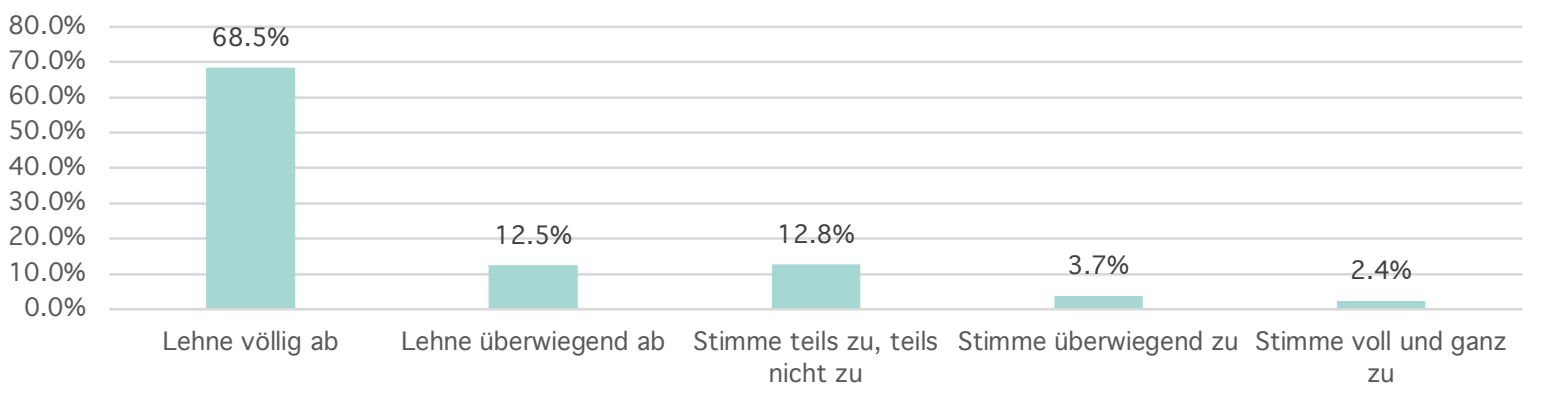




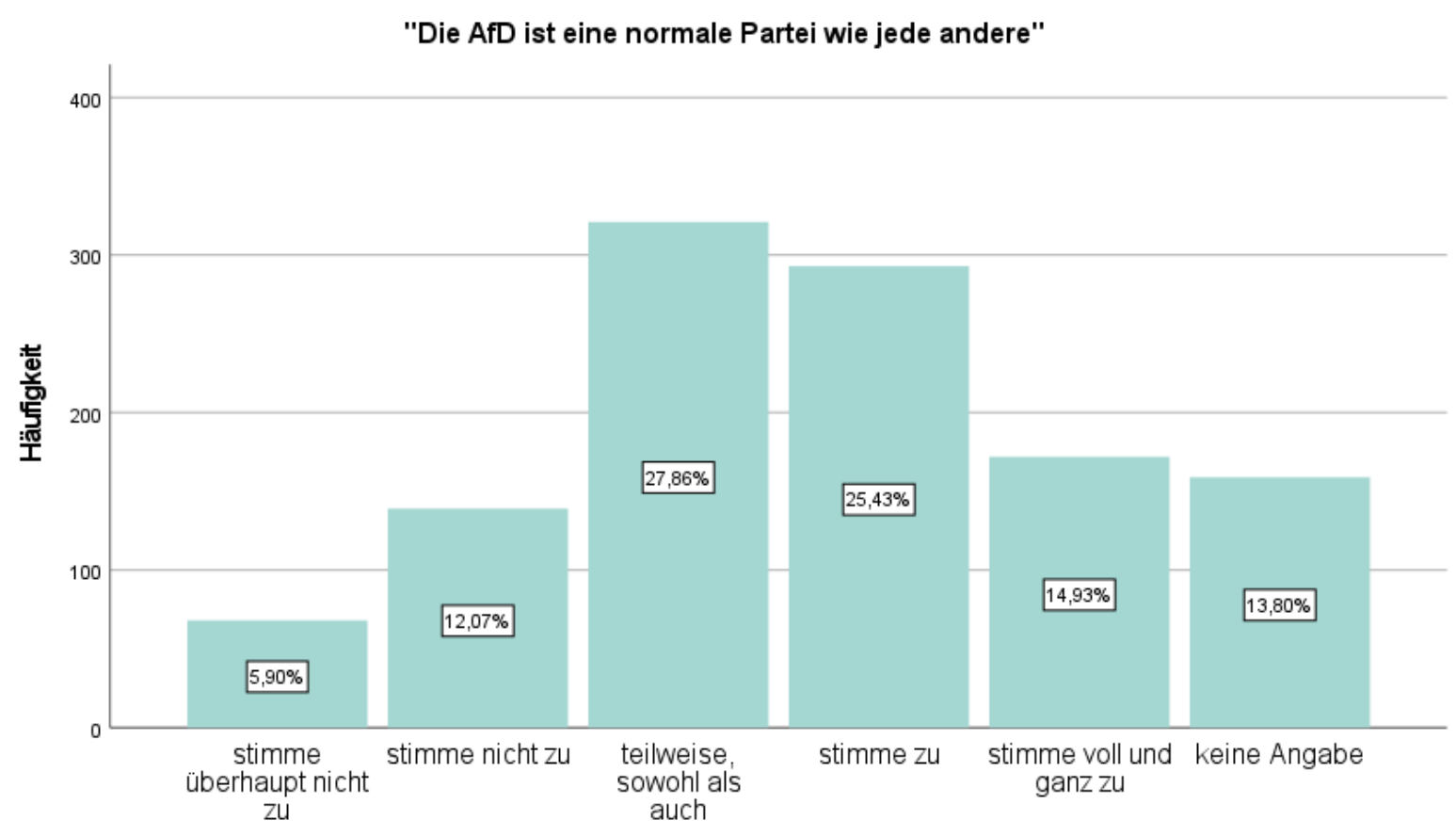

"Die Aufregung um schwarz-weiß-rote Fahnen bei Protesten gegen die Corona-Maßnahmen halte ich für

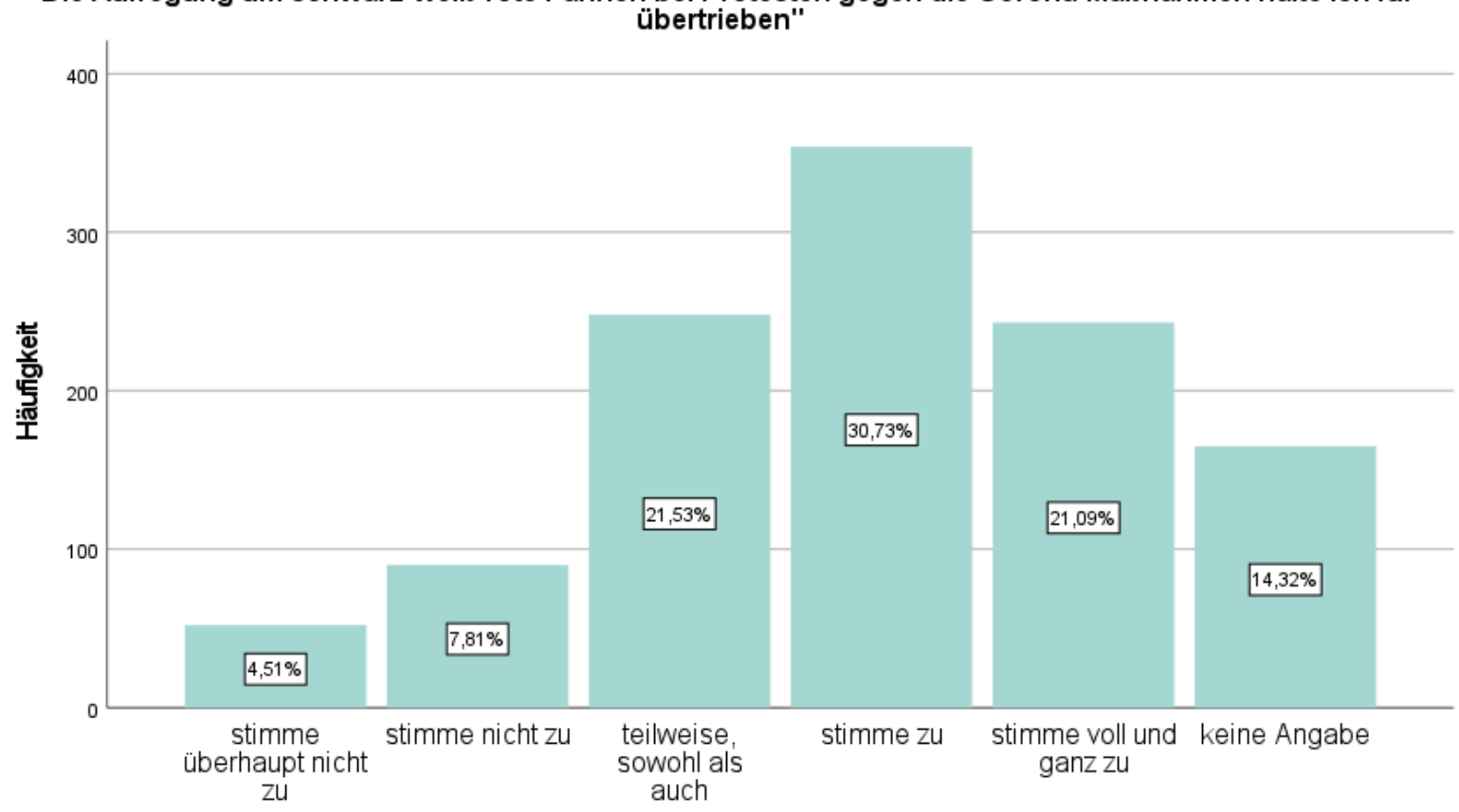




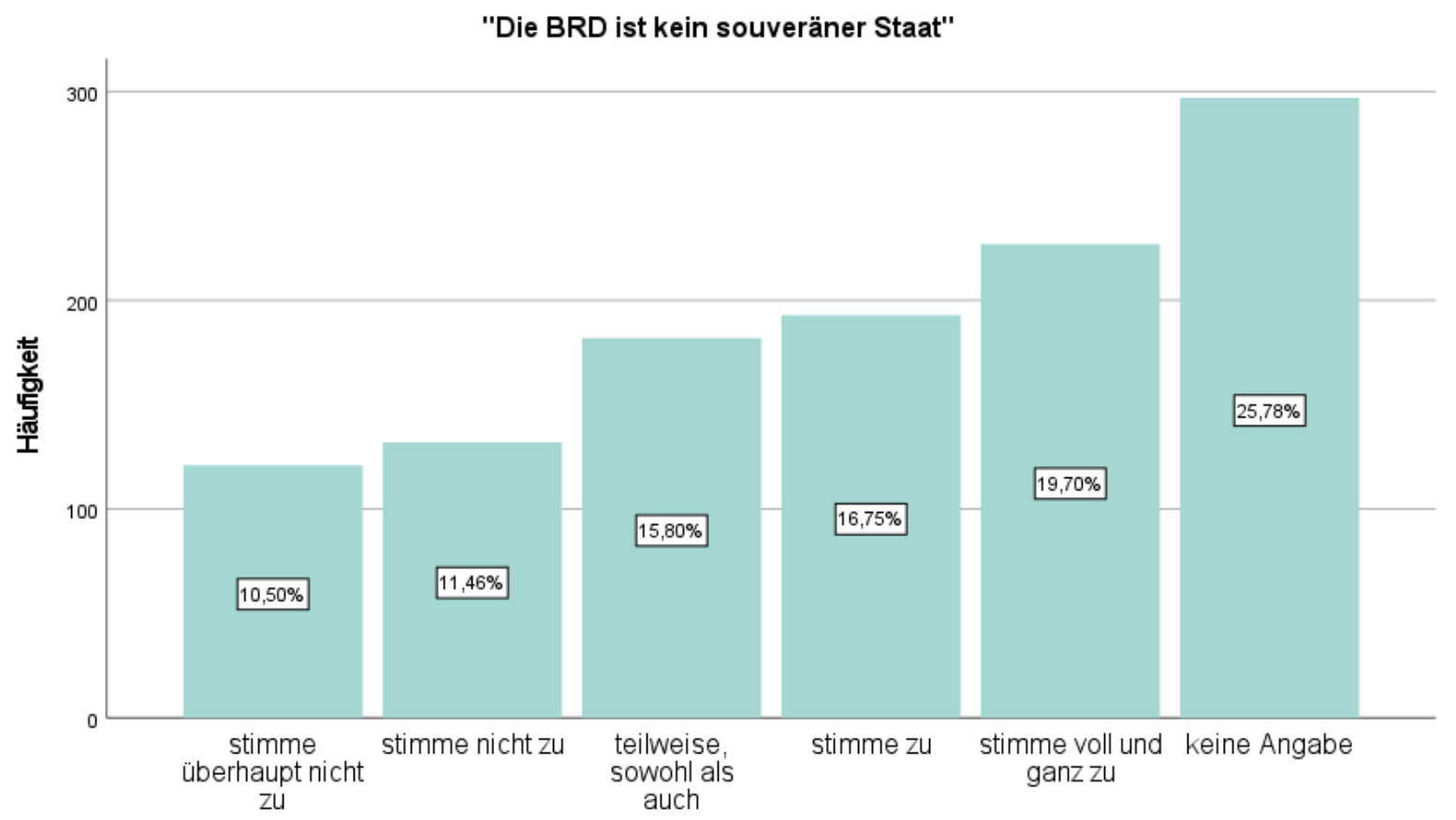

"Menschen aus anderen Ländern sollte es erlaubt sein, in mein Land zu kommen und dort dauerhaft zu leben"

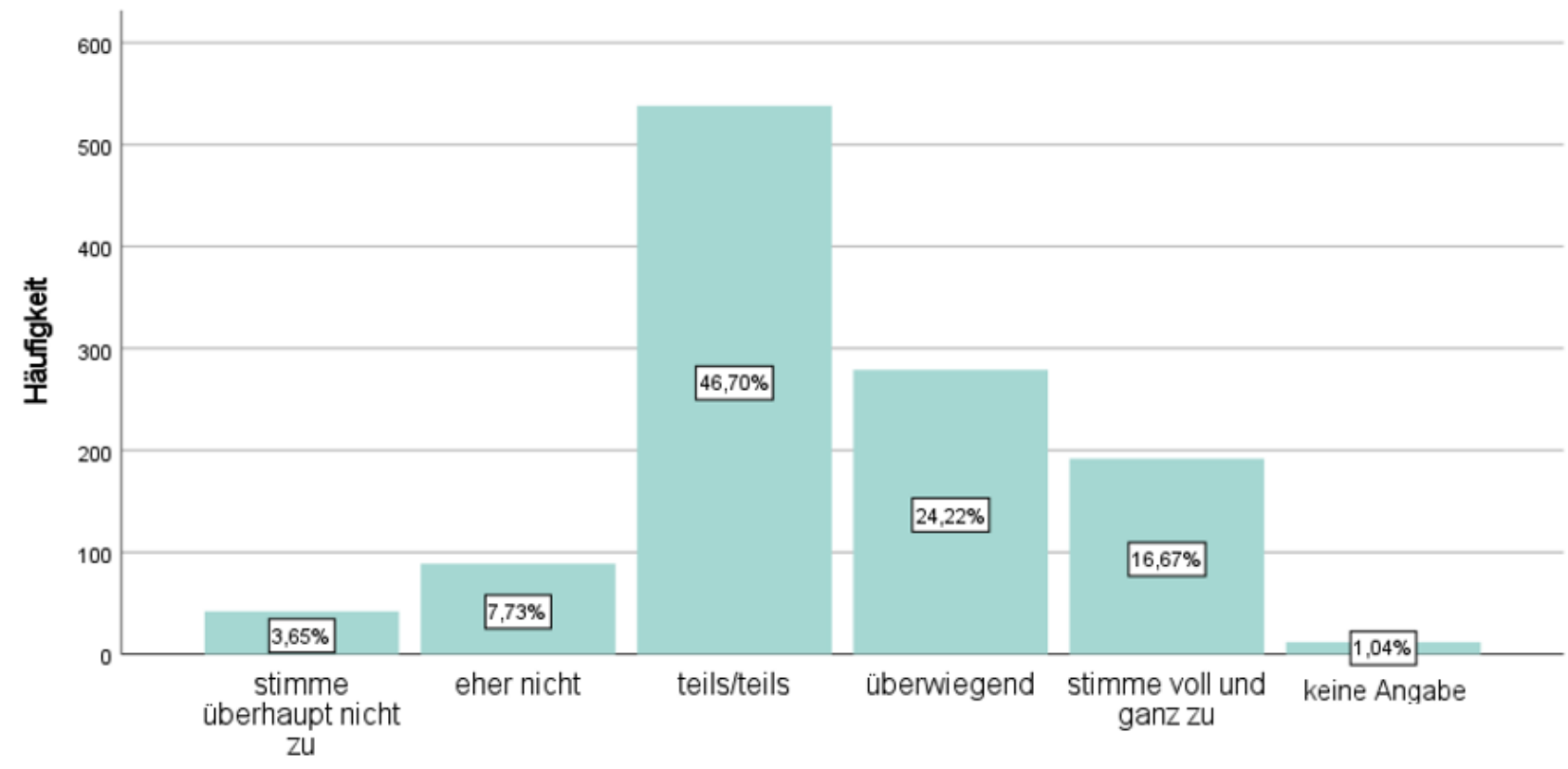




\section{Antisemitismus und Nationalsozialismus}
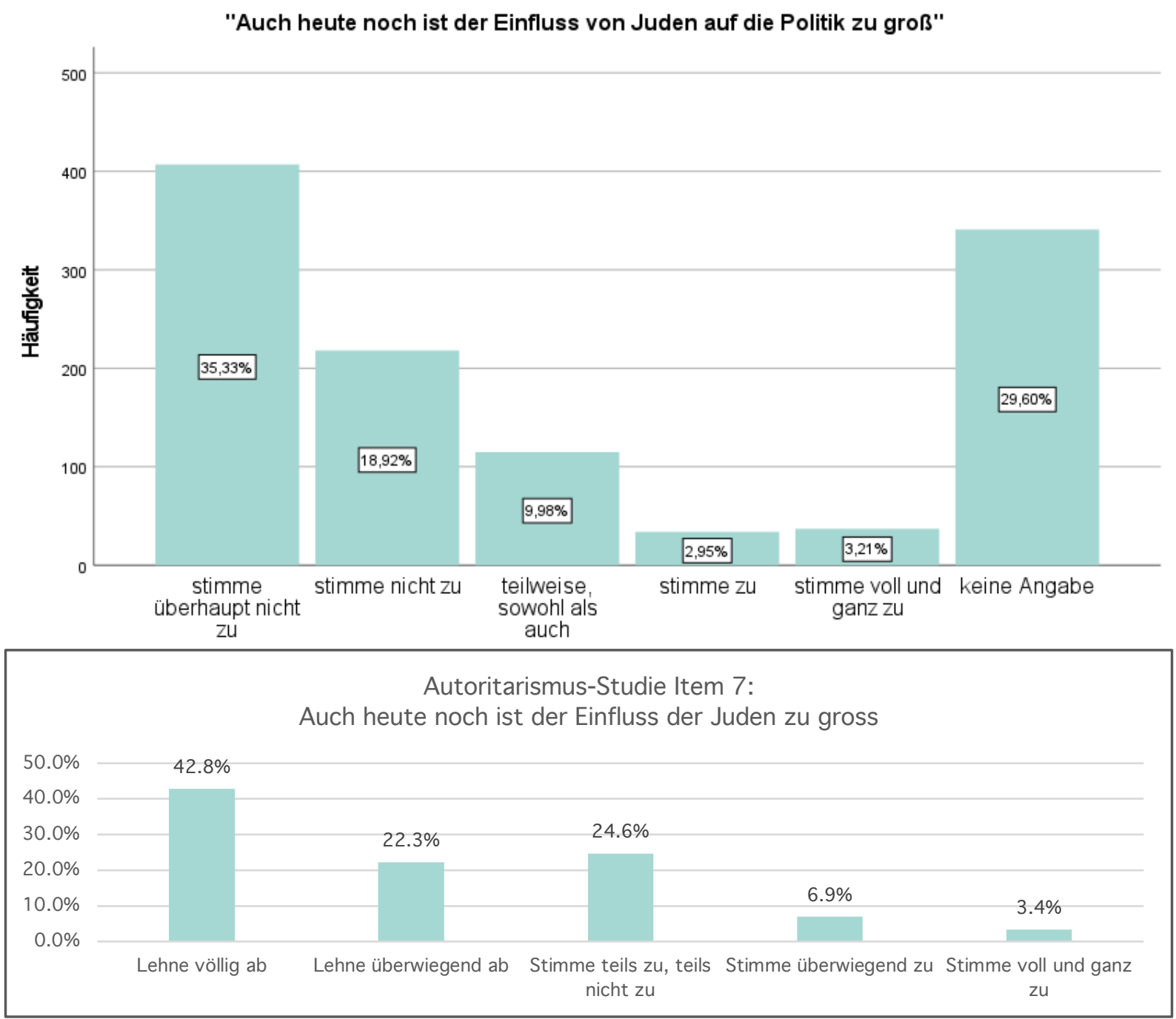

"Kindern sollte beigebracht werden Autoritäten zu gehorchen"

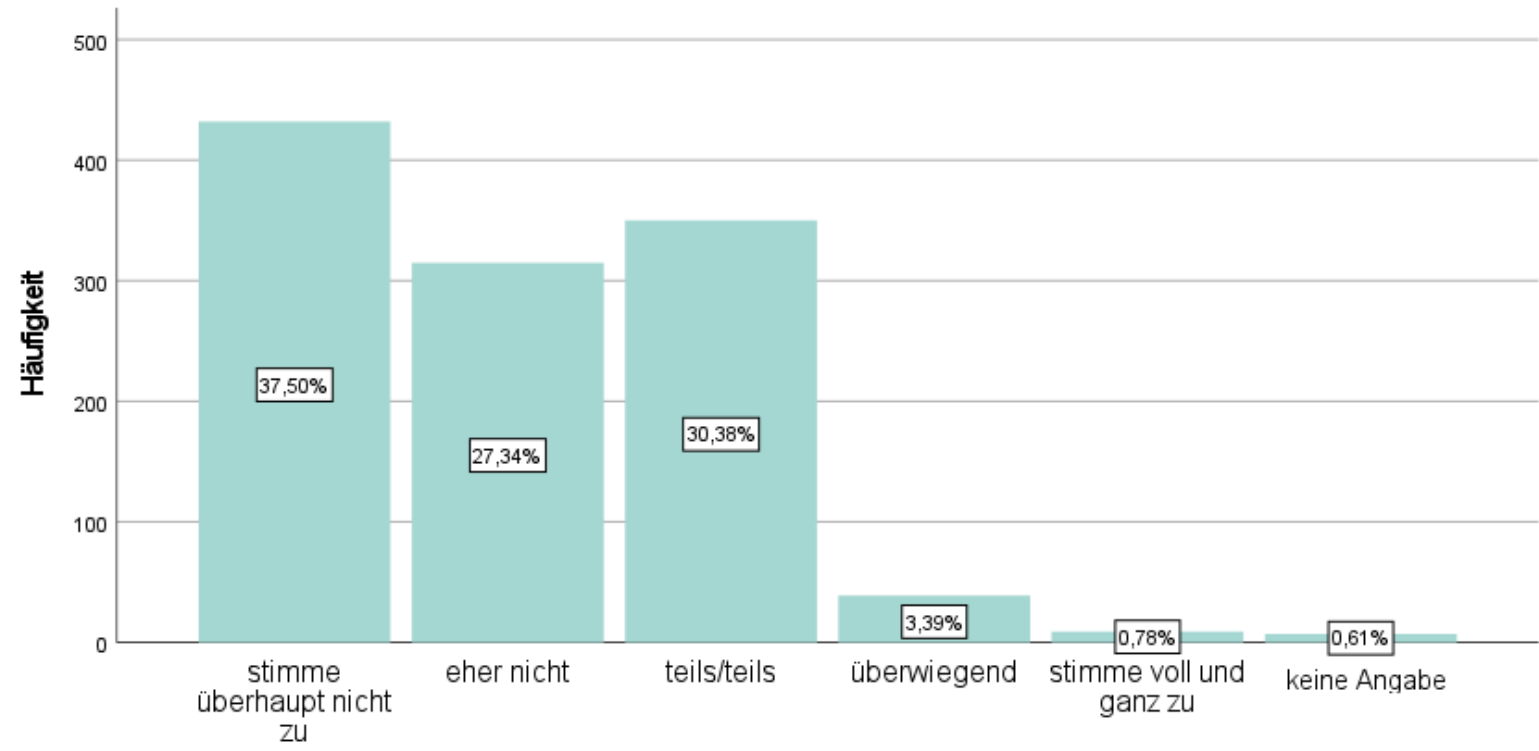


"Die Verbrechen des Nationalsozialismus sind in der Geschichtsschreibung weit übertrieben worden"

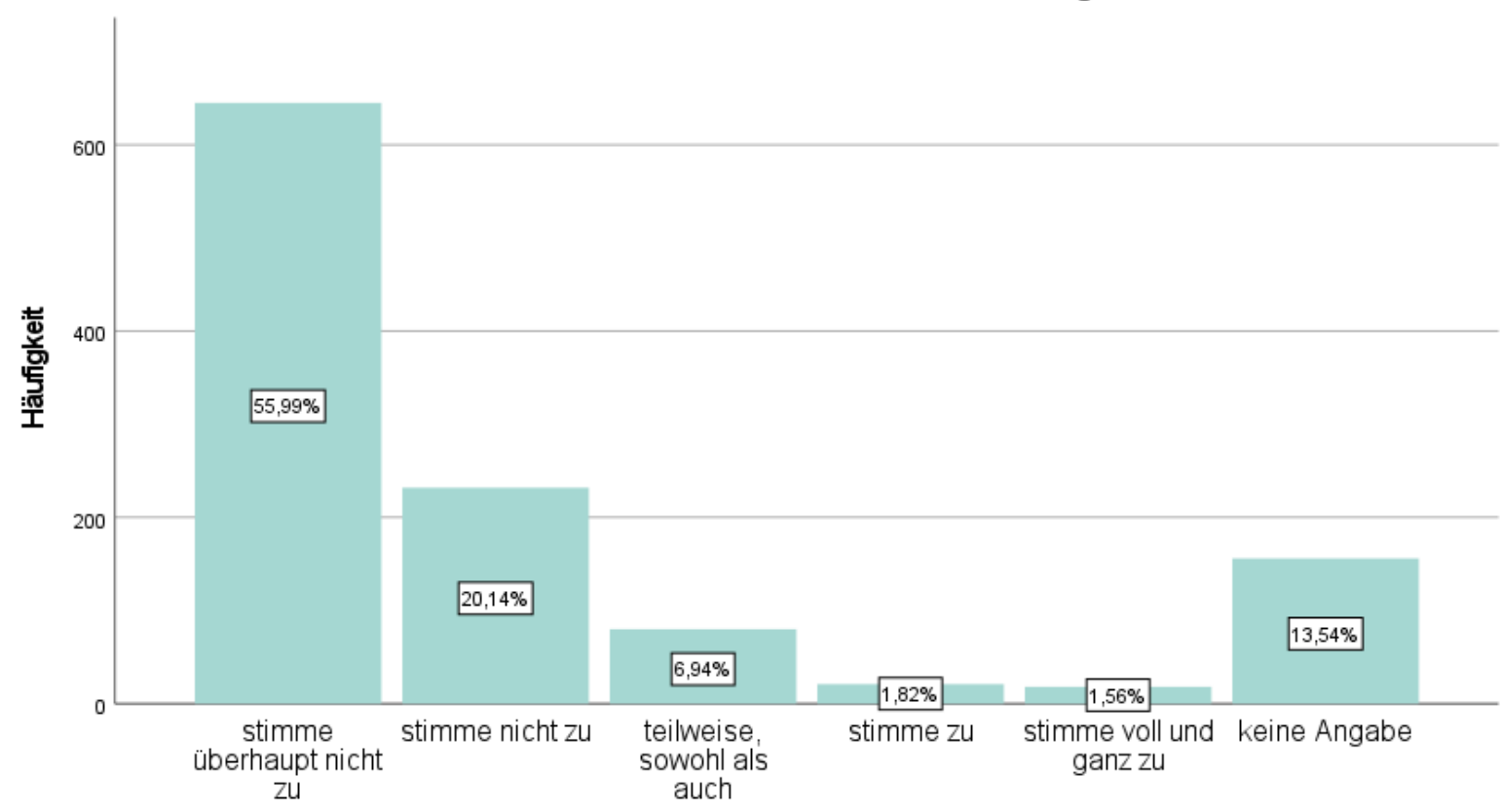

Autoritarismus-Studie Item 11: Die Verbrechen des Nationalsozialismus sind in der Geschichtsschreibung weit übertrieben worden.

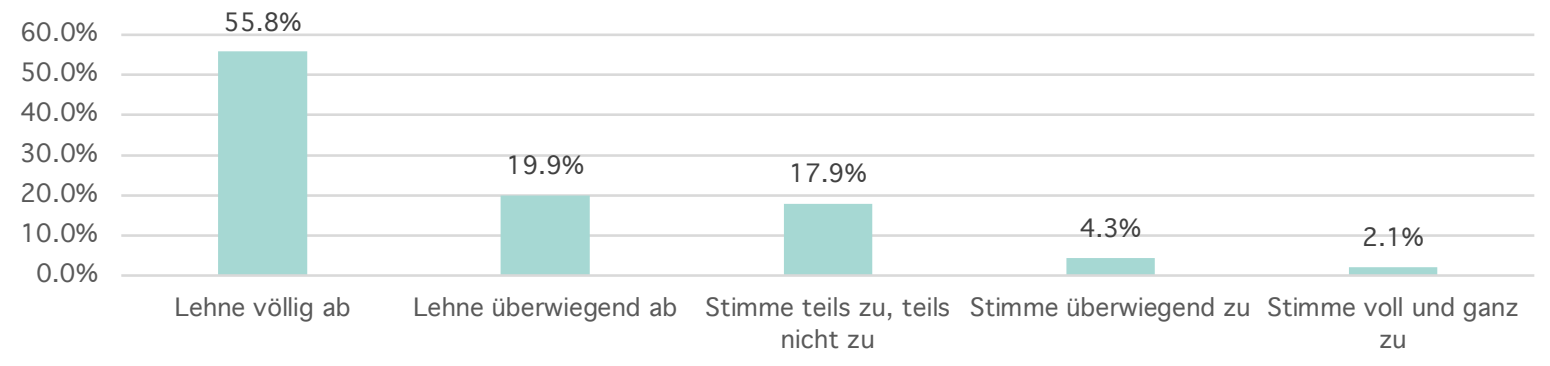

\section{Anthroposophisches/ Esoterisches Denken}

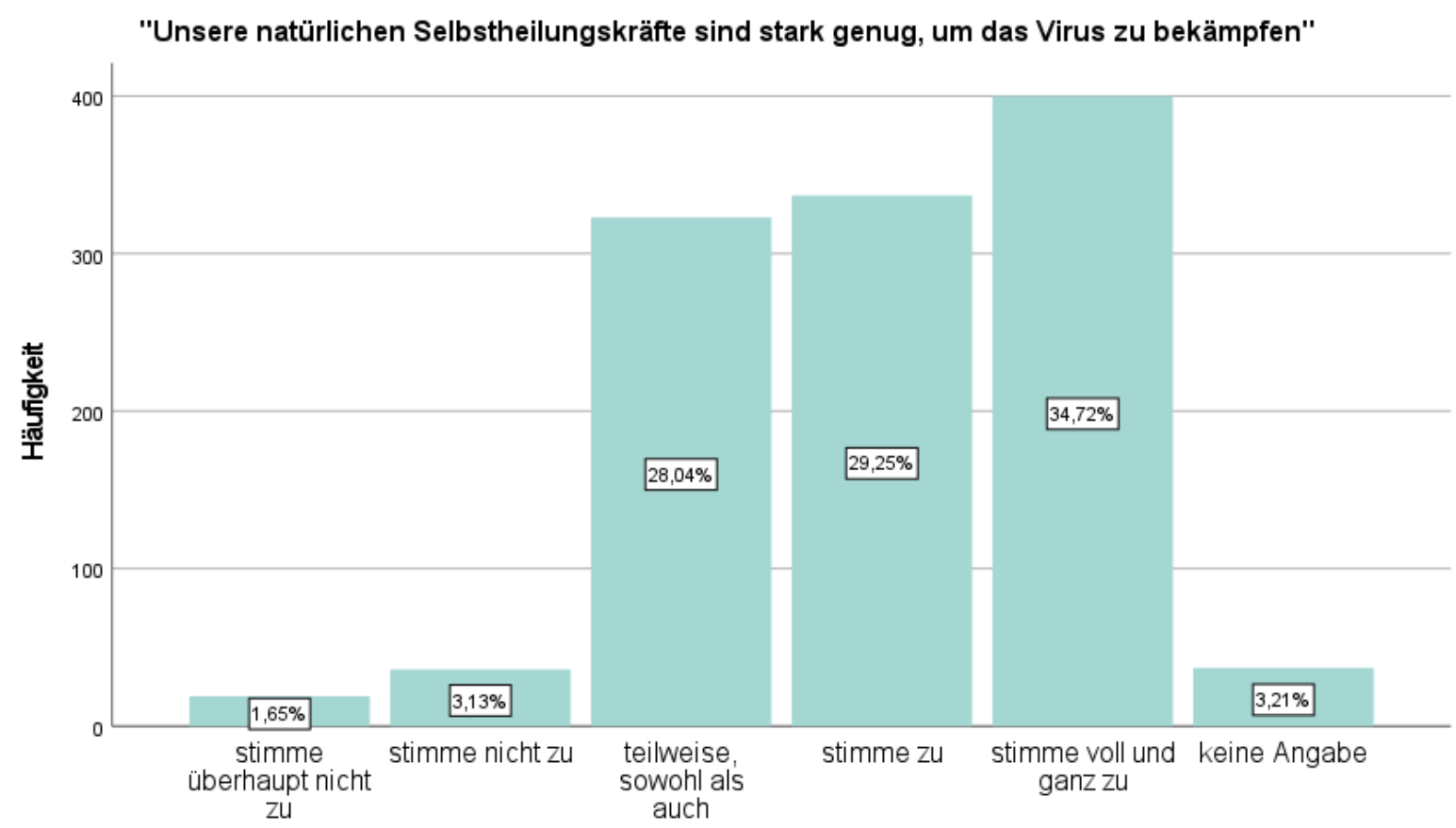



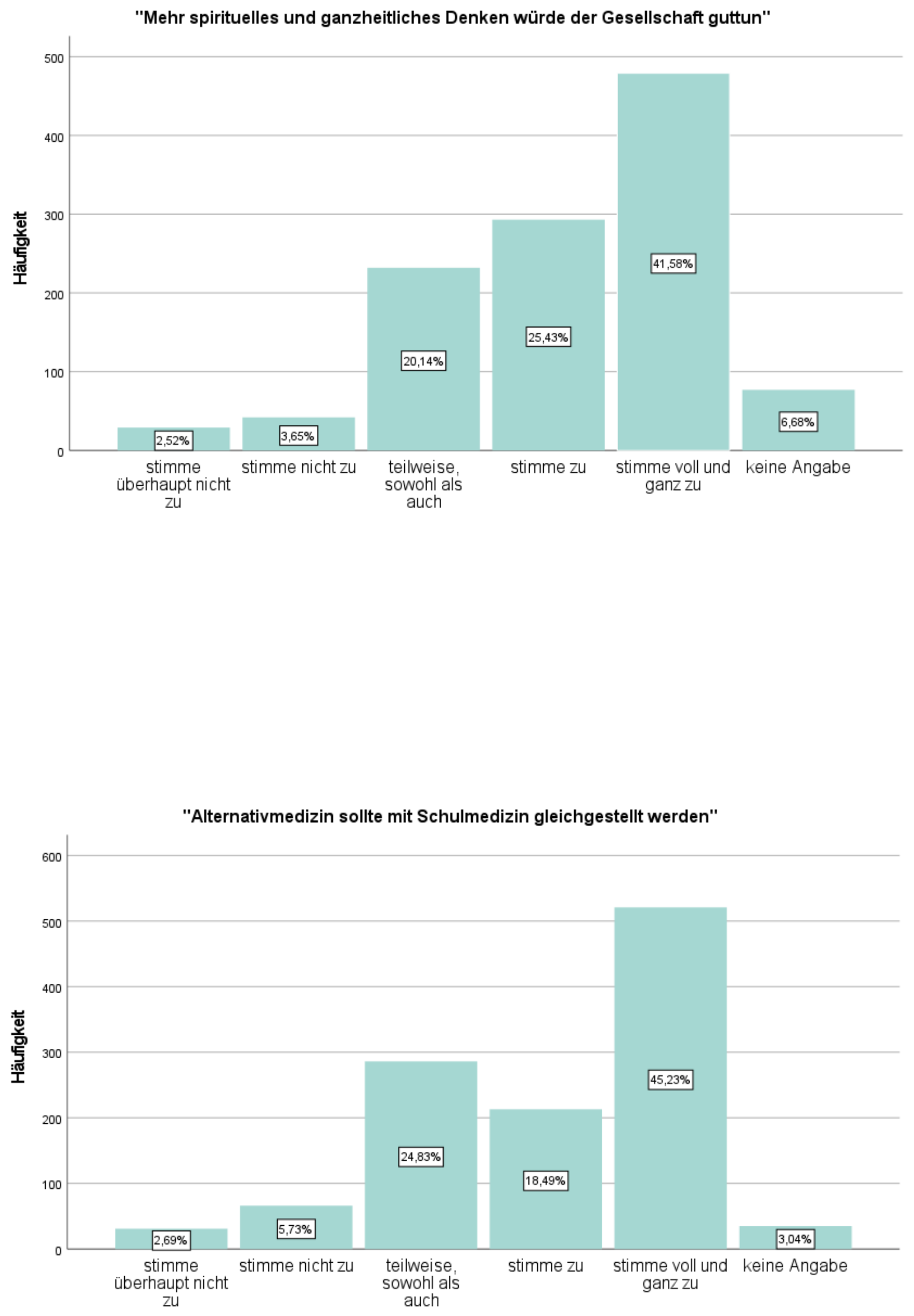


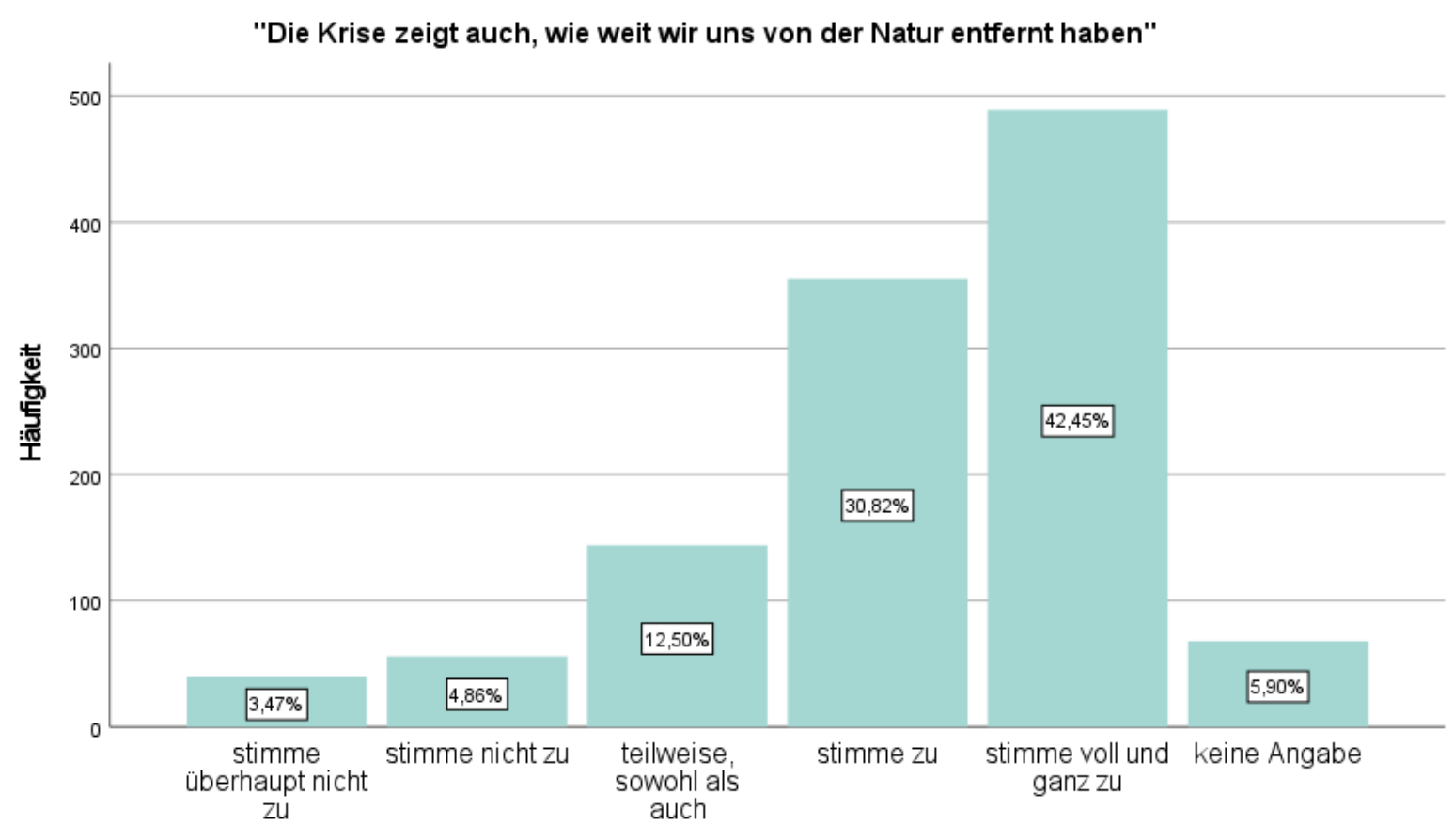

Impfen

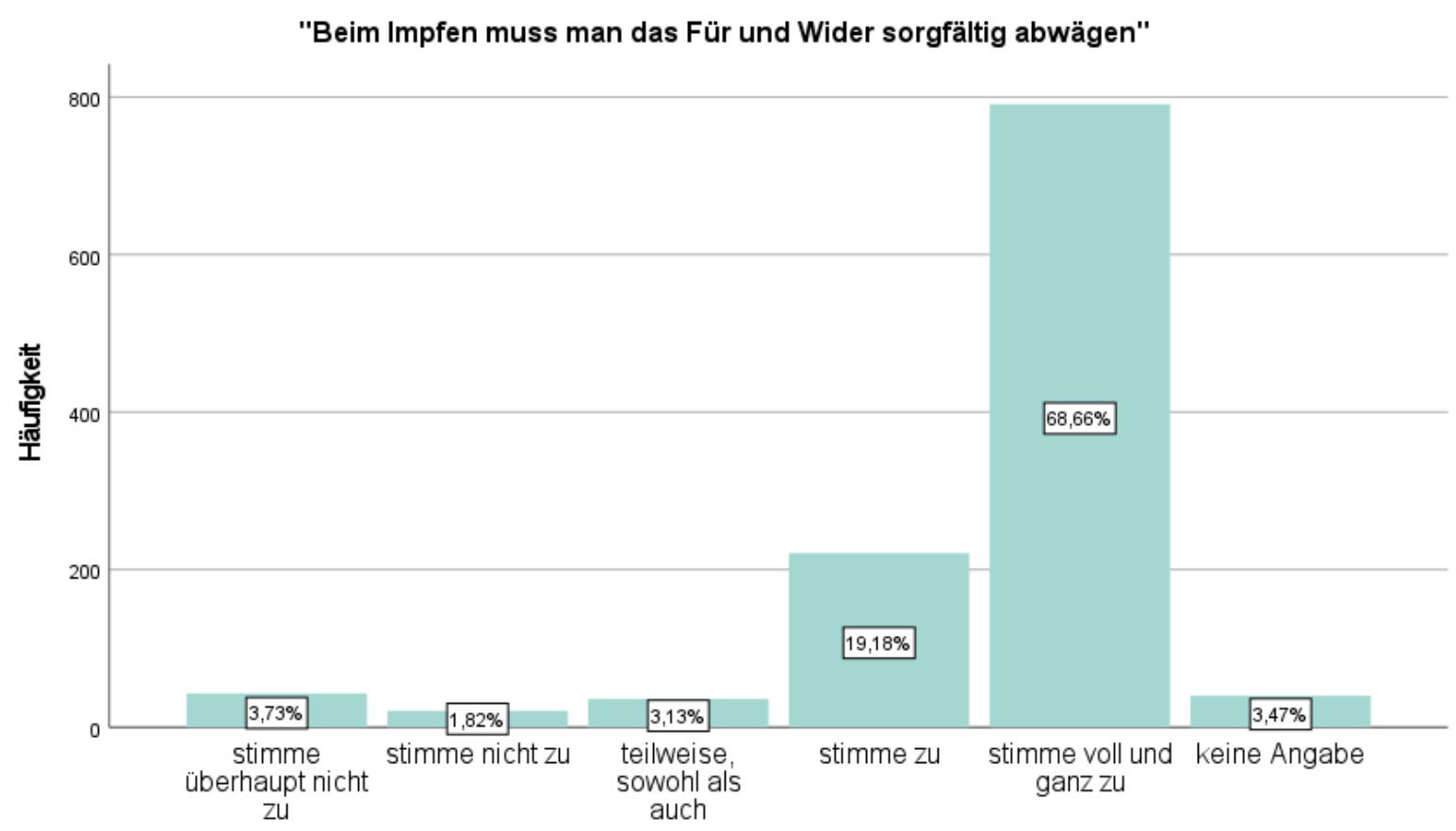




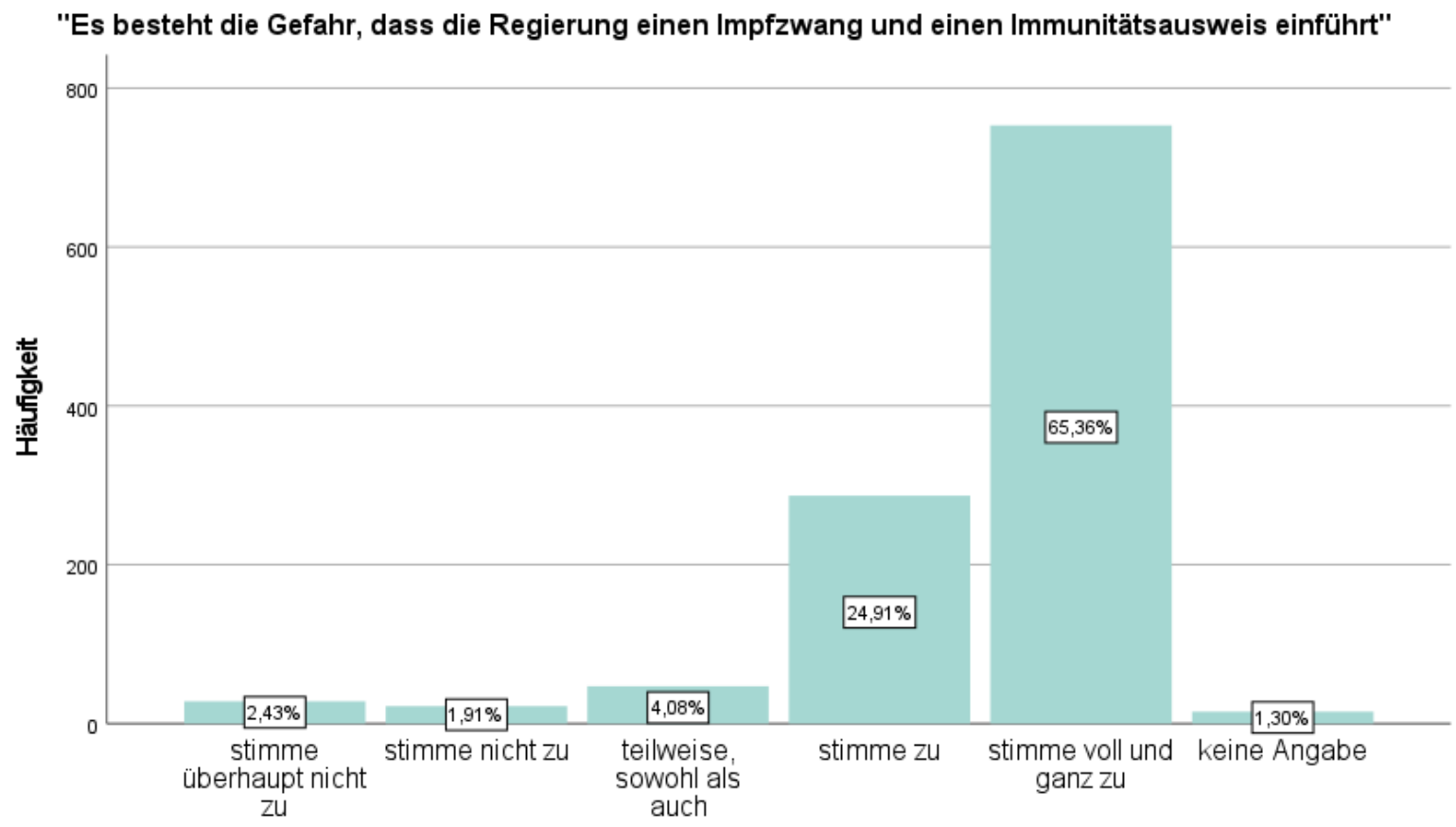

"Nehmen wir an, dass ein Impfstoff gegen das neuartige Coronavirus gefunden wird, der nachweislich keine nennenswerten Nebenwirkungen hat. Würden Sie sich freiwillig damit impfen lassen?"

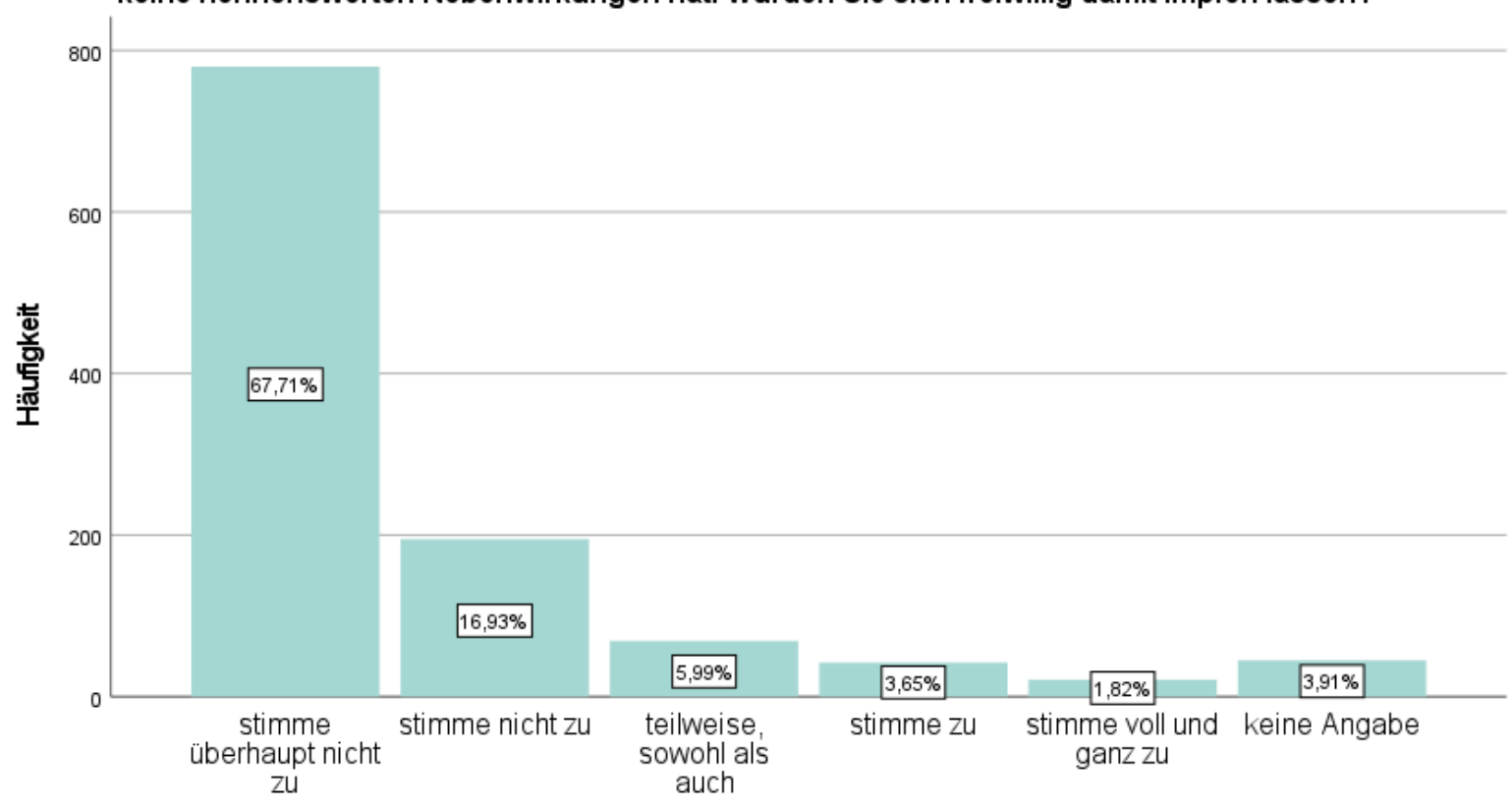




\section{Organisationszugehörigkeit/Engagement}

Waren Sie in den letzten 36 Monaten in einer der folgenden Organisationen tätig? Mehrfachnennungen möglich.

\section{Schüler*innenvertretung \\ Studierendenorganisation \\ Jugendorganisation \\ Frauenorganisation}

Antira- oder Migrant*innenorganisation

Dritte Welt, globale Gerechtigkeits- oder Friedensorganisation

Politische Partei

Menschen- oder Bürgerrechtsorganisation

Gewerkschaft oder Berufsverband

Umweltorganisation

Wohtätigkeitsorganisation

Kirche oder religiöse Organisation

Sport oder Kulturverein
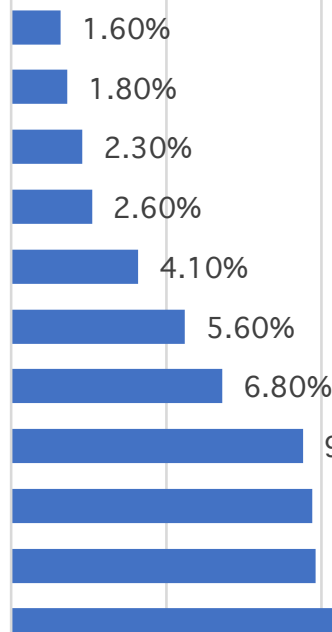

$9.40 \%$

$9.70 \%$

$9.80 \%$

$10.50 \%$

$12.10 \%$

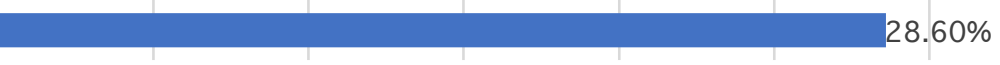

$0 \%$

Haben Sie sich in den letzten 36 Monaten an irgendwelchen der folgenden Aktivitäten beteiligt? Mehrfachnennungen möglich. Haben Sie..

Gewalttätige Aktionsformen unterstützt?

An einem Streik teilgenommen

An einer direkten Aktion teilgenommen

Einer politischen Organisation Geld gespendet?

Ihre Ernährung geändert

Politiker*innen oder Vertreter*innen der Verwaltung kontaktiert?

Gezielte Produkte gekauft?

Abzeichen einer Kampagne getragen oder angebracht

Produkte boykottiert

In Sozialen Medien auf politisches Anliegen aufmerksam gemacht

Eine Petition unterzeichnet

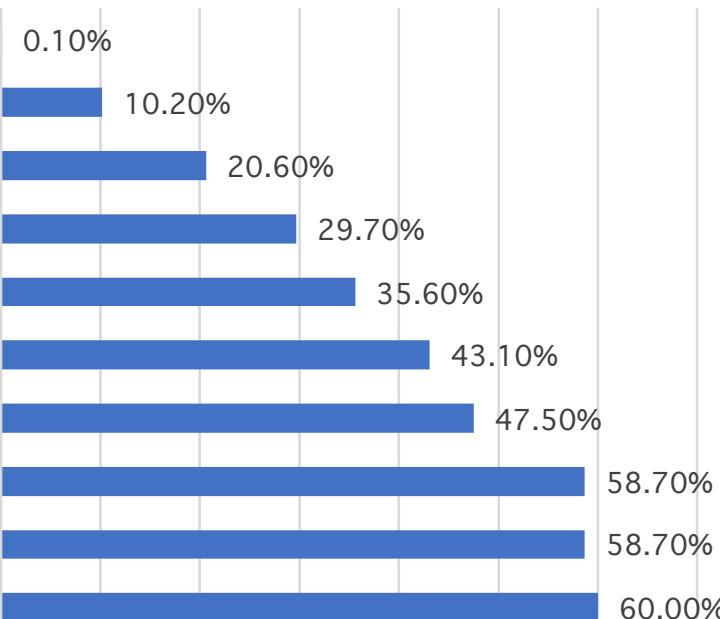

$60.00 \%$ 
Abgesehen von den Coronaprotesten, wie oft haben Sie in der

Vergangenheit an einer Demonstration teilgenommen?

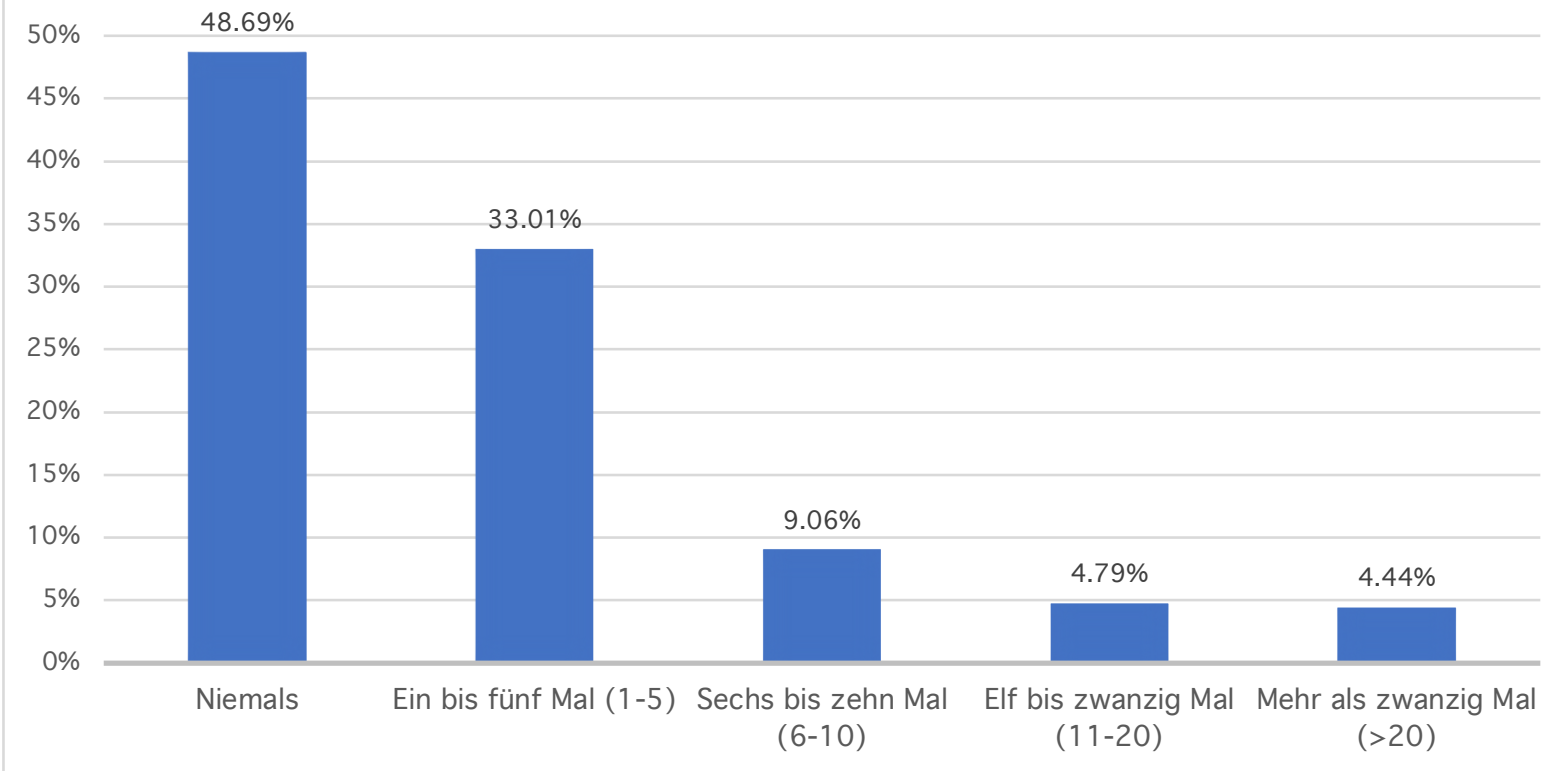

\section{Demokratievertrauen}

\section{Allgemein gefragt, wie zufrieden oder unzufrieden sind Sie mit der Demokratie wie sie in Ihrem Land} funktioniert? BRD

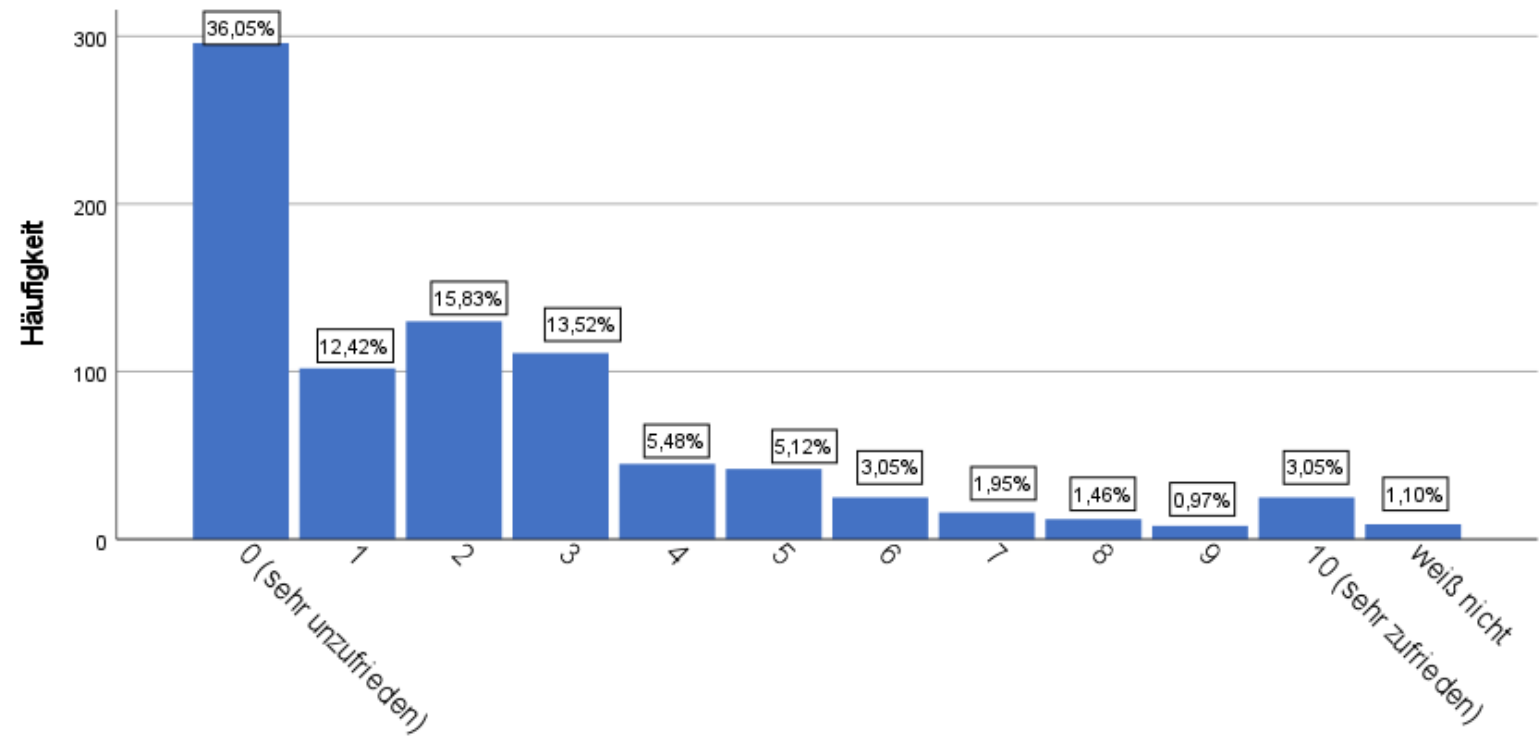


Allgemein gefragt, wie zufrieden oder unzufrieden sind Sie mit der Demokratie wie sie in Ihrem Land funktioniert? $\mathrm{CH}$

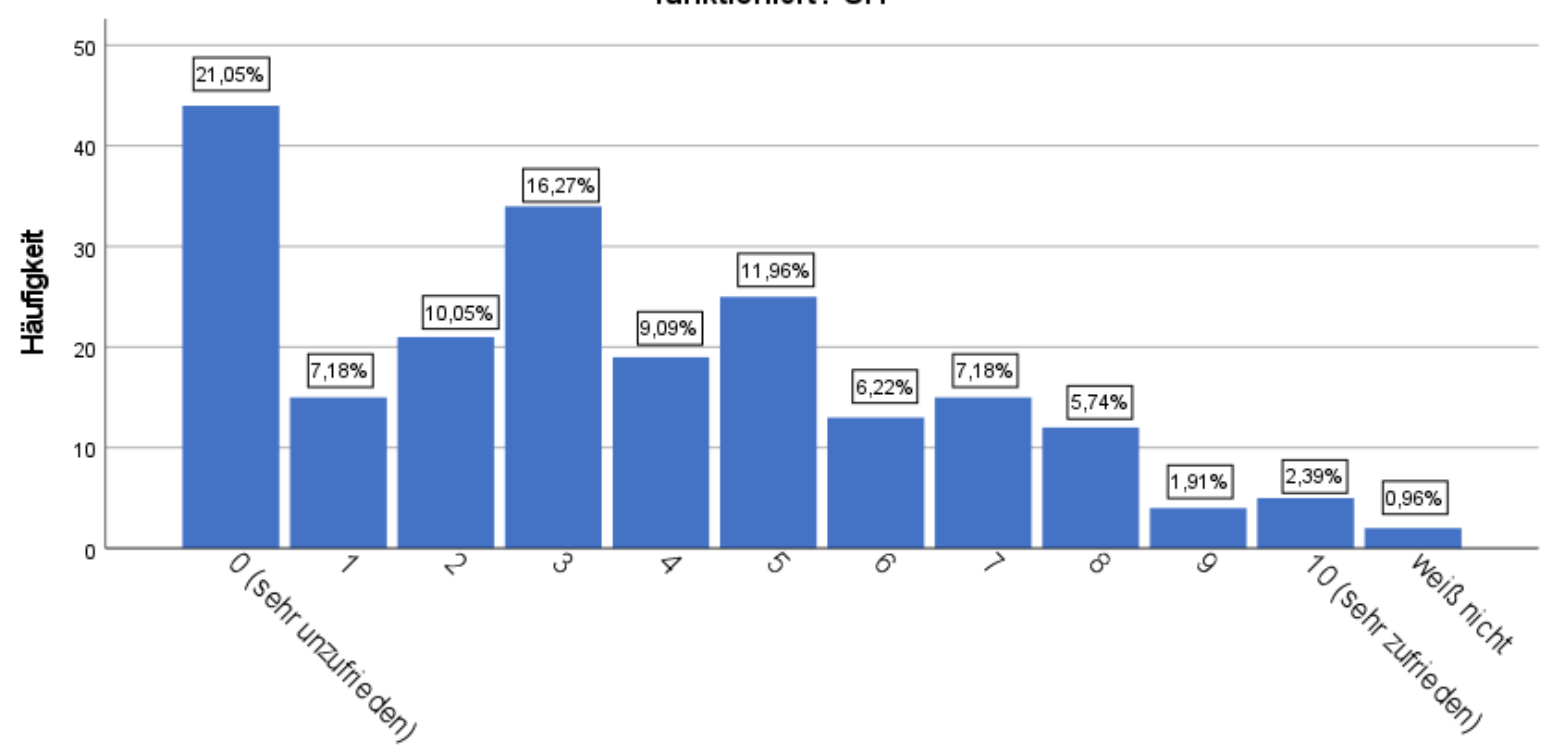

"Die Regierung sollte die Einkommen von den Bessergestellten zu den Schlechtergestellten umverteilen"

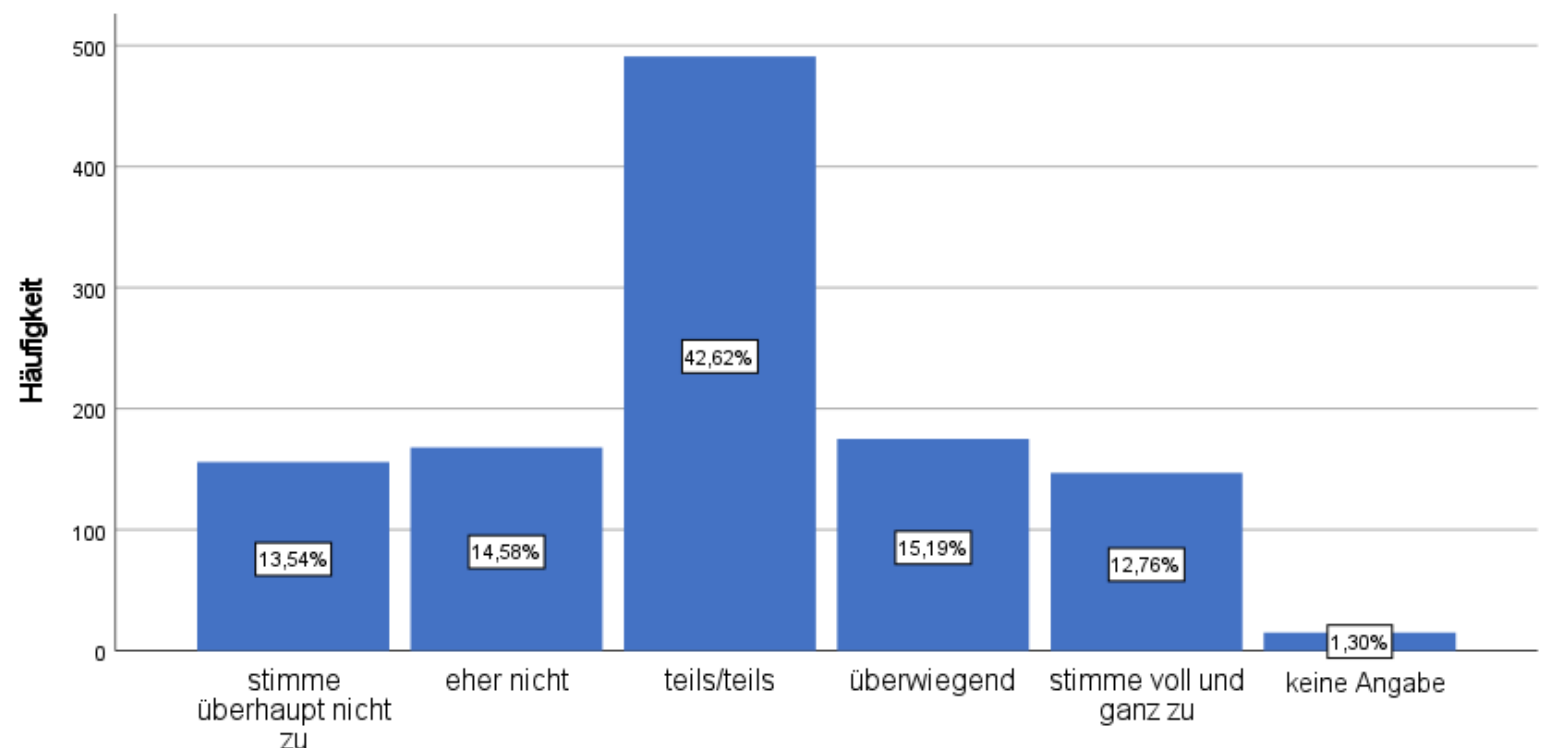


"Auch die wichtigsten öffentlichen Dienstleistungen sollten von privaten Unternehmen erbracht werden"

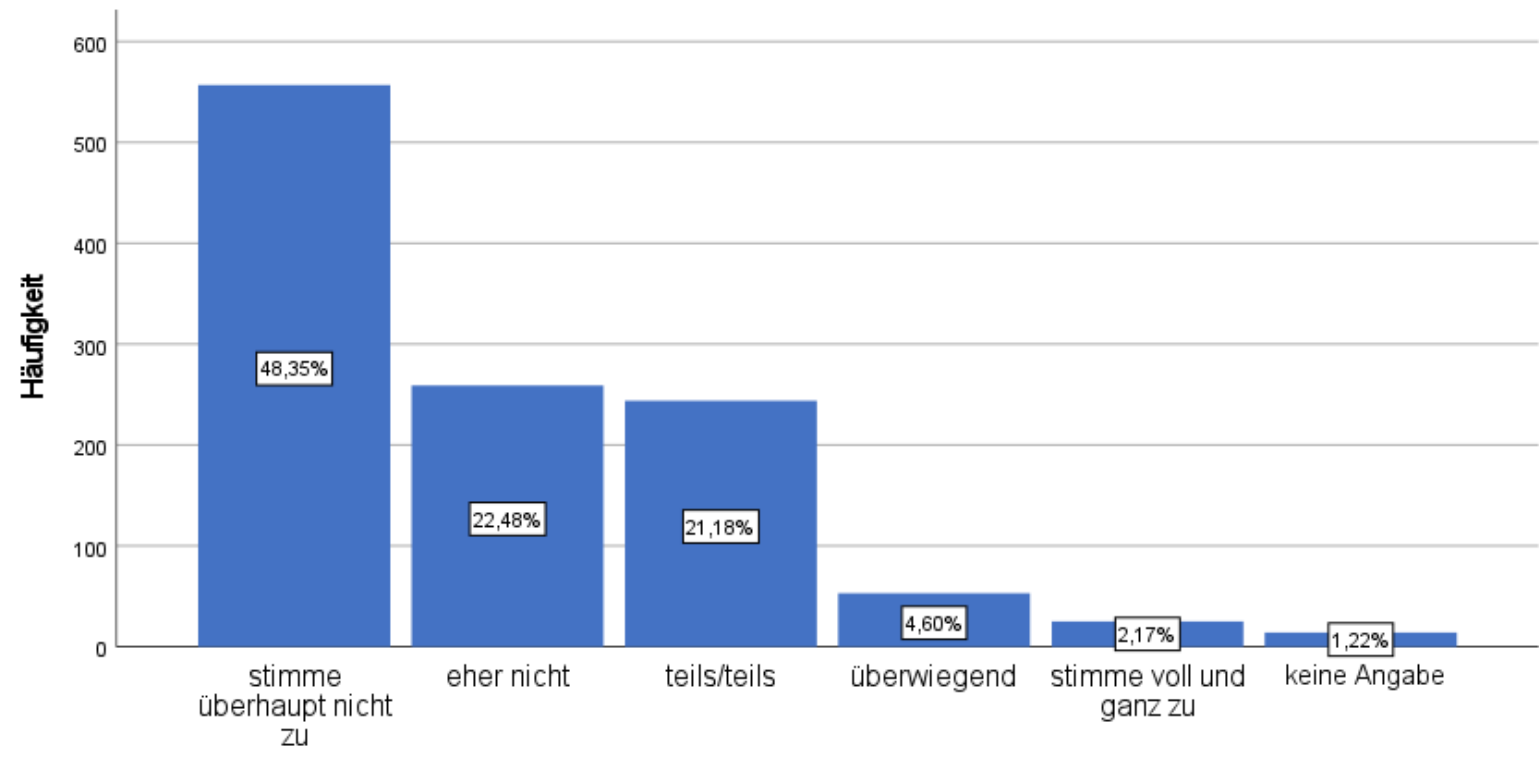

\section{Vertrauen in Institutionen}

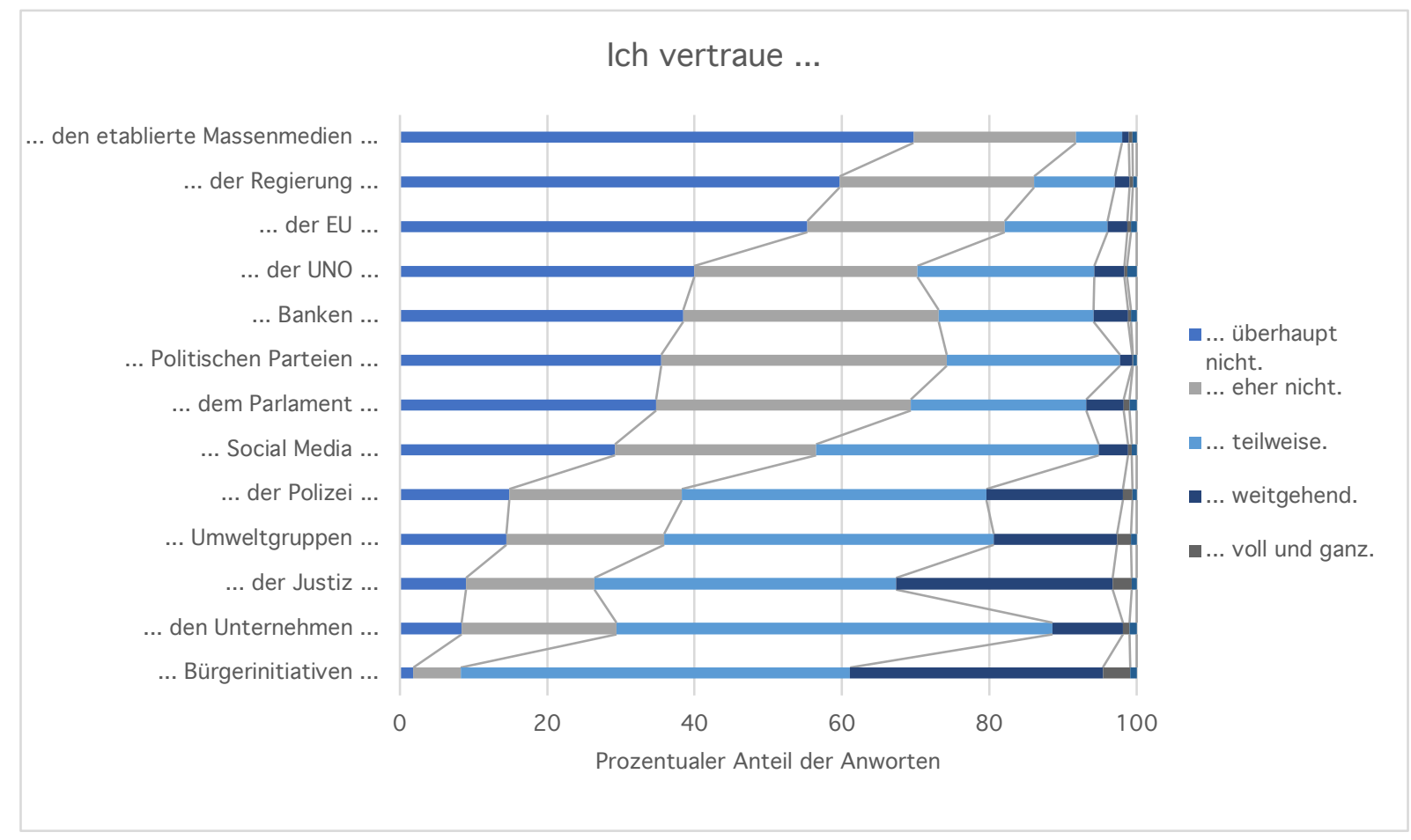



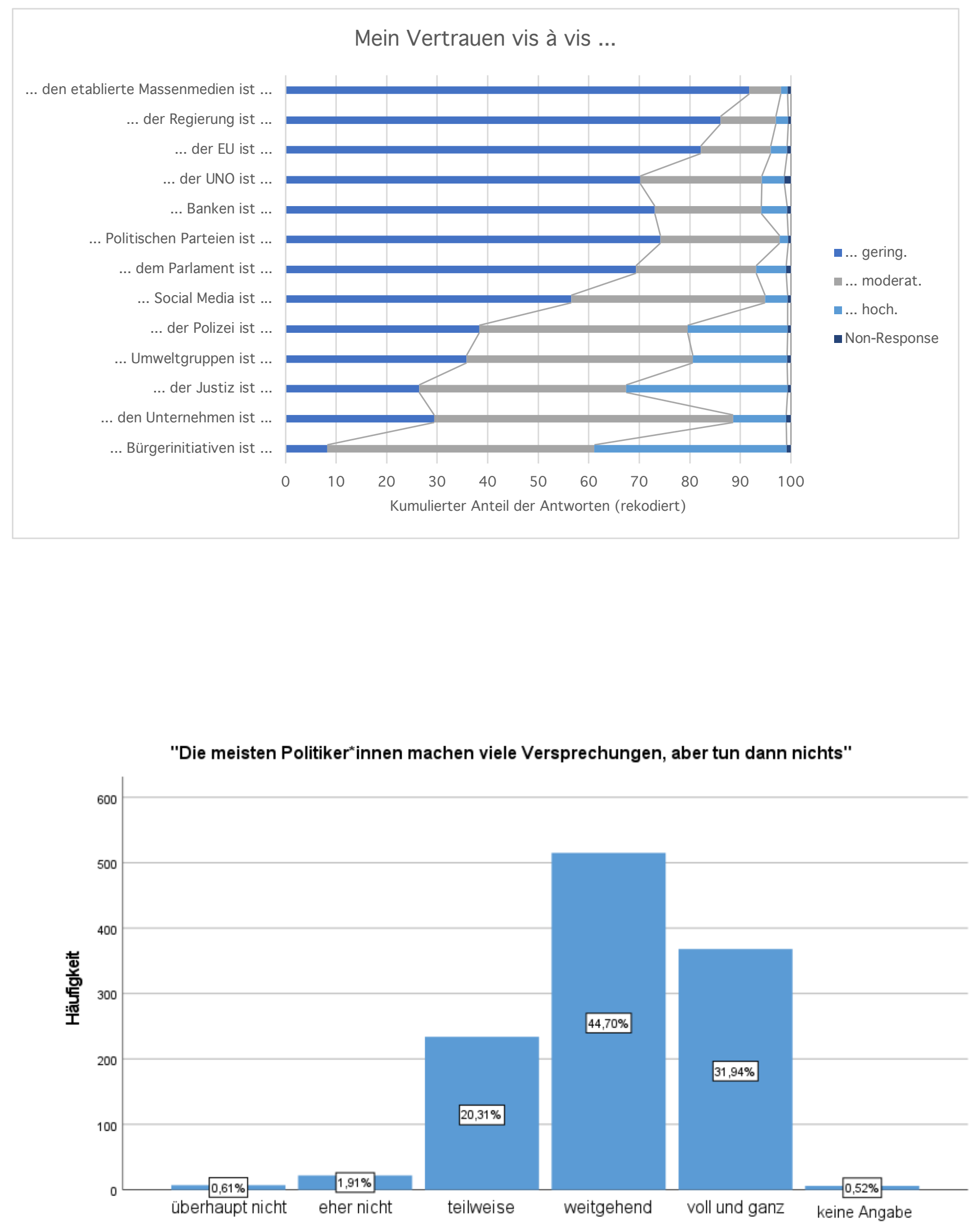

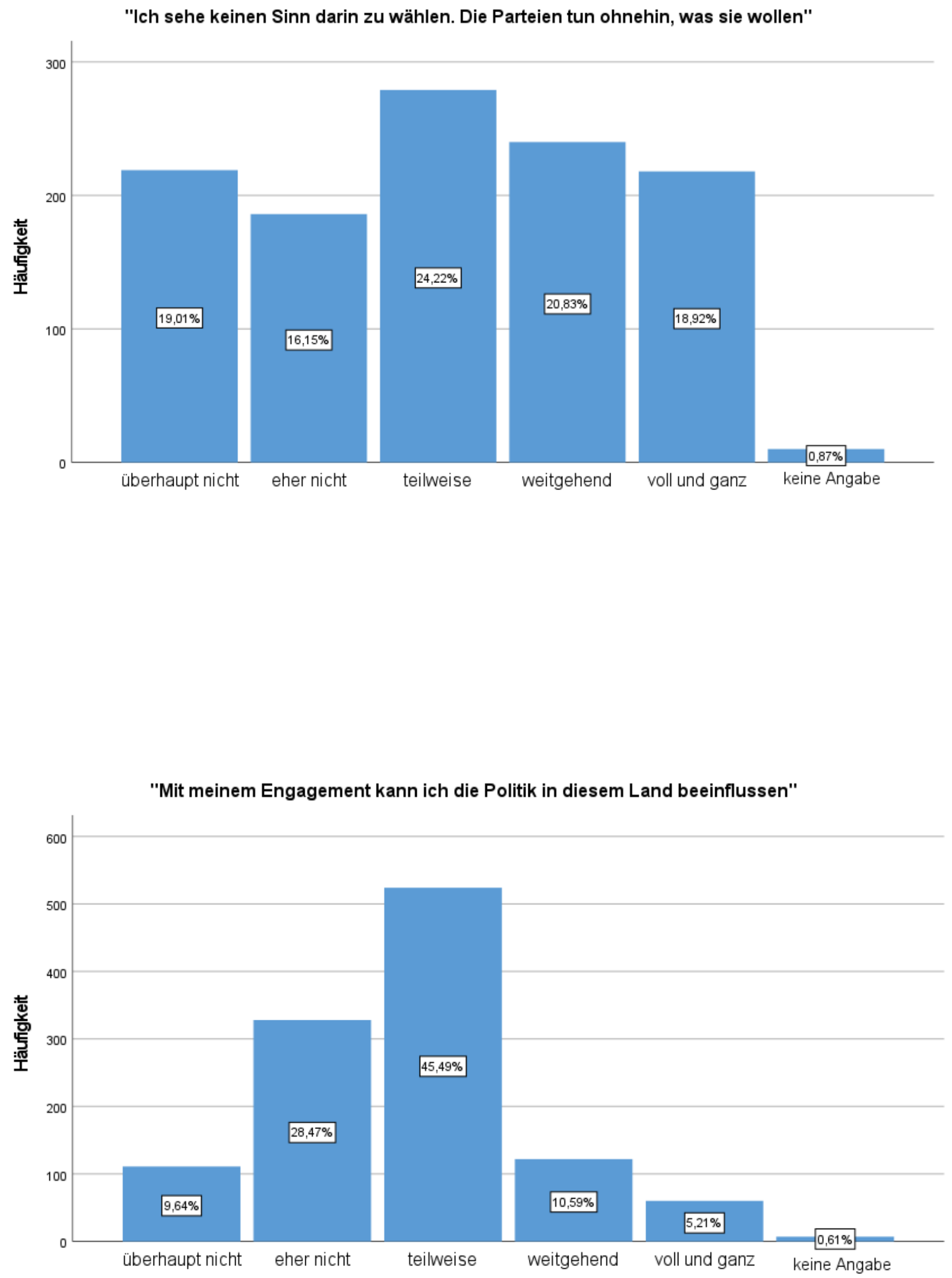
"Wenn sich Bürger*innen zusammenschließen, können Sie viel Einfluss auf politische Entscheidungen in diesem Land nehmen"
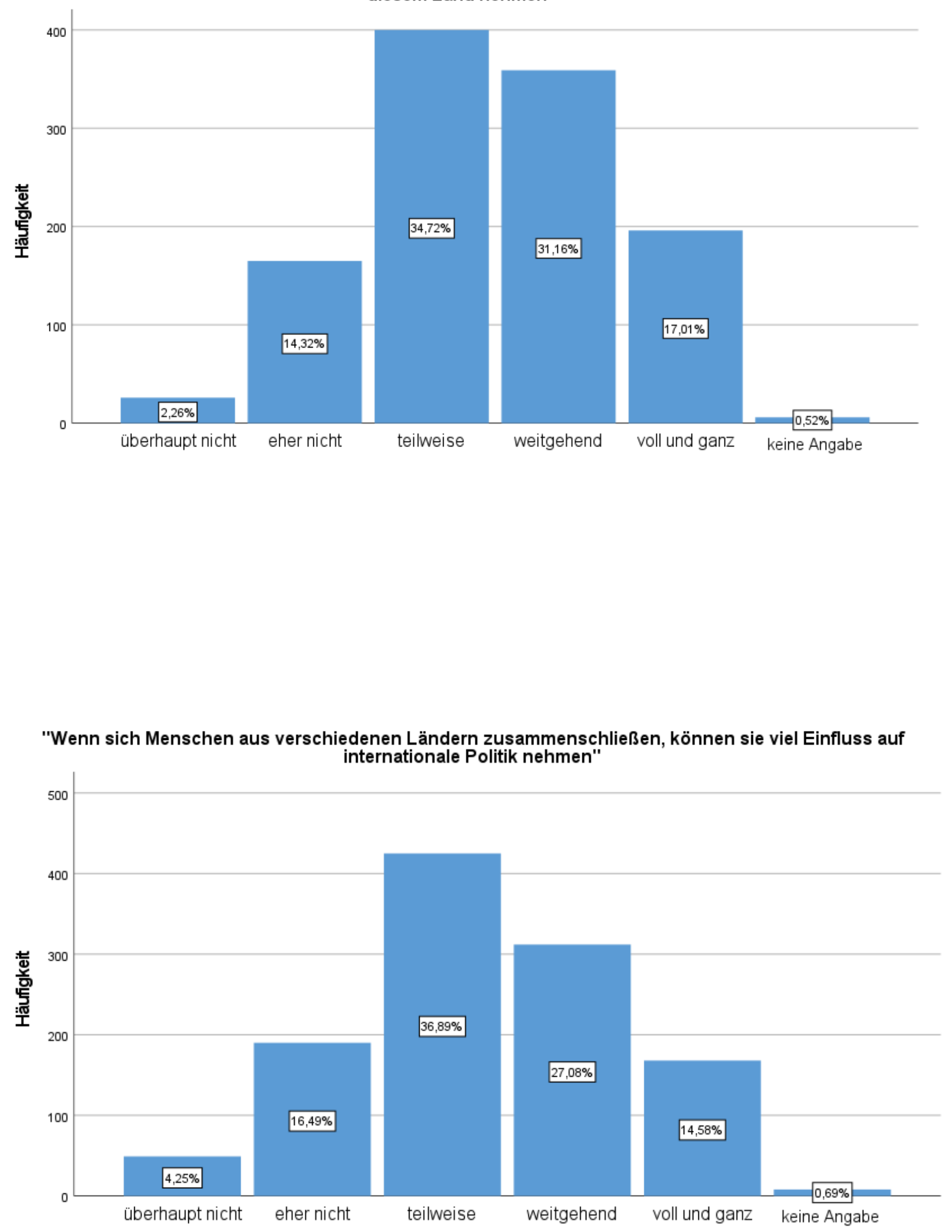


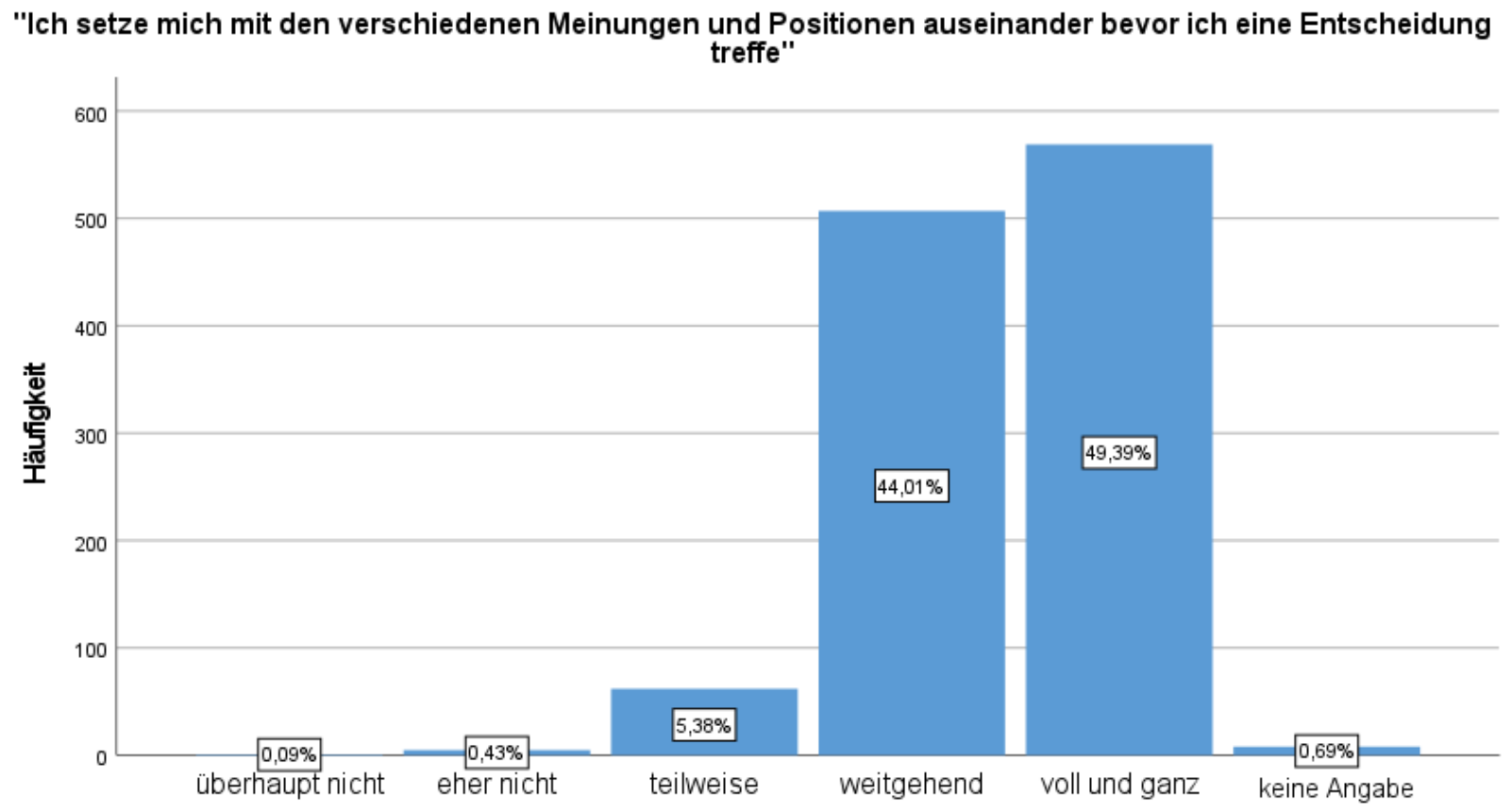

6. Ausgewählte bivariate Befunde ${ }^{6}$

Einfluss ausgewählter Indikatoren auf den Bezug zur Natur

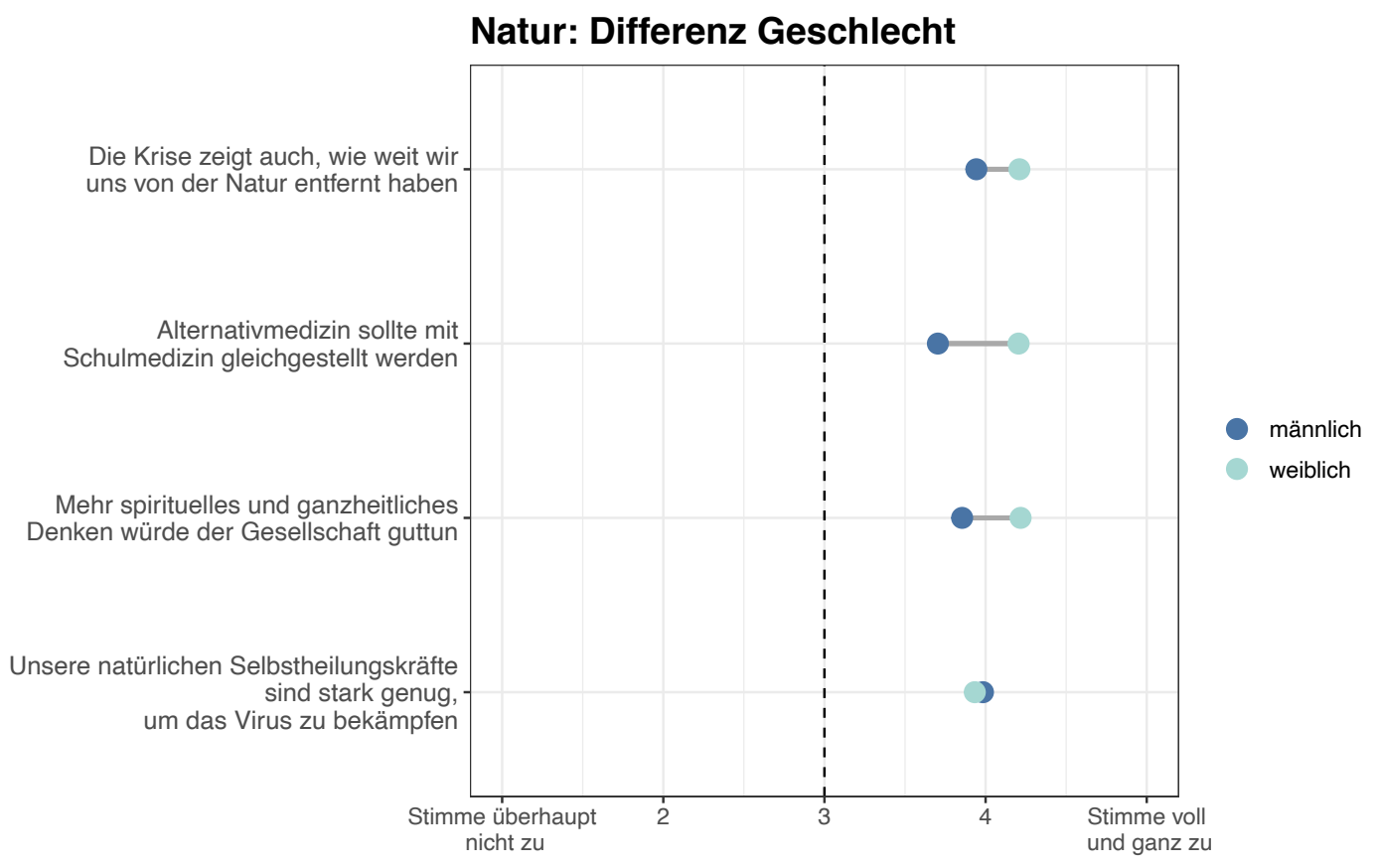

${ }^{6}$ Die Autor:innen des Berichts danken Prof. Dr. Denise Traber herzlich für diese Auswertungen. 


\section{Natur: Differenz Protestteilnahme}

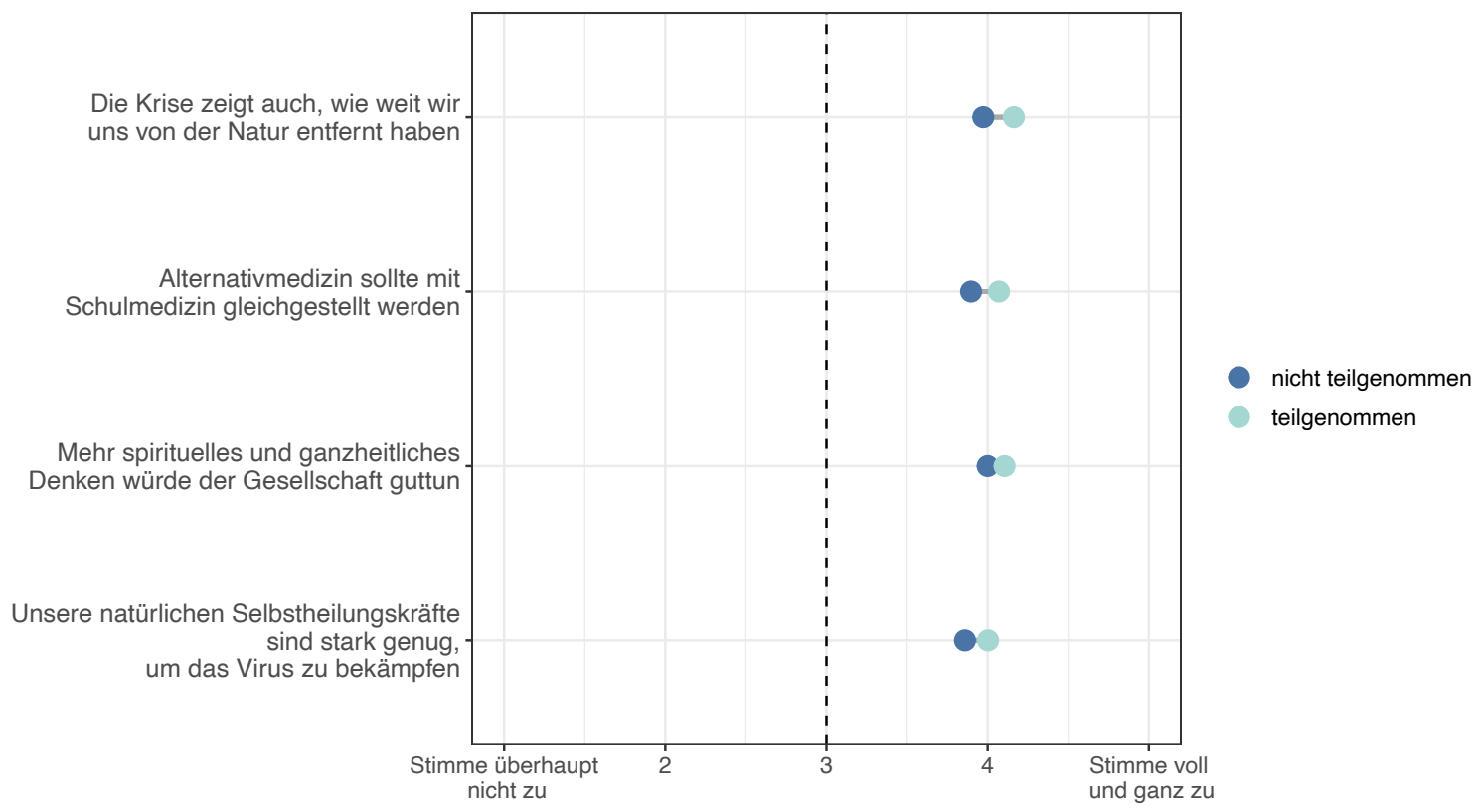

\section{Natur: Differenz Qualifikation}

Mehr spirituelles und ganzheitliches Denken würde der Gesellschaft guttun

Die Krise zeigt auch, wie weit wir uns von der Natur entfernt haben

Alternativmedizin sollte mit Schulmedizin gleichgestellt werden

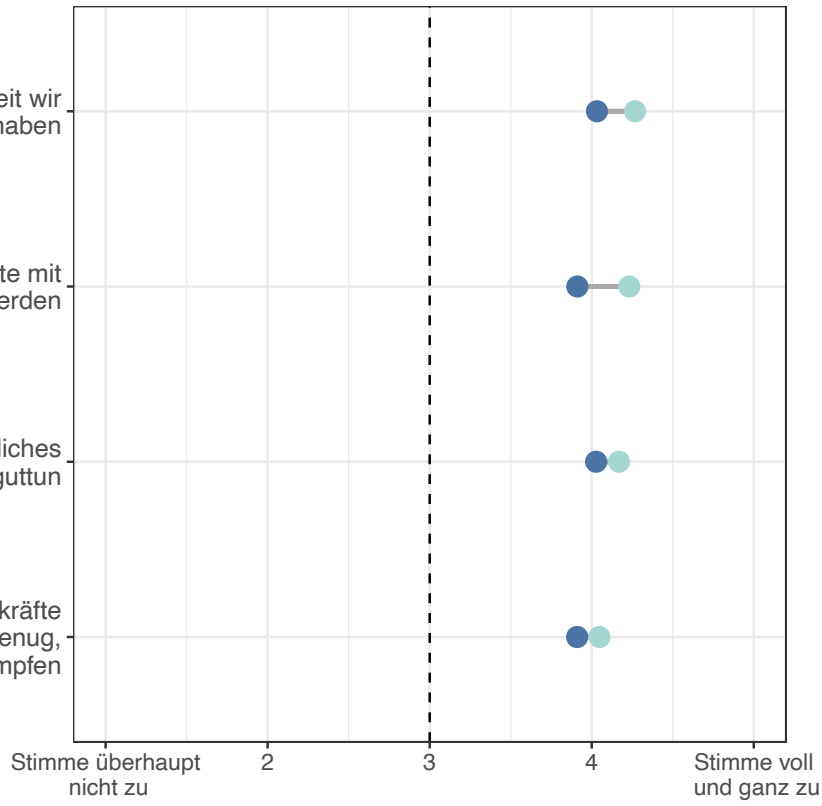

hochqualifiziert

niedrig/mittel qualifiziert

Unsere natürlichen Selbstheilungskräfte sind stark genug um das Virus zu bekämpfen 


\section{Einfluss ausgewählter Indikatoren auf populistische Haltungen}

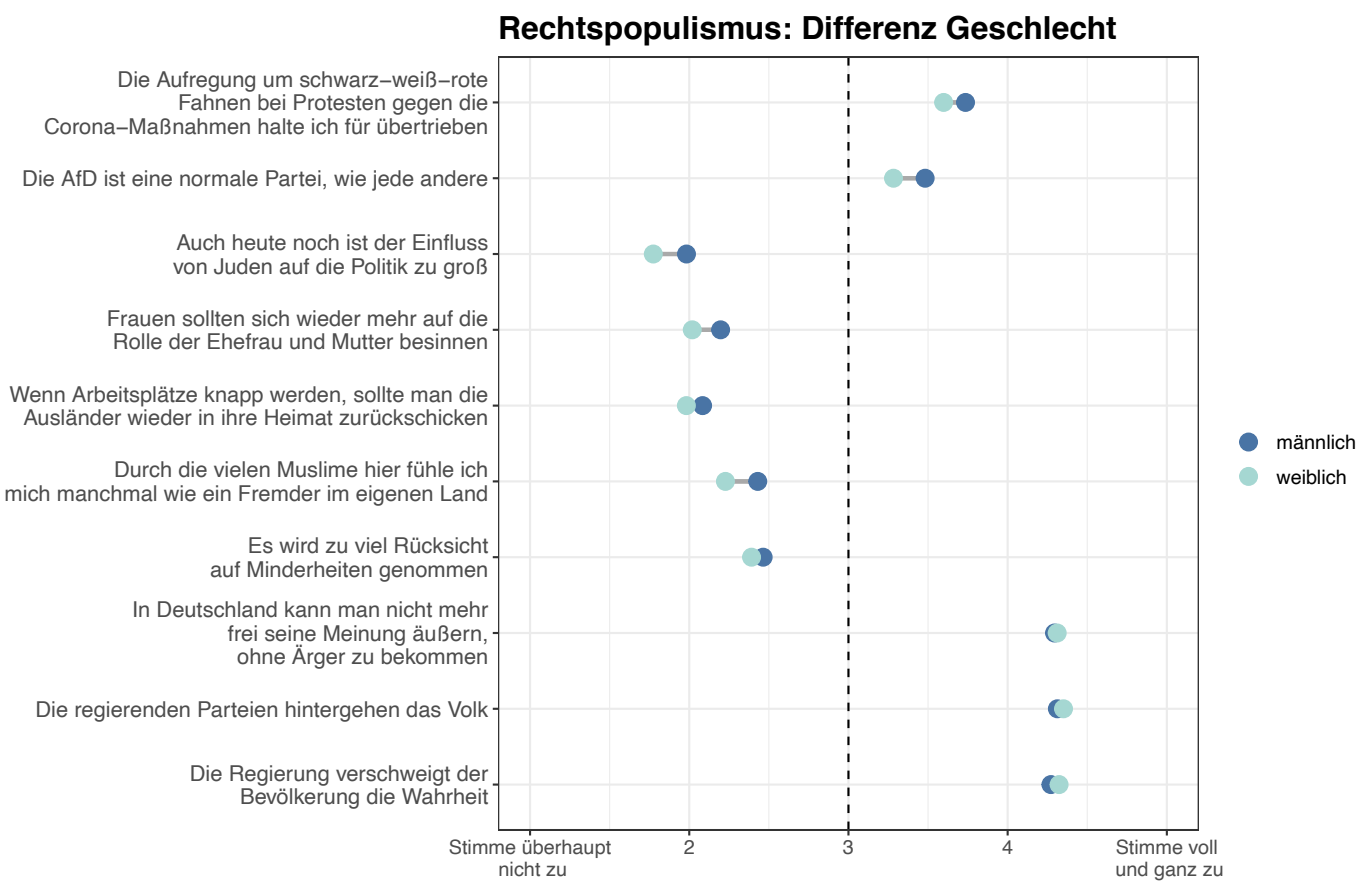

Rechtspopulismus: Differenz Protestteilnahme

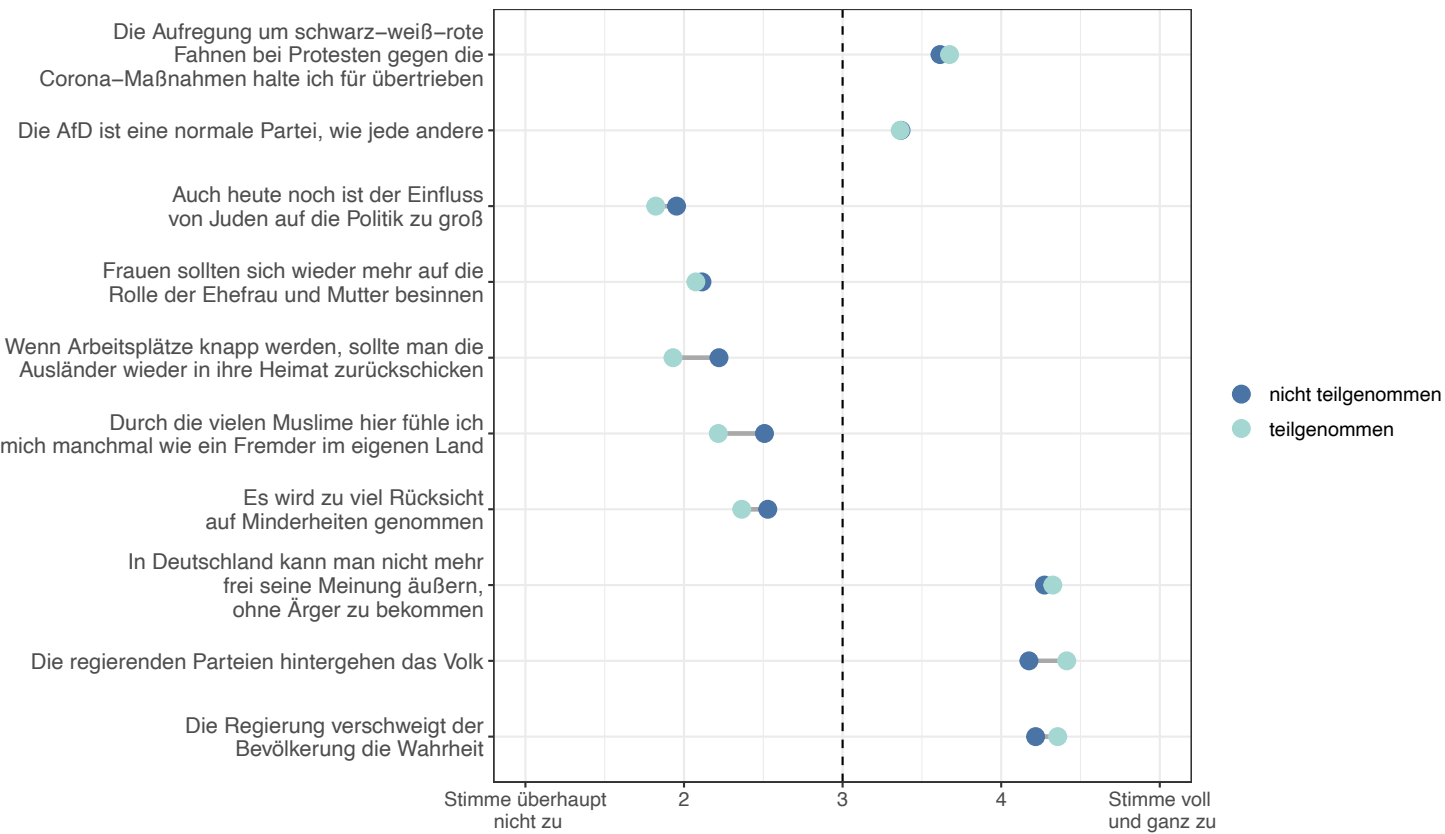




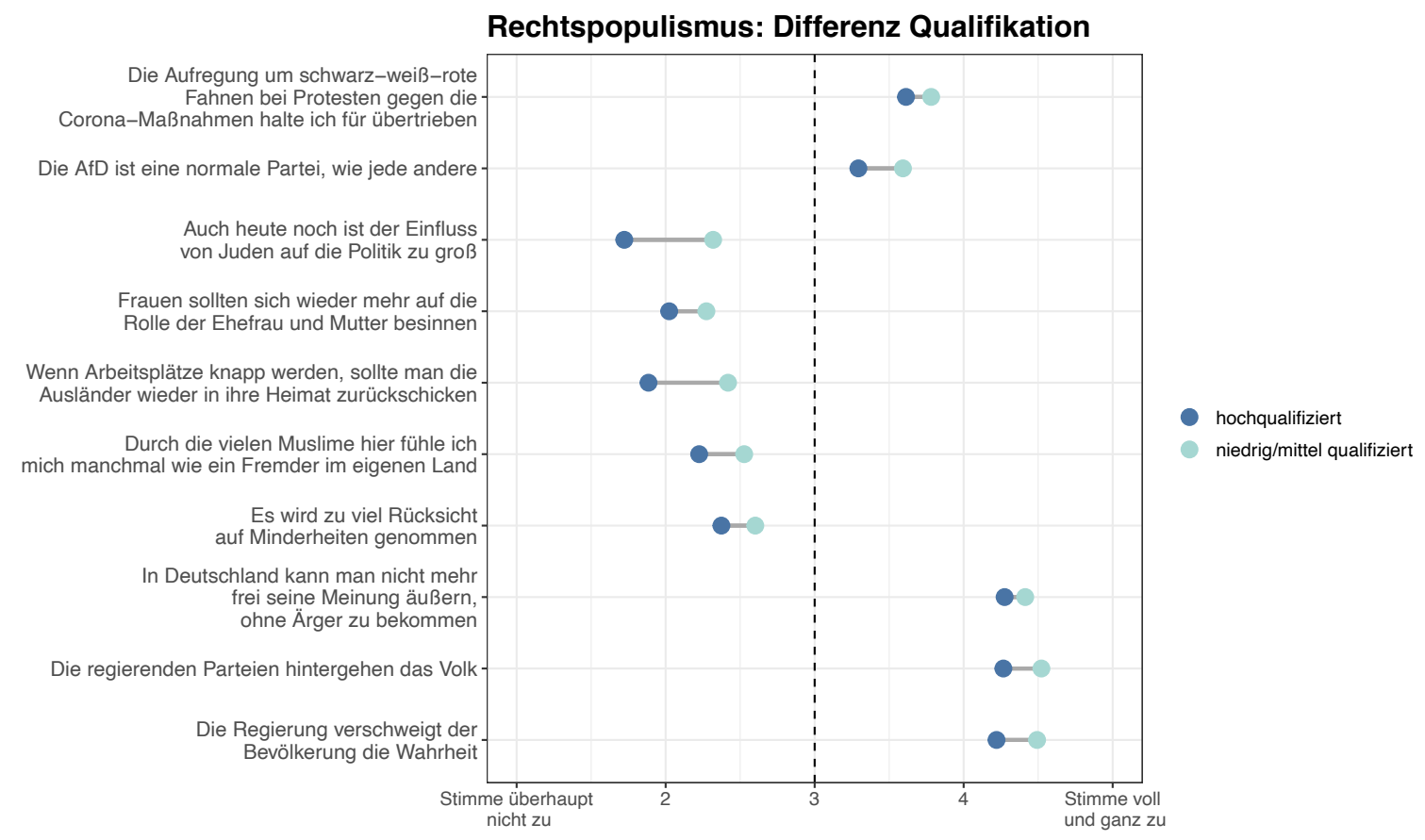

Einfluss ausgewählter Indikatoren auf rechtsextreme Haltungen

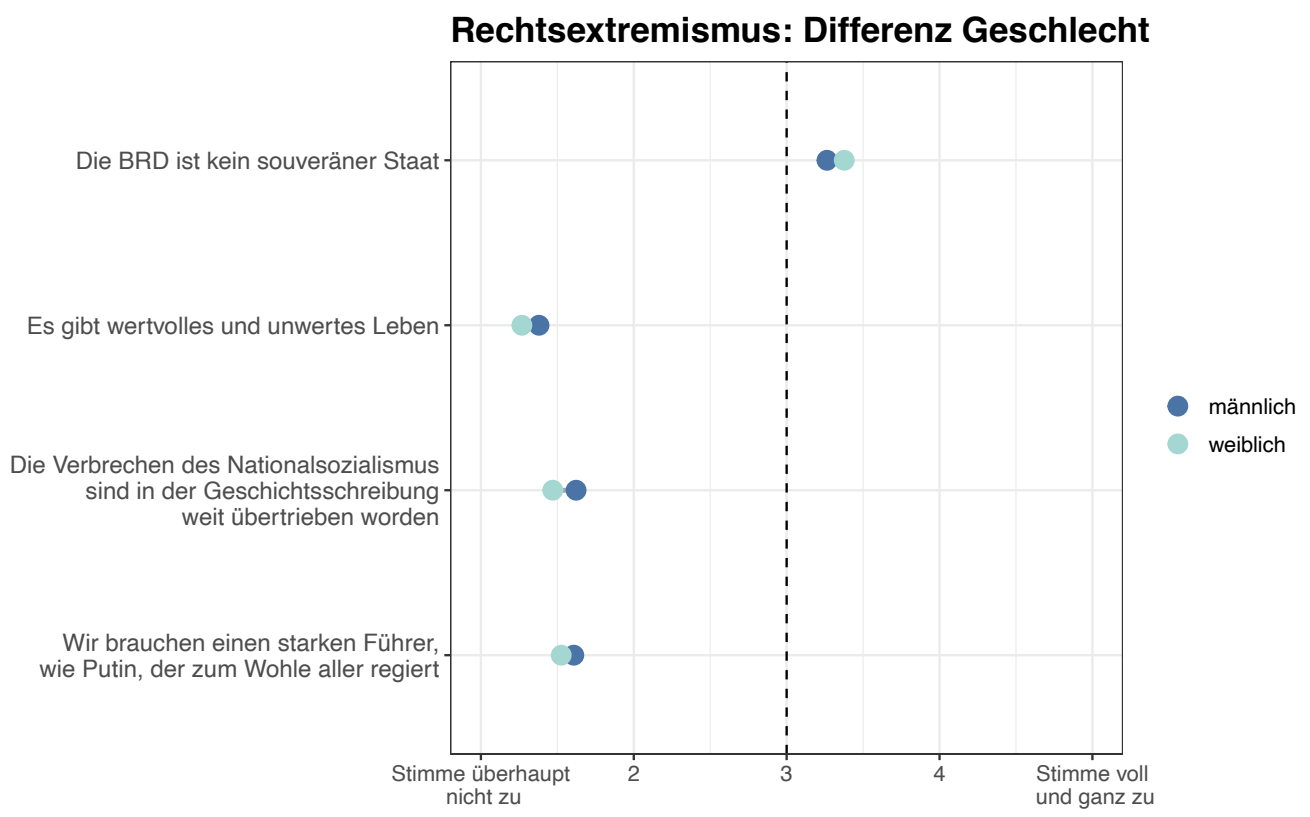




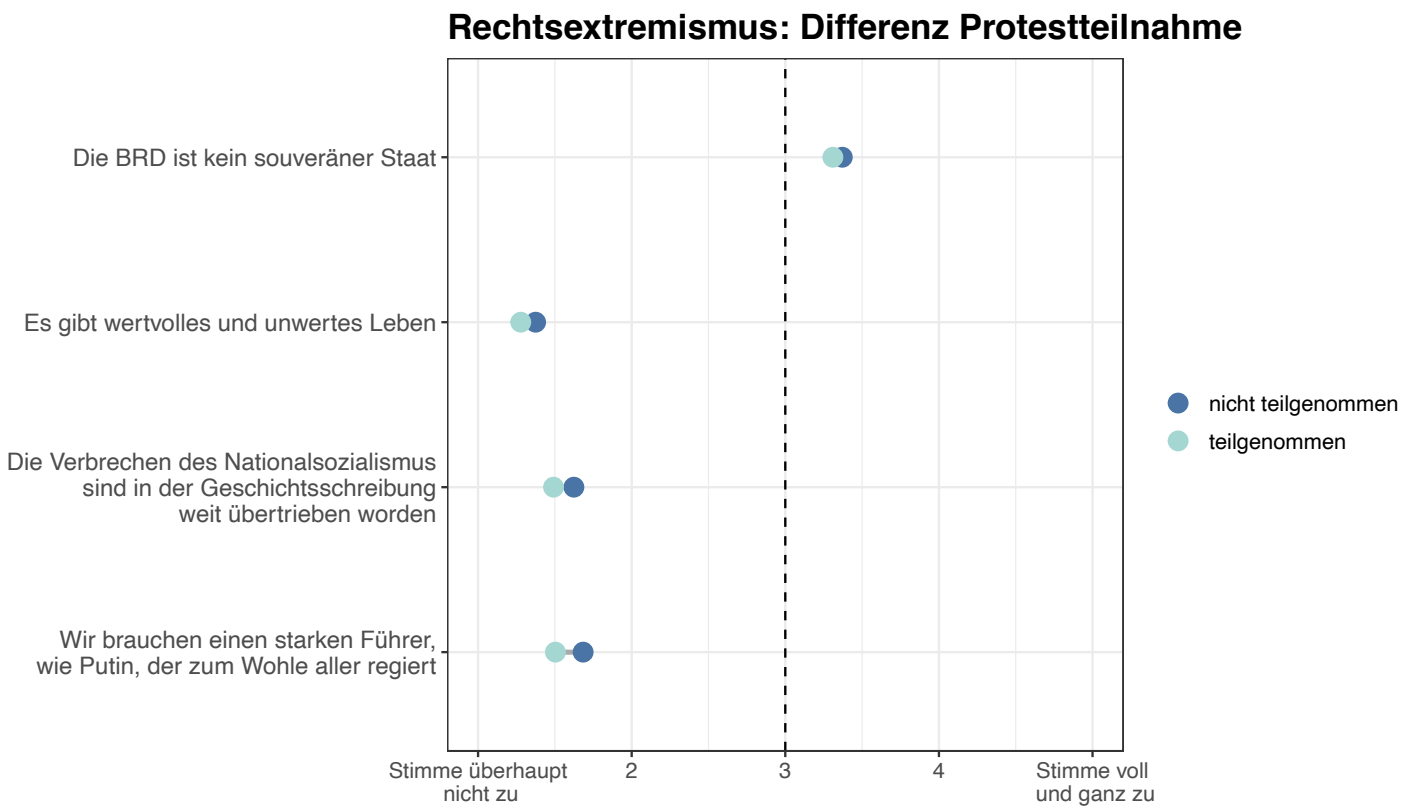

\section{Rechtsextremismus: Differenz Qualifikation}

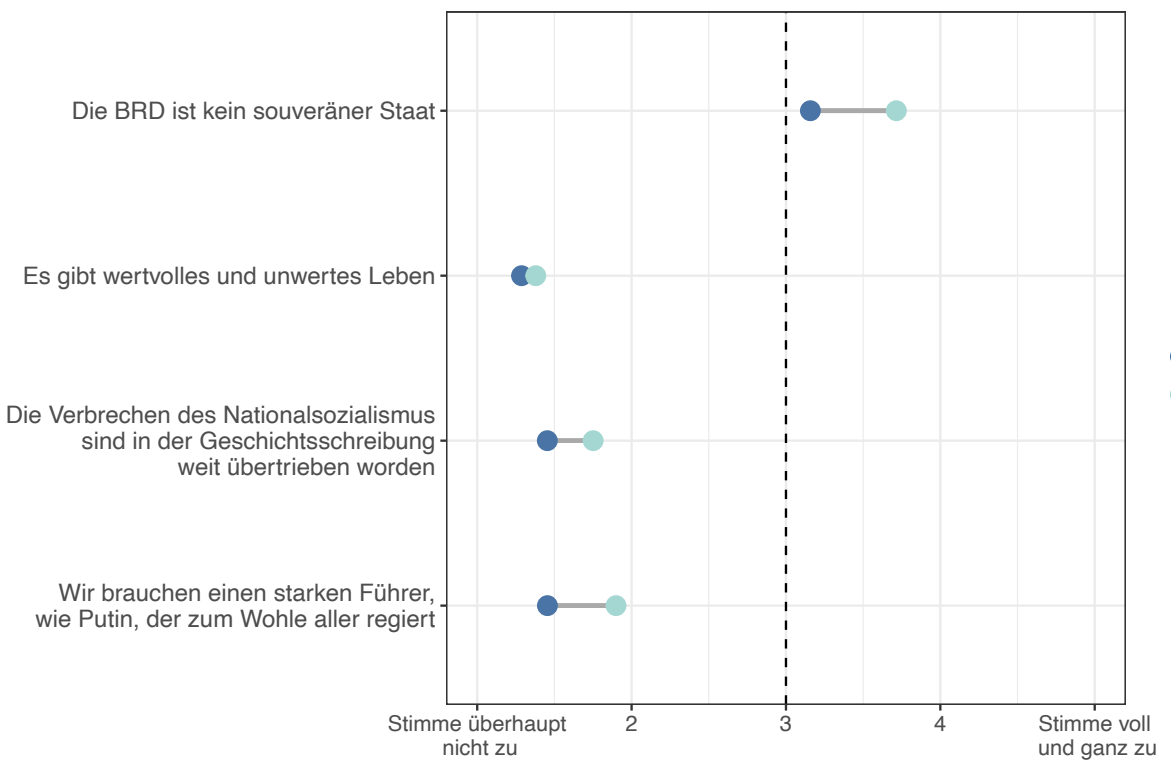

hochqualifiziert

niedrig/mittel qualifiziert 


\section{Einfluss ausgewählter Indikatoren auf konspirative Haltungen}

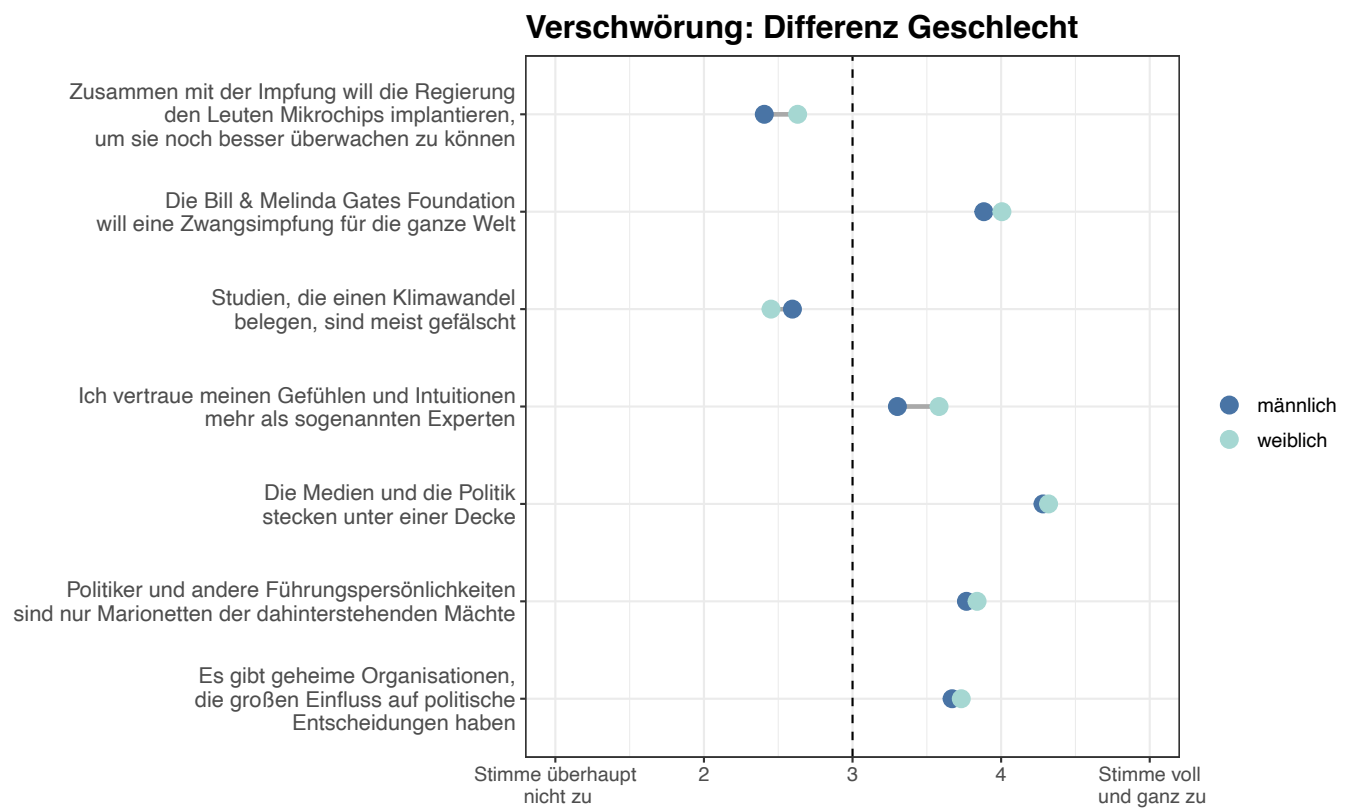

Verschwörung: Differenz Protestteilnahme

Zusammen mit der Impfung will die Regierung den Leuten Mikrochips implantieren, um sie noch besser überwachen zu können

Die Bill \& Melinda Gates Foundation will eine Zwangsimpfung für die ganze Welt Studien, die einen Klimawandel belegen, sind meist gefälsch

Ich vertraue meinen Gefühlen und Intuitionen mehr als sogenannten Experten

Die Medien und die Politik stecken unter einer Decke

Politiker und andere Führungspersönlichkeiten sind nur Marionetten der dahinterstehenden Mächte Es gibt geheime Organisationen, die großen Einfluss auf politische Entscheidungen haben

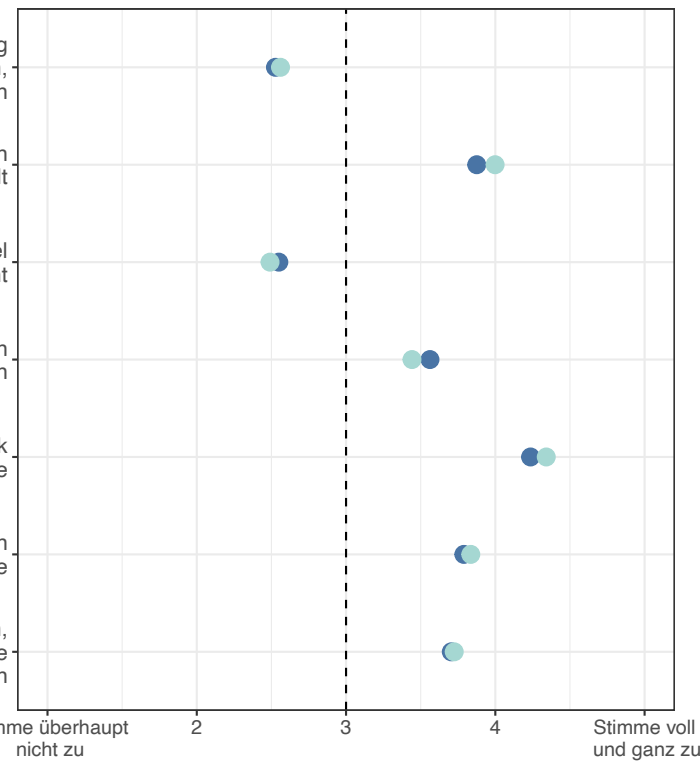

nicht teilgenommen

teilgenommen 


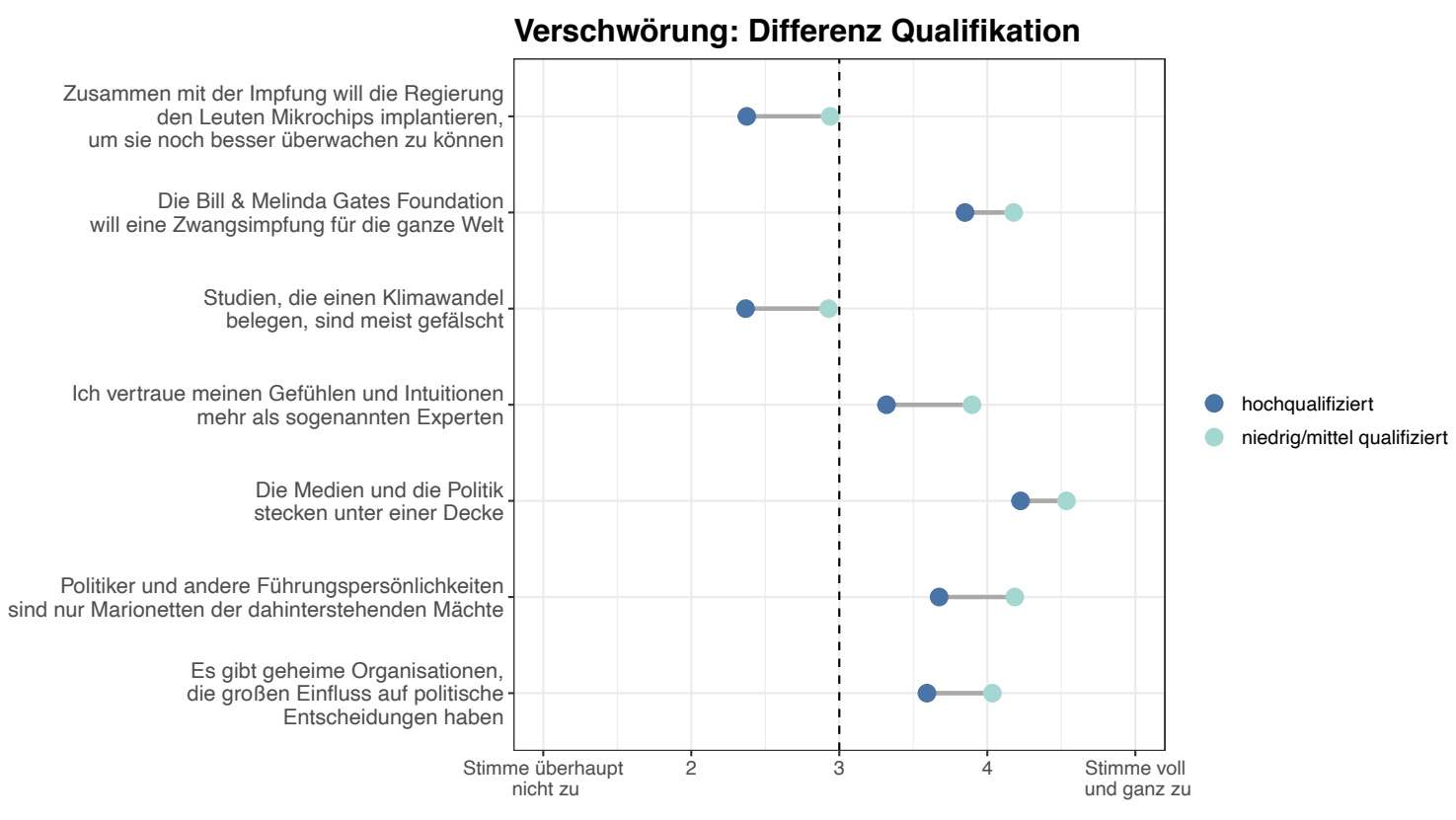

Wählerwanderungen BRD (Anhand der geäusserten Wahlabsicht)

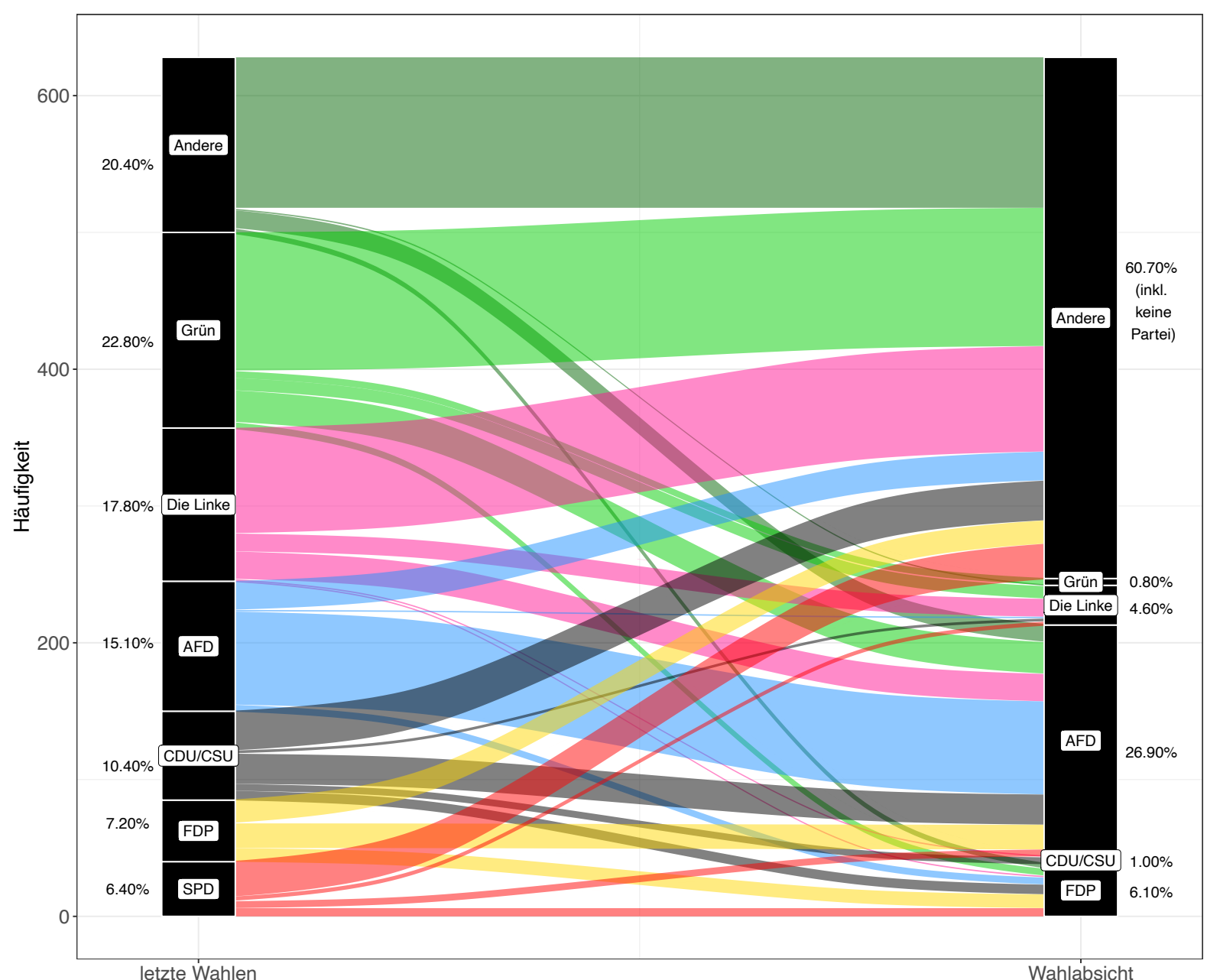




\section{Résumé quantitativer Teil: Wer sind die Querdenker:innen?}

Insgesamt gehen wir von einer grossen Heterogenität innerhalb der Bewegung der Corona-Kritiker:innen und Querdenker:innen aus. ${ }^{7}$ Es handelt sich nicht um eine, sondern um mehrere, häufig disparate soziale Gruppen, die über geteilte Mentalitäten verbunden sind. Gemeinsam ist ihnen, dass es sich mehrheitlich um gebildete Angehörige der Mittelschicht handelt. Unsere Analysen können deshalb nur als vorläufige Befunde einer Forschung betrachtet werden, die noch ganz am Anfang steht.

Im Folgenden diskutieren wir typische Merkmale der Querdenker:innen und analysieren zutage tretende Einstellungsmuster. Sozialstrukturell handelt es sich um eine relativ alte und relativ akademische Bewegung. Das Durchschnittsalter der Umfrageteilnehmer:innen beträgt 47 Jahre, 31\% haben Abitur, 34\% einen Studienabschluss. Letzteres ist höher als der Schweizerische Durchschnitt von $29.6 \%$ und fast doppelt so hoch wie in Deutschland, wo $18.5 \%$ über einen Hochschulabschluss verfügen. ${ }^{8}$ Überraschend ist der hohe Anteil Selbständiger, mit $25 \%$ ist er deutlich höher als in der Gesamtbevölkerung. Was die genauen Gründe hierfür sind, lässt sich noch nicht sagen. Mögliche Gründe wären unterschiedliche ökonomische Abhängigkeiten oder Erfahrungen im Arbeitsprozess, aber dies bedürfte weitergehender Analysen.

Bei der letzten Bundestagswahl in Deutschland haben 18\% die Linke und 23\% die Grünen gewählt. Der AfD haben 15\% ihre Stimme gegeben, bei der nächsten Bundestagswahl wären es allerdings rund $27 \% .{ }^{9}$ Die Volksparteien spielen praktisch keine Rolle. In der Schweiz verhält es sich anders. Die SVP ist von Beginn weg die stärkste Partei unter den Corona-Massnahmen-Kritiker:innen, aber sie liegt bei den Studienteilnehmer:innen etwas über dem Niveau ihrer nationalen Stärke in der Schweiz mit 33\%. Bei der künftigen Wahlabsicht hat die SVP das

\footnotetext{
7 Wie wir im Methodenteil beschrieben haben, halten wir es für wahrscheinlich, dass bestimmte radikale Teile der Querdenker:innen-Bewegung an der Studie systematisch nicht teilgenommen haben.

8 Vergleiche hierzu: www.destatis.de/DE/Themen/Gesellschaft-Umwelt/Bildung-ForschungKultur/Bildungsstand/_inhalt.html und www.bfs.admin.ch/asset/de/ind-d-406101

${ }^{9}$ Vorerst gingen wir von knapp 30\% aus, haben dies aber mit Rücksicht auf das Gesamtsample korrigiert.
} 
rot-grüne Lager, das bei der letzten Wahl zusammengenommen noch auf demselben Niveau lag, weit hinter sich gelassen: $43 \%{ }^{10}$ würden bei der nächsten Wahl der SVP ihre Stimme geben.

Charakteristisch für diese neue Bewegung ist eine starke Entfremdung von den Institutionen des politischen Systems, den etablierten Medien und - zumindest für Deutschland - den alten Volksparteien. In der Schweiz gilt dieser Befund nur eingeschränkt, da die SVP die stärkste Partei des Landes ist. Allerdings steht sie der AfD in rechtspopulistischen Belangen inhaltlich relativ nahe. Innerhalb der Institutionen der liberalen Demokratie werden der Justiz, der Polizei, den Umweltgruppen und den Bürgerinitiativen verhältnismässig viel Vertrauen geschenkt; auch Unternehmen wird weniger misstraut als den Medien, der Regierung, der EU, der UNO, den Banken, den Parteien und dem Parlament.

Insgesamt ist die Bewegung der Querdenker:innen intern, wie bereits erwähnt, heterogen und widersprüchlich. Mit Blick auf die Wahlabsichten lässt sich sagen, dass es sich um eine Bewegung handelt, die eher von links kommt, aber stärker nach rechts geht. Diese Analyse würden Menschen, die sich als Querdenker:innen verstehen, vermutlich ablehnen, da mehr als die Hälfte von ihnen sich gegen ihre Einteilung in eine links/rechts-Schematik positioniert.

Gleichwohl handelt es sich nicht um eine genuin autoritäre Bewegung, wie es etwa bei PEGIDA der Fall war. Die Statements, die eine traditionell antisemitische Einstellung exemplifizieren, werden in einem geringeren Masse abgelehnt als in der Leipziger Autoritarismus-Studie (vgl. Unterkapitel «Antisemitismus und Nationalsozialismus»). Es wird innen jedoch auch nicht stark zugestimmt. Die Rolle der sozialen Erwünschtheit spielt bei solchen Items immer eine große Rolle (vgl. hierzu den Methodenteil der Studie). Was auffällig ist: Fast 30\% der Studienteilnehmer:innen sind bei diesem Item auf "keine Angabe" ausgewichen, so viele wie nur bei einem anderen Item der Studie, welches auf eine

\footnotetext{
10 In einer ersten Fassung des Berichts wurden Daten der statistischen Auswertung an dieser Stelle versehentlich abweichend wiedergegeben
} 
Verschwörungstheorie Bezug nahm ("Die Regierung will den Menschen Mikrochips implantieren").

Bei allen anderen Items, auch bei kontroversen, bei denen eine soziale Erwünschtheit zu vermuten ist, gab es keinen derartig hohen Anteil von "keine Angabe". Und auch nicht bei anderen, die ebenfalls für Studienteilnehmer:innen kontrovers sind. Es ist nicht unwahrscheinlich, dass viele Personen mit latenten antisemitischen Vorurteilen durch Nichtbeantwortung der Frage gewissermassen "ausgewichen" sind. Um dies valide zu überprüfen, wären allerdings noch umfassendere Untersuchungen notwendig. Unsere Daten reichen dafür bisher nicht aus. Insgesamt ist die relative Neigung zum Antisemitismus insofern nicht überraschend, als wir es mit einer Bewegung zu tun haben, die viele Bezüge und eine hohe Neigung zum verschwörungstheoretischen Denken aufweist und Verschwörungstheorien häufig antisemitische Züge aufweisen.

Die Neigung zum Verschwörungsdenken haben wir sowohl hinsichtlich der Corona-Krise als auch bezüglich einer allgemeinen Verschwörungsmentalität überprüft. Diese fiel fast immer stark aus, soweit es Regierung, Medien und Corona-Massnahmen betrifft. Allerdings trifft dies nicht in gleichem Masse auf die Sicht zu Studien zum Klimawandel zu. Auch hier ist der Anteil der Personen, die "keine Angabe" machen mit 24\% relativ hoch, aber gemessen daran, dass die Leugnung des Klimawandels ein häufig angeführtes Narrativ der Rechten ist, zeigt sich auch hier, dass eine rechte Einordnung der Querdenker:innen nicht so einfach ist. Eine mögliche Deutung wäre, dass sich in diesem Item die grünen Wurzeln eines Teils dieser Bewegung zeigen - auch an dieser Stelle wären jedoch weitere Analysen, die wir an dieser Stelle noch nicht leisten können, nötig.

Insgesamt sind Querdenker:innen, soweit sie an unserer Erhebung teilgenommen haben, weder ausgesprochen fremden- oder islamfeindlich, in einigen wenigen Bereichen sogar eher anti-autoritär und der Anthroposophie zugeneigt. Ein Grossteil will die Alternativmedizin der Schulmedizin gleichstellen, zurück 
zur Natur und stärker auf ganzheitliches und spirituelles Denken setzen. 64\% sagen, man solle Kindern nicht beibringen, Autoritäten zu gehorchen. Eine Mehrheit der Befragten ist nicht der Auffassung, dass auf Minderheiten in unserem Land zu stark Rücksicht genommen wird - was häufig ein eher rechter Topos ist. Vermutlich spielt bei der Beantwortung dieser Frage eine Rolle, dass viele Teilnehmer:innen sich selbst als diskriminierte Minderheit betrachtet.

Der Nationalsozialismus wird seltener verharmlost als in der Gesamtbevölkerung, es finden sich kaum sozialdarwinistische Haltungen und eine grosse Mehrheit will es Menschen aus anderen Ländern erlauben, ins Land zu kommen und dauerhaft hier zu leben. Mehr als 70\% sind gegen eine Privatisierung der wichtigsten öffentlichen Dienstleistungen, nur 28\% gegen die Umverteilung der Einkommen. Die Querdenker:innen vertrauen der parlamentarischen Demokratie, den Medien und der Wissenschaft nicht bzw. nicht mehr. In der Zivilgesellschaft, in Vereinen und in anderen Organisationen sind sie jedoch aktiv und verhalten sich in ihrer Lebensführung durchaus politisch. Viele von ihnen sind neu-politisiert, fast die Hälfte von ihnen hat in der Vergangenheit noch an keinem anderen Protest teilgenommen. Mit anderen Worten, die Querdenker:innen entsprechen - soweit das unsere Daten und ihre Interpretation zulassen - in ihrer Grunddisposition nicht unbedingt dem Bild einer rechten Bewegung, wie sie gerade in vielen Diskussionen eingeordnet werden.

Allerdings handelt es sich klar um eine Bewegung, die nach rechts offen ist und über ein beträchtliches immanentes Radikalisierungspotenzial verfügt. Eine Mehrheit hält die AfD für eine normale Partei und empfindet die Aufregung um Reichskriegsflaggen auf den Demonstrationen für übertrieben. Bewegungen sind nie statisch, sondern können - gerade wie im vorliegenden Fall affektueller Bewegungen - starke Dynamiken entwickeln, die auch eine Radikalisierung wahrscheinlicher machen. 


\section{Teil B: Qualitative Grundauswertung}

\section{Ethnographische Beobachtungen}

Teil der empirischen Untersuchung ist die Beobachtung von Kundgebungen und Demonstrationen in Form von soziologischen Ethnographien. Eine systematische Beobachtung erfolgte am 4. Oktober 2020 in Konstanz mit 14 Forscher:innen ${ }^{11}$ und am 7. November 2020 in Leipzig mit 9 Forscher:innen - zu beiden Kundgebungen wurde von der Initiative »Querdenken « aufgerufen. ${ }^{12}$

Die Kundgebung in Konstanz, die bereits am Morgen begann und bis in den Abend dauerte, zeichnete sich durch eine Festivalstimmung mit affektivem Potential aus. Der beobachtete Habitus der Teilnehmer:innen an dieser Kundgebung erlaubte ihre Zuordnung zur Mittelschicht, die meisten von ihnen waren über 40 Jahre alt und das Geschlechterverhältnis war ausgeglichen. Es gab zwar einzelne Familien, aber vor allem viele Paare und kleinere Gruppen nahmen an dieser Kundgebung teil. Schon zu Beginn gab es durch Redner:innen und Moderator:innen auf der Bühne Animationsversuche, um ein Gefühl der Gemeinschaft herzustellen. Diese Gemeinschaftsbildung lässt sich auf einer inhaltlichen und formalen Ebene anordnen. Betrachtet man den Verlauf des Tages auf formaler wie inhaltlicher Ebene, lässt sich eine Verschiebung von der Festgemeinschaft zur Leidensgemeinschaft hin zur Widerstandsgemeinschaft feststellen. So wurden Friede-Freiheit-Rufe etabliert, zu gemeinsamen Formen von einem Herz mit den Händen aufgerufen, musikalischen Darbietungen auf der Bühne Platz eingeräumt oder auch die Möglichkeit für offene Performances im Sinne von Trommelkreisen und Riesen-Seifenblasen geschaffen. Dabei spielten verschiedene Themen eine zentrale Rolle, von denen zwei im Folgenden ausgeführt werden.

\footnotetext{
${ }^{11}$ Ein im Kollektiv erarbeiteter Demonstrationsbericht der ethnographischen Beobachtung in Konstanz erscheint im Januar.

12 Weitere Beobachtungen in kleineren Teams erfolgte in Basel, Bern und Zürich.
} 


\section{Masken}

Der Mundnasenschutz, alltagssprachlich als Maske bezeichnet, ist innerhalb der Coronaproteste zu einem zentralen Symbol des Widerstandes avanciert. Die Genese dieser Maskenablehnung ist noch unerforscht, deutlich wurde aber an der Kundgebung in Konstanz, dass die Bezugnahme auf dieses Symbol von den Teilnehmer:innen breit geteilt wurde. Es gab unterschiedliche Begründungen für das Nichttragen einer Maske, zum Beispiel wurde der medizinische Schutz in Frage gestellt, die Maske als Zeichen der Diktatur und freiwilligen Unterwerfung gedeutet oder als Störmittel für Kommunikation empfunden. ${ }^{13}$

Mögliche Gründe dafür, warum die Maske zum Symbol wurde, sind zum Beispiel, dass andere coronabedingte Maßnahmen (Restaurant- und Schlussschliessungen) nicht einfach boykottiert werden können, das Nichttragen einer Maske hingegen individuell umsetzbar ist. Es ist ein einfaches Erkennungsmerkmal und es eignet sich durch seine Sichtbarkeit zur Verfestigung der Identität innerhalb der Eigengruppe.

\section{Kritik an etablierten Autoritäten}

Charakteristisch für die Gemeinschaftsbildung innerhalb der Coronaproteste sind die Dichotomisierung zwischen innen und aussen ${ }^{14}$, inhaltlich ähnliche Bezugnahmen auf etablierte Autoritäten und das Hervorbringen bzw. die Idealisierung von alternativen Autoritäten. Unsere Beobachtungen lassen den Schluss zu, dass das Verhältnis zu etablierten Institutionen wie den Staat, die Medien oder die Wissenschaft als insgesamt ambivalent bis hin zu entfremdet bezeichnet werden kann.

\footnotetext{
${ }^{13}$ Auf vielfache Weise wurden die coronabedingten Massnahmen mit ihren Auswirkungen auf Kinder thematisiert und gleichzeitig problematisiert. Nicht nur seien die Masken für ihre Kommunikation und Emotionalität schädlich, sondern auch für ihre Gesundheit.

14 Melucci (1995), der kollektive Identitäten sozialer Bewegungen untersucht, nennt die Abgrenzung gegenüber anderen Gruppen als elementar für die Herausbildung einer kollektiven Identität. Melucci, A. (1995): The Process of Collective Identity, in: Johnston, H. \& B. Klandermans (Hrsg.): Social Movements and Culture, Minnesota: University Press, S.41-63.
} 
Das institutionell Etablierte scheint unter dem ständigen Verdacht der Parteilichkeit, der Einseitigkeit oder sogar der Unterwanderung zu stehen. In den Reden, in einzelnen Gesprächen mit einzelnen Teilnehmer:innen und in den verschiedenen Flyern und Plakaten zeigte sich eine personalisierte Kritik, zum Beispiel gegen Spahn, Drosten oder Merkel, und es wurde eine grundsätzliche Institutionenkritik einhergehend mit einem Vertrauensverlust deutlich. Vertrauen und Glaubwürdigkeit wird dagegen alternativen Medien und Mediziner:innen geschenkt, die qua ihrer Andersartigkeit Authentizität beanspruchen können und damit in diametraler Abgrenzung zum »Mainstream« stehen.

Thematisiert wird eine Spaltung der Gesellschaft, eine Diffamierung der Skeptiker:innen an den coronabedingten Massnahmen - es wird unterschieden in etabliert und ausgegrenzt. Hier spielt eine weitere Dichotomisierung hinein, indem die Metapher der Aufgewachten im Kontrast zu den Schlafenden ("Schlafschafe«) bedient wird. Zwar wird eine Leidensgemeinschaft heraufbeschworen, doch wird gleichzeitig ein Opferstatus abgelehnt. So wird zur Selbstinitiative und zum Aneignen von Wissen aufgerufen, in Form von selber hinterfragen, informieren, recherchieren und überprüfen. Es zeichnete sich auf dieser Kundgebung bereits ab, dass eine Widerständigkeit gegen etablierte Autoritäten und Diskurse als ehrenvoller Akt der Selbstaufopferung inszeniert werden kann. Ein mögliches Gefühl der Isolation wird in der neu geschaffenen Gemeinschaft aufgelöst, wofür eine Trennungslinie zur feindlich verstanden Gesellschaft gezogen wird.

\section{Emotionen und Affekte}

Emotionalität und affektive Momente während der Kundgebung, auch im Rekurs auf Frieden, Freiheit, Liebe und Gerechtigkeit, nehmen eine wichtige Rolle in der Etablierung einer Gemeinschaft ein. So zum Beispiel wurde einem Gegenprotest, der in der Nähe der Querdenken-Kundgebung von der Polizei eingekesselt wurde, mit Friedlichkeit und Wohlwollen begegnet, aber von einzelnen auch mit einer harten Ablehnung oder sogar Beschimpfung. 
Die Friedens- und Liebesrhetorik weicht damit, jedenfalls punktuell, einer «Wirgegen-die-Mentalität». Diese affektiven Aufladungen ergaben sich zum einen spontan durch die Teilnehmer:innen am Protest, zum anderen wurden diese durch Reden auf der Bühne orchestriert. Die Kundgebung in Konstanz lässt sich als Happening mit affektivem Potential beschreiben, in der eine Trennung zwischen »uns« und »den anderen« latent vorhanden ist. Manifest wird diese Trennung in Leipzig. ${ }^{15}$ Bereits im Vorfeld gab es kontroverse Diskussionen zur geplanten Kundgebung und Demonstration, angemeldet unter dem Motto «2. Friedliche (R)Evolution ${ }^{16}$, aufgrund der angepassten Coronaschutz-Verordnung im November, aber auch aufgrund von Sicherheitsbedenken, da sich im Vorfeld organisierte Strukturen der extremen Rechten ankündigten. ${ }^{17}$

Das gewaltsame Durchbrechen der Polizeiketten, eine Notwendigkeit, um die Demonstration auf den Innenstadtring zu erzwingen, erfolgte nicht spontan, sondern wurde von Personen aus dem neonazistischen Umfeld organisiert und umgesetzt. Eine affektive Entladung zeigte sich schließlich in der darauf folgenden «fröhlichen» Aneignung der Straße.

In Leipzig zeigte sich die Bezugnahme auf 1989 als zentral ${ }^{18}$ und es erfolgte auf unterschiedliche Weise, viele Kundgebungsteilnehmer:innen verliessen die Kundgebung nach der offiziellen Auflösung dieser durch die Polizei, ein Zelebrieren des Widerstandes.

\footnotetext{
${ }^{15}$ Eine durch die Stadt verordnete Verlegung der Kundgebung vom Augustusplatz auf das Neue MesseGelände ausserhalb der Stadt wurde einen Tag vor der Kundgebung vom Oberverwaltungsgericht Bautzen kassiert. Damit blieb zwar eine Demonstration auf dem Innenstadtring verboten, doch unter Einhaltung der Kundgebungsauflagen konnte die Kundgebung auf dem Augustusplatz durchgeführt werden.

${ }^{16}$ Vgl. www.facebook.com/BewegungLeipzig/photos/a. $162028368839457 / 182387493470211$ (zuletzt aufgerufen am: 16.12.2020).

17 Vgl. www.lvz.de/Leipzig/Polizeiticker/Polizeiticker-Leipzig/Querdenken-in-Leipzig-Verfassungsschutzwarnt-vor-rechter-und-linker-Gewalt www.kreuzer-leipzig.de/2020/11/10/die-wahl-zwischeninkompetenz-und-boesartigkeit/ www.zeit.de/2020/47/leipzig-demonstration-querdenken-coronaleugner-polizei/ www.taz.de/Corona-Protest-nach-Leipzig-Demo/!5724075/ www.sueddeutsche.de/politik/leipzig-corona-querdenken-demonstration-1.5107891 (alle zuletzt aufgerufen am: 16.12.2020)

${ }^{18}$ Vgl. Stach, S. und G. Hartmann (2020): "Friedliche Revolution 2.0? Zur performativen Aneignung von 1989 durch "Querdenken" am 7. November 2020 in Leipzig“, erschienen in: Zeitgeschichte Online, online verfügbar unter: www.zeitgeschichte-online.de/node/58284\#_ftn8 (zuletzt aufgerufen am: 16.12.2020).
} 


\section{Interviews und Dokumentanalysen}

Interessant sind bereits die Reaktionen, die sowohl unsere Umfrage in den Telegram-Chat-Groups als auch die Anfragen für Interviews ausgelöst haben. Sie sind einerseits ausgesprochen negativ, geradezu wissenschaftsfeindlich.

Einerseits wurde hervorgehoben, dass universitäre Forschung immer abhängig sei von ihren Geldgebern, zweites wurde die Vertrauenswürdigkeit der Forscher selbst in Frage gestellt und drittens wurde gar davor gewarnt, an der Umfrage teilzunehmen, da es nur der Registrierung widerständiger Akteure diene.

Andererseits wird unsere Forschung aber auch positiv aufgenommen, wenn auch die Hoffnung, die dem zugrundeliegt, enttäuscht werden wird. So haben einige Personen das Interview als Gelegenheit verstanden, die Wissenschaft als ihr Sprachrohr zu nutzen. Sie sahen ihre Aufgabe darin, die Interviewer:innen über die «wirklichen Fakten» der Coronakrise aufzuklären, damit diese in der Öffentlichkeit dann besser gehört werden.

Die Analyse der Interviews sind geleitet von der Frage, welche Formen von Gesellschaftskritik sich darin manifestiert und welche Weltanschauungen dahinter stehen. Die Einstiegsfrage lautet stets: «Was stört sie an den aktuellen Massnahmen gegen die Ausbreitung des Coronavirus?» ${ }^{19}$

Bislang zeichnen sich drei Antworten auf die forschungsleitende Fragestellung ab. Vorwegzunehmen ist, dass es sich um eine reflexive Kritik handelt. Es ist keine naive Kritik, sondern eine, die darum weiss, dass sie als solche wahrgenommen wird und entsprechend auch in der Lage ist, mögliche Gegenkritik vorwegzunehmen. Die zentralen analytischen Punkte aus den Interviews und den Dokumentanalysen werden nachfolgend dargestellt.

\footnotetext{
${ }^{19}$ Es handelt sich um ein offenes Interview, nachgefragt wird rein immanent, d.h. nur bezogen auf das, was der/die Befragte von sich aus erwähnt hat. Sollten zentrale Themen fehlen, werden diese erst am Schluss von der interviewenden Person eingebracht. Die Interviews werden in Gruppen sequenzanalytisch ausgewertet.
} 


\section{Formen der Gesellschaftskritik}

1. Die Kritik zielt weniger auf konkrete Massnahmen, sondern auf die Tatsache, dass Kritik nicht möglich sei. Demgegenüber wird hervorgehoben, dass alle Meinungen möglich sein sollten und auch das Recht haben, angehört zu werden, oder wie es im Jargon heisst: Man will Fragen stellen können. Kritik bekommt dadurch einen ethischen Eigenwert, sie wird sich selbst zum Hauptzweck, Dissens wird als solcher honoriert. Wichtig ist nicht, wogegen man konkret ist, sondern dass man dagegen ist.

Darin zeigt sich eine Strategie der ostentativen Distinktion, d.h. das Streben nach dem Anderssein. Das ist mit Individualisierung nicht zu verwechseln, sondern ist im Gegenteil die Grundlage von Vergemeinschaftungsprozessen: «Wir sind anders!» Dadurch beantwortet sich auch eine zentrale Unterfrage unserer Forschung: Wie wird für die (alternativen) Informationsquellen, auf die die Kritik referiert, Glaubwürdigkeit hergestellt? Die Glaubwürdigkeit dieser Quellen beruht wiederum nicht (nur) auf fachspezifischen Expertisen, sondern vor allem darauf, dass es sich eben um kritische Stimmen handelt. Die Glaubwürdigkeit der Kritik ist also eigentlich eine Glaubwürdigkeit durch Kritik.

2. Die Kritik zielt weniger auf einzelne Massnahmen, sondern gewissermassen auf alles gleichzeitig. Es handelt sich um einen «Generalverdacht» ${ }^{20}$ und die Coronakrise scheint eine gute Möglichkeit zu sein, einmal zu sagen, dass man eigentlich gegen alles ist - gegen die Reichen und Mächtigen, gegen die Wissenschaft, die Schulmedizin, die Justiz und Polizei etc. Die Kritik schweift deshalb auch oft ab, schnell ist man bei 9/11 und zieht Parallelen zum Nationalsozialismus.

3. Wichtiger als die Darstellung der Kritik ist die Selbstdarstellung als Kritiker:in. Hier findet sich das genuin romantische Motiv der mutigen, heldenhaft-standfesten Widerstandskämpfer:innen, die bereit sind, Opfer zu

20 Vgl. hierzu: Boltanski, L. (2013): Rätsel und Komplotte. Kriminalliteratur, Paranoia, moderne Gesellschaft. Berlin: Suhrkamp. 
bringen. Das erklärt umgekehrt die zentrale Rolle, die das Thema der Angst in der Interviews einnimmt. Es werde strategisch Angst erzeugt, da sich so die Menschen so besser kontrollieren liessen. Dagegen sei es wichtig, eben keine Angst zu haben, sondern mutig zu sein. Mit Weber lassen sich die Corona-Dissident:innen als typische Gesinnungsethiker bezeichnen, verantwortlich nicht für die konkreten Konsequenzen ihrer Handlungen, sondern nur dafür, «dass die Flamme der reinen Gesinnung, die Flamme z. B. des Protests gegen die Ungerechtigkeit der sozialen Ordnung, nicht erlischt. $)^{21}$

Dieses Narrativ zeigt sich auch in verschiedenen anderen Dokumenten, die analysiert werden sollen. Dabei handelt es sich um eine Vielzahl von Flyern, die wir auf den Demonstrationen sammeln konnten und die unterschiedlichsten Themenbereiche der Corona-Dissidenz abdecken, massenmediale Produkte, wie etwa das Kultbuch «Corona-Fehlalarm», ${ }^{22}$ Dokumentarfilme und Reportagen sowie die einschlägigen Webseiten und Chatgruppen.

\section{Fazit und Forschungsperspektiven}

Im Folgenden präsentieren wir Analysen und Deutungen, die zwar aus unserer bisherigen Forschung hervorgehen, aber vertieft zu analysieren wären. Das vorliegende Fazit der Studie umfasst daher tendenziell vorläufige Überlegungen und Thesen, die noch weiterer Forschungen bedürfen, die wir aber dennoch bereits zur Diskussion stellen. Unsere tentativen Versuche, die bisherigen Einsichten gesellschaftstheoretisch zu verorten, führten bislang in die Richtung, die gegenwärtige Corona-Dissidenz als Ausdruck einer fundamentalen Legitimationskrise der modernen Gesellschaft zu interpretieren.

\footnotetext{
21 Weber, M. (1926). Politik als Beruf. München: Duncker \& Humblot, S. 58. Online verfügbar unter: www.nbn-resolving.org/urn:nbn:de:0168-ssoar-59888-1, zuletzt aufgerufen am: 16.12.2020.

22 Reiss, K. und S. Bhakdi (2020): Corona Fehlalarm? Zahlen, Daten und Hintergründe. Zwischen Panikmache und Wissen. Berlin: Goldegg.
} 
Das Projekt der Moderne hat bei den von uns untersuchten Personen seine normative Anziehungskraft eingebüsst. Der normative Gehalt der Moderne, der durch ihre zentralen Versprechen - Aufstieg durch Leistung, Freiheit durch Demokratie, Gleichheit durch Rechtssicherheit, Wahrheit durch Wissenschaft, steigende Lebenserwartungen durch die Errungenschaften der modernen Schulmedizin oder ganz allgemein: Die Menschheitsgeschichte als Fortschritt im Bewusstsein der Freiheit - gekennzeichnet war, hat seine Glaubwürdigkeit verloren. Die Moderne legitimiert sich selbst stets dadurch, dass sie Kritik ermöglichte; doch genau dieses Element ist in den Augen der Querdenker:innen verloren gegangen.

Die Entfremdung von der industriell geprägten und durchrationalisierten Hypermoderne zeigt sich nicht nur in der Skepsis gegenüber ihren Institutionen, wie z.B. den Parteien, sondern auch bezüglich einer romantisch inspirierten Hinwendung zu ganzheitlichen, anthroposophischen Denkweisen, dem Glauben an die natürlichen Selbstheilungskräfte des Körpers, Forderungen nach mehr spirituellem Denken und dem Wunsch, Schulmedizin und alternative Heilmethoden gleichzustellen.

Die Bewegung der Querdenker:innen ist vor allem durch eine tiefe Entfremdung von Kerninstitutionen der liberalen Demokratie zu charakterisieren. Der parlamentarischen Politik und den Parteien, der Wissenschaft und den Medien - allen Institutionen schlägt grosses Misstrauen entgegen. Einzig die Gerichte und das Justizsystem geniessen noch eine schmale Vertrauensbasis. Die Kritiker:innen sehen sich in ihrer Abweichung vom Mainstream verkannt und geächtet; gleichzeitig werten sie sich und ihre Expertise im Vergleich zum Mainstream auf. So überrascht es auch nicht, dass die Querdenker:innen-Bewegung sich durch eine starke normative Unordnung kennzeichnet, die sich beinahe ausschliesslich jenseits der tradierten Formen politischer Repräsentation bewegt. 
Die Bewegung der Querdenker:innen kommt jedoch nicht einfach aus dem Nichts. In den letzten Jahren gab es bereits eine Reihe von Bewegungen - linke wie rechte - die sich jenseits tradierter Formen der Repräsentation verorteten. Zu ihnen können etwa die Montagsmahnwachen für den Frieden, Pegida und Occupy gezählt werden, anders als ausserparlamentarische Bewegungen, wie die Klimabewegung oder der Schweizer Frauenstreik, wo die Bewegungsakteure auf einen direkten Einfluss auf das Parteiensystem zielten und in vielen Fällen sogar mit ihm verwoben waren.

Die Forschung zu diesen Protesten steht - nicht nur für uns - erst am Anfang. Es bedarf noch weiterer Untersuchungen, um zu genaueren und empirisch belastbareren Erkenntnisse zu gelangen. Eine wichtige Frage, die sich aus unserer Perspektive und aus unseren Befunden ergibt, ist, weshalb die Corona-Proteste im deutschsprachigen Europa (sowie etwas weniger in England und den USA) so viel stärker sind als im Rest der Welt. ${ }^{23}$ Als aufschlussreicher Vergleich böte sich etwa Frankreich an, wo es streckenweise härtere Restriktionen gab, aber weniger Protest dagegen.

Im Umgang mit diesen Protesten ist es aus unserer Sicht wichtig, die Kritiker:innen der Corona-Massnahmen nicht einfach zu pathologisieren. Das ist zwar verführerisch und entlastend, hilft aber nicht wirklich weiter. Für den Soziologen Niklas Luhmann nahmen Proteste und soziale Bewegungen die Rolle des "Immunsystems" der Gesellschaft ein, das die Selbsterhaltung der Gesellschaft sichere. ${ }^{24}$ Man könnte allerdings auch die Perspektive umdrehen und - statt nur einen Umgang mit den existierenden Bewegungen zu suchen - einen Prozess der gesellschaftlichen Selbstreflexion beginnen und fragen: Was für eine Gesellschaft bringt derartige Bewegungen hervor, was sind ihre strukturellen Voraussetzungen?

\footnotetext{
${ }^{23}$ Eine Ausnahme ist Serbien, wo sich die Proteste im Juli aber wohl primär gegen die Regierung Vučić richten, nicht gegen die Corona-Massnahmen als solche.

${ }^{24}$ Luhmann, N. (1999): Protest. Systemtheorie und soziale Bewegungen, Frankfurt am Main: Suhrkamp.
} 